\title{
The impact of points of impasse on conflict escalation during the special education conflict resolution process
}

DeEdra Jane Lundeen

West Virginia University

Follow this and additional works at: https://researchrepository.wvu.edu/etd

\section{Recommended Citation}

Lundeen, DeEdra Jane, "The impact of points of impasse on conflict escalation during the special education conflict resolution process" (2005). Graduate Theses, Dissertations, and Problem Reports. 3432.

https://researchrepository.wvu.edu/etd/3432

This Dissertation is protected by copyright and/or related rights. It has been brought to you by the The Research Repository @WVU with permission from the rights-holder(s). You are free to use this Dissertation in any way that is permitted by the copyright and related rights legislation that applies to your use. For other uses you must obtain permission from the rights-holder(s) directly, unless additional rights are indicated by a Creative Commons license in the record and/ or on the work itself. This Dissertation has been accepted for inclusion in WVU Graduate Theses, Dissertations, and Problem Reports collection by an authorized administrator of The Research Repository @ WVU.

For more information, please contact researchrepository@mail.wvu.edu. 
The Impact of Points of Impasse on Conflict Escalation

During the Special Education Conflict Resolution Process

DeEdra Jane Lundeen

\author{
Dissertation submitted to the \\ College of Human Resources and Education \\ at West Virginia University \\ in partial fulfillment of the requirements \\ for the degree of
}

Doctor of Education

in

Educational Leadership Studies

\author{
Paul Chapman, Ph.D., Chair \\ Nancy Brown, J.D. \\ Van Dempsey, Ph.D. \\ Elizabeth Dooley, Ed.D. \\ Ernest Goeres, Ph.D. \\ Paul Rosier, Ed.D. \\ Department of Advanced Educational Studies
}

Morgantown, West Virginia

2005

Keywords: Parent-School Partnerships, Special Education, Conflict Resolution, Trust Copyright 2005 DeEdra Jane Lundeen 


\author{
ABSTRACT \\ An Analysis of the Impact of Points of Impasse on \\ Conflict Escalation during the Special Education \\ Conflict Resolution Process
}

DeEdra Jane Lundeen

Current literature reveals the disparity between the knowledge that strong parentschool partnerships are integral to planning and implementing educational programming for exceptional children, and the ability of parents and school personnel to identify and deescalate conflict when it occurs. Several studies acknowledged variables that helped build and maintain strong parent-school collaboration, and identified factors that escalated or de-escalated parent conflict. However, the research is sparse regarding factors that impact points of impasse on conflict escalation between parents and school districts during the special education conflict resolution process. Such information could provide stakeholders with deeper insight into the dynamic aspects of the parent-school relationship that may escalate conflict between the two parties, and allow stakeholders to pinpoint where errors in conflict resolution arise.

The case study approach was used to provide a rich description of how one family and school district experienced factors that impacted points of impasse on parent-school conflict escalation during the special education resolution process. Data from the archived record of The Board of Education of Community Consolidated School District 21 v. Illinois Board of Education (1991) were analyzed using the constant comparative method as described by Maycut and Morehouse (1994).

Lake and Billingsley (2000) identified eight factors that contributed to parentschool conflict. The findings in this study suggested that trust was the fundamental factor that impacts parent-school conflict escalation in this case. If trust was present, the impact of key and contributing factors on parent-school conflict diminished. If trust was not present, key factors of communication and discrepant view of the child directly impacted points of impasse and influenced contributing factors' impact on conflict escalation. This study also found that trust and the key factors were not identified by the parties as factors that impacted conflict. Yet, the contributing factors of valuation, constraints, knowledge, reciprocal power and service delivery were readily identifiable by the parties in this case. 


\section{DEDICATION}

To my husband, Conrad, who patiently supported me throughout this endeavor. Thank you, Conrad, for lighting my path with your experience, your time, and your unconditional love. I will forever look to you for my inspiration; you are the teacher I have always hoped to be. I love you.

And to my mother, Wanda Brown, whose unwavering love and encouragement helped me accomplish this dream. Thank you, Mom, for believing in me. 


\section{ACKNOWLEDGMENTS}

It is with deepest gratitude that I acknowledge the contributions made by the members of my dissertation committee. Always modeling the humble demeanor of a truly great qualitative researcher, Dr. Paul Chapman gave me the professional and personal guidance that supported my growth as a researcher, professional educator, and human being. Thank you, Dr. Chapman, for your time, your insight, and your goodness. Dr. Goeres used his vast academic experience to provide me with inspiration and organization, buoying my spirits while consistently keeping me on the path to completion. Thank you, Dr. Goeres, for your wonderful sense of humor and your selflessness. Thanks also to Dr. Dempsey and Dr. Dooley, who gave the committee balance, helping me focus on and fine tune the qualitative processes used in this study. Dr. Rosier was "that professor" who inspired me and made me realize that education was my true calling. He taught me to love the law, and to apply it in the educational setting with integrity, diligence, and care. Thank you, Dr. Rosier, for setting high expectations and demanding that I meet them. I hope to pass on the gift you have given me. Nancy Brown, Esquire, gave of her extensive education law experience and expertise, providing welcomed feedback that enabled me to navigate the nuances of the legal practices and procedures that were the underpinnings of this study. Thank you, Dr. Brown, for your continual encouragement and your belief in my abilities. I am truly fortunate to have you as a mentor, a colleague, and a friend.

Heartfelt thanks are also extended to Dr. Janice Christopher, my immediate supervisor, co-worker and friend. Dr. Christopher taught me the traits of an excellent school administrator: the ability to collect and use data to make sound educational decisions; the ability to identify and effectively solve problems with skill and diplomacy; and the ability to lead others with integrity, dignity and grace while fostering their own professional and personal growth. Thank you, Dr. Christopher, for mentoring me for the past 10 years. I hope to make you proud as I strive to internalize these traits and practice them as you did every day of your career.

Finally, I would like to acknowledge the strong women in my life, who have given so much of themselves to teach me to live, laugh, love and trust. They never let me give up my dream of completing my doctorate. Thank you Mom, Laura, Lexi, Toni, Kelly, Barbara, Lisa Ann, Nancy, Janice, Sandy, Jana, Debbie, Sharon, Lyn, Becky and Judy. You lovingly forgave the times that I was unable to "be there" and were a constant source of encouragement. I love you all. 


\section{TABLE OF CONTENTS}

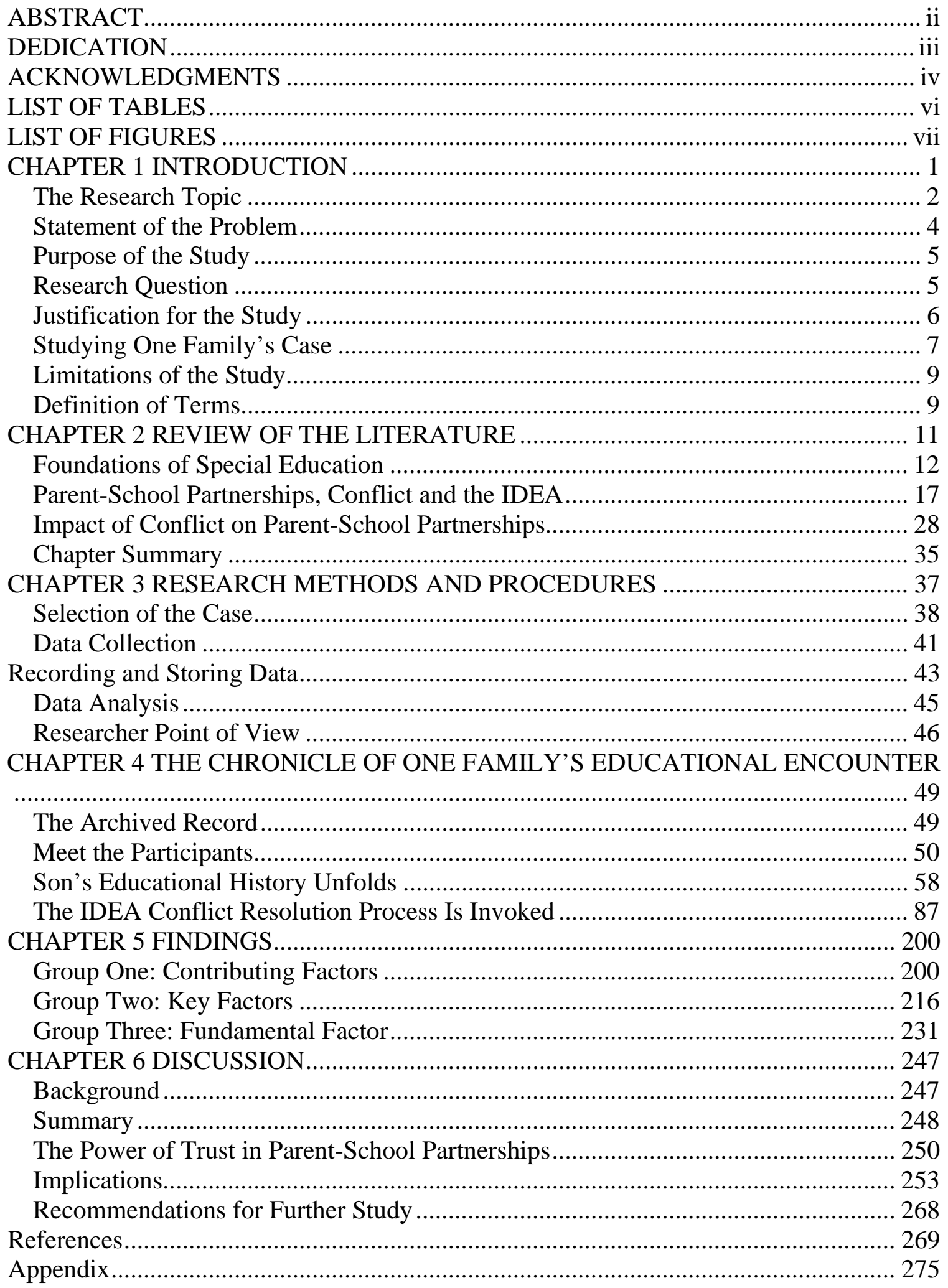




\section{LIST OF TABLES}

Table 1. Timetable for Conducting the Research ............................................................. 48 


\section{LIST OF FIGURES}

Figure 1. Development of conflict. Note. From "An Analysis of Factors that Contribute to Parent-School Conflict in Special Education,” by J. Lake and B. Billingsley, 2000, Remedial and Special Education, 21(4), p. 244. Adapted from The Resolution of Conflict (pp. 5-8, 350-353), by M. Deutsch, 1973, New Haven, CT: Yale University Press. Copyright 1973 by Yale University Press. Reprinted with permission.

Figure 2. Factors that escalate and deescalate conflict. Note. From "An Analysis of Factors that Contribute to Parent-School Conflict in Special Education,” by J. Lake and B. Billingsley, 2000, Remedial and Special Education, 21(4), p. 244. Copyright 2000 by Remedial and Special Education. Reprinted with permission.

Figure 3. Framework for authentication of records and documents. Note. Adapted from Case study research in education: A qualitative approach (pp. 107-108), by S. B. Merriam, 1990, San Francisco: Jossey-Bass. Copyright 1990 by Jossey-

Bass. 


\section{CHAPTER 1}

\section{INTRODUCTION}

Federal and state laws have long established the right of all children to attend public school in the United States (Alexander, 1995). Public schools are required to educate children with identified disabilities as early as age zero through age 21, depending on the state. During this extensive period of time, effective parent-school partnerships are considered fundamental to ensure that students with special needs have access to a Free, Appropriate, Public Education (FAPE). However, the relationship between parents and schools is not always without conflict. Conflict is a naturally occurring phenomenon inevitable in most long-term relationships. But conflict does not have to result in a negative outcome. If parents and schools viewed each conflict as an opportunity for growth, the conflict would be a positive force, driving change that would result in improved services to special needs students (Lake \& Billingsley, 2000). All too often parents and schools do not have the knowledge, skills, or the will to identify and deescalate conflict in a constructive manner. Without these requisite skills, one or both parties can view conflict negatively.

When conflict is experienced negatively by parents, schools or both, they are often unable to resolve the conflict. It then escalates; the parent-school relationship can become irreparably damaged. In extreme circumstances, the conflict might worsen to such a degree that the parent-school partnership is permanently broken and their relationship becomes so hostile that the special needs student cannot receive FAPE within that school district. School districts must do everything in their power to avoid that happening. Unveiling the dynamic aspects of the parent-school relationship that may 
escalate hostility between the two parties is essential to better serve students with disabilities.

\section{The Research Topic}

When the United States Congress reauthorized the Individuals with Disabilities Education Act (IDEA) in 1997, one of its primary purposes was to strengthen long-term partnerships between parents and schools. IDEA 97 focused on fostering cooperation and communication between the two in order to appropriately support the needs of identified students with disabilities. Congress’s action to promote a positive parentschool relationship is supported by an increasing awareness among professionals that a strong collaborative partnership between schools and families of students with disabilities enhances positive, trust-building interactions. This leads to early conflict resolution and the prevention of more costly actions such as due process hearings or civil litigation (Feinberg, Beyer, \& Moses, 2002). Ideally, parents and school district staff work together in partnership to build and deliver appropriate Individual Educational Programs (IEP) necessary for students with disabilities to benefit from their education. However, parent-school conflict is inevitable (Lake \& Billingsley, 2000). When parents and schools do not have the knowledge, skills, or the will to identify and resolve the conflict, it has the potential to escalate. Both parents and schools negatively experience this impasse. Zirkel (1998) points out that "it is not at all unusual or unexpected that parents become the adversary of the school district, sometimes to the point of 'irreconcilable differences', irrationally undermining the proposed program or services for their child” (p. 9). When parents, schools or both become contentious, they can exhibit a position inconsistent with the collaborative ideal of the IDEA. 
When a conflict has escalated to the point that parents and schools can no longer work together to find a constructive solution, a process must be in place to mediate or arbitrate the conflict. The United States Congress acknowledged that conflict between parents and school districts would occur and therefore outlined specific regulations regarding conflict resolution in the IDEA, including mediation and due process hearings. If parents and school districts cannot resolve their differences through informal discussion, either party may request voluntary mediation, a due process hearing, or both. Goldberg and Huefner (1991) contend that the conflict resolution procedures as outlined in the IDEA rarely accomplish the goal of complete conflict resolution as envisioned by Congress. Although "mediation is a voluntary, time-efficient, inexpensive and emotionally comfortable process” (Lake \& Billingsley, 2000, p. 241), one or both parties often choose not to participate. The due process system currently in place is quite expensive, time consuming, adversarial, and emotionally draining for all parties involved (Goldberg \& Huefner, 1991). Yet Fiedler (2000) indicated the number of due process hearing requests in the United States has increased 7.5\% annually, from 4,125 in 1991 to 5,497 in 1995, even though the cost of special education due process hearings has increased over 300\% in the past 5 years (Wilson, 1997, p. 30). These important statistics support the fact that parents and schools proceed through the formal IDEA conflict resolution process, regardless of its inability to resolve the disagreement, because they do not have the knowledge, skills, or the will to identify the factors that cause conflict escalation.

When the conflict between parents and school districts escalates to a point of impasse, either party may request a due process hearing. An administrative hearing 
officer (AHO) presides over the trial-like process, hearing testimony from both parties concerning the contentious issue. The AHO considers all facts and precedent case law, and then renders an objective, binding, written decision. When making this decision, the AHO’s primary responsibility is to ensure that the identified special needs student receives a FAPE, regardless of possible outside factors that might influence the FAPE of the student. If a due process decision is disputed, one or both parties may appeal up through the state or federal court system, or both. Throughout the appeals process, all AHOs and judges are compelled to ensure compliance with IDEA, guaranteeing the provision of a FAPE to students with disabilities.

The relationship between parents and the school system should not impact the AHOs’ or courts' decisions with regard to FAPE. In some cases, however, the relationship between the parents and the school district completely breaks down. In extraordinary cases, AHOs and judges have held that the egregious nature of the parentschool partnership breakdown precluded the student from receiving FAPE anywhere within the school district without the student's FAPE being obstructed, impaired or prohibited (Zirkel, 1998). Therefore, the AHO and the courts ordered the students' outof-district placement at the school district's expense.

Statement of the Problem

The purpose of the IDEA 97's conflict resolution component is to ensure objective, expedient conflict resolution between the parent and the school district. Getty and Summy (2004) believe the following:

The course of a due process hearing can have many emotional ramifications for all parties involved. These ramifications may be founded or unfounded; 
nonetheless, these ramifications, or perceptions, may impede a student's educational progress. This impediment is the ultimate contradiction to the initial intent of the law, yet one that cannot be disregarded. Therefore, an awareness of these perceptions by various stakeholders may positively affect educational outcomes during and after the course of a due process hearing (p. 41).

The breakdown of the parent-school relationship during attempted conflict resolution has the potential to jeopardize the FAPE of students with disabilities. Existing literature regarding special education conflict resolution is narrow, primarily focusing on three issues: identification of the disputed legal issues; conflict resolution and the perceived outcomes of mediation; and conflict resolution and the perceived outcomes of due process hearings (Lake \& Billingsley, 2000, p. 241). Not enough is known about the stakeholders' emotional experiences within the parent-school relationship during conflict to pinpoint where errors in conflict resolution arise.

\section{Purpose of the Study}

The purpose of this study is to bring to bear the researcher's lens on the relationship between the factors of conflict escalation and each point of impasse during the conflict resolution process.

\section{Research Question}

The following research question will be addressed:

What is the impact of points of impasse between parents and schools on conflict escalation during the conflict resolution process as evidenced in the court case, The Board of Education of Community Consolidated School District 21 v. Illinois Board of Education (1991)? 


\section{Justification for the Study}

Lake and Billingsley (2000) acknowledged that not much is known about how to maintain an effective parent-school partnership in the face of adversity. Furthermore, they recognized that it is necessary to understand how conflict is perceived in order to be able to deescalate conflict. By studying this issue within the special education arena, Lake and Billingsley identified eight categories of factors that cause conflict to escalate between parents of students with disabilities and schools. It is critical to acquire further knowledge of these factors and how they relate to parent-school conflict escalation.

There are three reasons for conducting this study. First, the information gained from this study will increase stakeholders' awareness of the impact of parent-school points of impasse on conflict escalation. Better understanding of stakeholders’ experiences during conflict and their effect on the parent-school relationship will enhance the probability of identification and resolution of conflict. This, in turn, will foster a continued constructive parent-school partnership, enabling them to collaboratively and proactively support the students with disabilities' educational concerns when conflict arises.

Secondly, this study will influence policy makers regarding the importance of providing appropriate staff development and subsequent resources, including suitable laws and regulations, which support the development and maintenance of cooperative parent-school partnerships. These partnerships, nurtured by the knowledge and skill to identify and deescalate conflict when it occurs, would increase their ability to work together to support a FAPE to all special needs students even when the parties disagree. 
Finally, this study will add pertinent information to the literature regarding the current special education conflict resolution process and its impact on the parent-school district partnership. Lake and Billingsley (2000) stated that understanding how situations that "escalate conflict are handled is critical to developing appropriate response strategies” (p. 242). Increasing the scope of the literature on this topic will support better awareness and understanding of the conflict resolution process and provide another stepping stone on which to develop appropriate response strategies to parent-school conflict.

\section{Studying One Family’s Case}

Parent-school conflict often begins with a disagreement about a specific issue pertaining to the student's education, such as placement or program issues (Newcomer \& Zirkel, 1999). But the parents’ or schools’ response to the initial disagreement can impact conflict resolution. Lake and Billingsley (2000) indicated that when two or more interactive stakeholders perceive incompatible differences regarding their resources, needs or values, they behave in response to that interaction. The stakeholders' behavioral response determines whether the initial conflict is escalated or deescalated. The interaction between the stakeholders, the perceptions drawn by the stakeholders through that interaction, and the subsequent stakeholders’ behavioral reactions to their perceptions become overlays of the initial point of disagreement at each point of conflict impasse.

Yin (1984) states that when a "single case can represent a significant contribution to knowledge and theory-building,” it should be studied so as to help focus future investigations in a new area, or field, of research (p. 43). Yin (1984) also stipulated that 
when an investigator has the opportunity to "uncover some prevalent phenomenon previously inaccessible to scientists, such conditions justify the use of a single-case study"; a unique case that is quite rare is "worthy of documenting and analyzing” (p. 43). The Board of Education of Community Consolidated School Dist. No. 21 v. Illinois State Board Of Education (BOE v. ILL., 1991) is just such a case. This case was chosen for examination because it is unique in two ways: it is the only case involving conflict escalation to the point of irreconcilable differences that has ever been appealed to the United States Supreme Court (cert. denied); it is also recognized as the pivotal, landmark decision in the area of irreconcilable differences between parents and schools. BOE $v$. ILL. follows one parent-school partnership through the formal conflict resolution process over a period of years. The primary outcome of this seminal case revolves around parentschool conflict. The relationship between the parents and the school district completely broke down. The AHOs and judges held that the egregious nature of the parent-school partnership breakdown precluded the student from receiving FAPE anywhere within the school district without the student's FAPE being obstructed, impaired or prohibited. Therefore, the AHO and the courts ordered the student's out-of-district placement at the school district’s expense.

A qualitative, archival case study approach using the constant comparative method (Maycut \& Morehouse, 1994) of document analysis allowed this one, unique case's complex relationships to be carefully studied. The subsequent statements of the archival record provided thoughtful insight that proved instrumental in defining the impact of points of impasse factors on conflict escalation during the conflict resolution process. This, in turn, refined the overall understanding of the effect and consequences 
of conflict escalation on the parent-school partnership with respect to the special needs students’ ability to benefit from a FAPE.

\section{Limitations of the Study}

The research was conducted to provide an understanding of the impact of points of impasse on the factors that escalate conflict during conflict resolution. This archival case study was based on one particular parent-school relationship and the conflict resolution process in which they took part. Because the findings of this study were based on one individual and unique case, the findings are not generalizible to large populations. However, a single case perspective gave a close up view of the phenomenon.

This research was conducted by a central administrator of special education (CASE). From a CASE perspective, the school district's main goal is to provide the special needs student with FAPE as IDEA dictates. At times it seems impossible to do so because the parent-school partnership is jeopardized by the negative, emotional experiences of moving through the conflict resolution procedures. I "wear the hat" of a school administrator, which allowed a dual perspective: one of the frustrations of all stakeholders involved in an escalating conflict; the other, the ability to discern the need for further examination of this event.

\section{Definition of Terms}

These following terms have been selected specific to this study because they address the research question:

Conflict: "Conflict is defined as real or perceived differences that arise from specific educational circumstances that engender negative emotion as a consequence”

(Deutsch, 1973 as cited in Lake \& Billingsley, 2000). 
Point of Conflict: “How people react in response to interacting with one another when one or both perceive incompatible differences or threats to their resources, needs, or values” (Deutsch, 1973 as cited in Lake \& Billingsley, 2000).

Impasse: “A situation that has become so difficult or complicated that no further progress is possible; deadlock; stalemate” (Reader’s, 1966. p.672). 


\section{CHAPTER 2}

\section{REVIEW OF THE LITERATURE}

A review of the literature revealed information in the form of statutory, regulatory and case law, legal briefs, educational research, reviews, articles, and publications pertaining to the importance of parent-school partnerships and their positive effect on the education of students with disabilities. A small number of empirical studies were uncovered that examined conflict between schools and parents of students with disabilities. Even fewer studies were found that analyzed conflict and its possible effects on students, parents and school districts. Blue-Banning, Summers, Frankland, Nelson and Beegle (2004) wrote, “The development of collaborative partnerships between parents and professionals is too often unsuccessful. One reason for this failure may be the lack of empirical understanding of the components of interpersonal partnerships” (p. 167).

For a full examination of conflict between parents and schools in the special education arena, it is essential to understand the legal parameters that govern the relationship between school districts, parents and students with special needs. Therefore, this review highlights the legal history and rationale for collaborative parent-school relationships, and focuses more intensely on the investigations into the breakdown of parent-school partnerships.

This chapter is divided into three sections. Each section summarizes information pertinent to the foundations of special education, the Individuals with Disabilities Education Act, its’ provisions for collaborative parent-school partnerships and conflict 
resolution, and the impact of conflict on the parent-school partnership. The chapter ends with a summary of the literature presented.

\section{Foundations of Special Education}

\section{General Education}

Conflict between parents and governance regarding education has historically been viewed as one of the principle reasons for emigration to and colonization of the American Colonies by freedom-seeking peoples. Prior to the settlement of the "New World”, the layman's right to an education without excessive political or religious intrusion was virtually unknown. Although the American founding fathers believed that education was a birthright and that there would be no viable democracy without an educated electorate (Yell, 1998, p. 54), they wanted to protect the individual freedom of its citizens to educate posterity as the citizens saw fit. Therefore, the United States Constitution does not set forth explicit provisions regarding the education of its citizens. Education is the sovereign responsibility of each individual state. The U.S. Congress, however, oversees education indirectly via two important components of the U.S. Constitution: the General Welfare clause and the $14^{\text {th }}$ Amendment. The General Welfare clause allows Congress to enact public laws and regulations that "promote the general welfare” of all citizens (U.S. Const., art. 1). The $14^{\text {th }}$ Amendment states that no person will be denied property rights without due process, or equal protection, of the law (U.S. Const., $14^{\text {th }}$ amend.). Because education has been determined through case law to be a property right, the Congress enacts public laws and regulations to ensure due process for all students and their parents. Some of these federal laws are funding statutes that provide financial assistance through federal entitlement funds that flow through to the 
states. States must abide by the federal regulations in order to receive these entitlement funds for public schools. If the states do not adhere to the regulations, they risk revocation of these funds (Yell, 1998, p. 3).

Special Education

The landmark decision of Brown v. the Board of Education became the cornerstone that enabled students with disabilities to access public education. United States Supreme Court Chief Justice Earl Warren wrote:

In these days, it is doubtful that any child may reasonably be expected to succeed in life if he is denied the opportunity of an education. Such an opportunity, where the state has undertaken to provide it, is a right that must be made available to all on equal terms (Brown v. BOE., 1954, p. 493).

In 1966, the U.S. Congress addressed the fact that there was a lack of educational services for students with disabilities by amending the Elementary and Secondary Education Act of 1965(Pub. L. 89-750, 1966) to establish a grant program "for the purpose of assisting the States in the initiation, expansion, and improvement of programs and projects...for the education of handicapped children” (Ruesch, 1996). This program was repealed with the adoption of the 1970 Education for the Handicapped Act, which provided grant monies to be used for this purpose (Pub. L. 91-230, 1970). Congress was dissatisfied with the progress of the 1970 law, and in 1974 determined the need to "study what federal assistance would be needed to meet the needs of handicapped children” (H.R. Rep. No. 332, 1975). With regard to children with disabilities, the U.S. Congress utilized the General Welfare clause and the $14^{\text {th }}$ Amendment of the U.S. Constitution, enabling it to enact a funding statute, the Education of All Handicapped Children Act in 
1975. This Act was amended in 1986, 1990 (when the name changed to the Individuals with Disabilities Education Act (IDEA)), and 1997 (Yell, 1998). Congress last reauthorized IDEA as the Individuals with Disabilities Education Improvement Act (IDEIA) on December 3, 2004 as Public Law 108-446 (IDEA, Pub. L. 108-446, 2004). The IDEIA takes effect on July 1, 2005. Because this law did not go into effect until July 1,2005 , no case law or other commentaries were available to interpret how this new law would develop or have impact on the current law (N.W. Brown, personal communication, March 18, 2005). Therefore, at the time of this writing, IDEA 97 was discussed and employed for the purposes of this study.

The IDEA outlines its purpose as follows:

... assure that all children with disabilities have available to them a free, appropriate, public education which emphasizes special education and related services designed to meet their unique needs, to assure that the rights of children with disabilities and their parents or guardians are protected, to assist states and localities to provide for the education of all children with disabilities, and to assess and assure the effectiveness of efforts to educate children with disabilities (IDEA, 20 U.S.C. sec. 1400 (c), 1997).

Yell (1998) lists 9 major principles of IDEA:

1. Zero Reject: all students with disabilities, regardless of severity who are eligible for services under IDEA, are entitled to a free, appropriate, public education (Alexander, 1995, p. 229).

2. Free Appropriate Public Education (FAPE): “special education and related services which (a) have been provided at public expense, under 
public supervision and direction, and without charge, (b) meet standards of the state educational agency, (c) include appropriate preschool, elementary, or secondary school education in the state involved, and (d) are provided in conformity with the Individualized Education Program (IEP)” for all identified students with disabilities (IDEA 20 U.S.C. Sec. 1400, 1997).

3. Least Restrictive Environment (LRE): students with disabilities will be educated, to the extent possible with their age appropriate, non-disabled peers (IDEA Reg. 34 C.F.R., 1998).

4. Identification and evaluation: evaluation and assessment procedures must be fair and accurate to assure proper placement and appropriate education (Yell, 1998).

5. Confidentiality of Information: the confidentiality of disabled students' educational records is protected (IDEA Reg., 1998) (Sean R. v. BOE, 1992).

6. Technology-related assistance: "The regulations indicate that assistive technology devices and services should be included in the IEP if necessary to provide a FAPE as a special education service or a related service or to maintain children and youth with disabilities in the LRE through the provision of supplementary aids and services” (Yell, 1998, p.82). 
7. Personnel development: states must assure that there are appropriately trained teachers and support staff to ensure that students with disabilities can receive FAPE (Yell, 1998).

8. Placement in Private Schools: when the school district is unable to provide FAPE and places a student in a private facility, the district retains responsibility of the student, and therefore is responsible for all costs incurred by the placement (IDEA Reg., 1998)

9. Procedural safeguards: equal protection under the law is assured by ensuring the parent(s) or guardian(s) is an equal participant in the special education process. Importantly, mandatory procedural safeguards fall into 4 major categories: 1 ) requirement of the local education agency (LEA) to notify parents and obtain consent from parents; 2) LEA must give parent access to independent evaluation at public expense when parent disagree with evaluation results; 3) the LEA has the responsibility of appointing a surrogate parent, if appropriate, to ensure the student's rights are represented, and; 4) the provision of access to dispute resolution, including the use of mediation and due process for both the LEA and the parent (IDEA, 34 C.F.R. Sec. 300, 1999). IDEA also stipulates that states are required to have procedures in place that assure all children with disabilities and their parents are guaranteed procedural safeguards; parents must be informed of their rights in writing. Specifically, the contents of the written procedural safeguards shall include a full explanation of the procedural safeguards relating to, among other things, mediation and due 
process hearings (including requirements for disclosure of evaluation results and recommendations), state level appeals, civil actions and recoupment of attorney's fees. (IDEA 20 U.S.C. Sec 1415 (d) (2), 1997).

Parent-School Partnerships, Conflict and the IDEA

\section{Parent-School Partnerships}

Lake and Billingsley (2000) wrote, “Collaboration between schools and parents rests on two IDEA principles: parent participation and procedural due process” (p. 240). Congress envisioned parents and schools collaborating together as equal partners to ensure students with disabilities could benefit from a Free, Appropriate, Public Education (FAPE). The IDEA's findings include:

Over twenty years of research and experience has demonstrated that the education of children with disabilities can be made more effective by...strengthening the role of the parents and ensuring that families of such children have meaningful opportunities to participate in the education of their children at school and at home...(IDEA, Sec. 601(c)(5B), 1997).

The language in the IDEA mirrors Turnbull and Turnbull's (1986) discussions regarding the benefits of family-professional partnerships. They wrote:

When family and professionals respect, trust and communicate openly with one another, a partnership is formed. Both families and professionals have unique contributions to bring to a partnership. Such partnerships can be beneficial not only to the child, but for parents and professionals as well (p. 116).

Turnbull and Turnbull reviewed the findings of Heward, Dardig, and Rossett (1979), which described the following advantages of parent-professional relationships: 
A productive parent-professional relationship provides professionals with:

1. Greater understanding of the overall needs of the child and the needs and desires of the parent.

2. Data for more meaningful selection of target behaviors that are important to the child in his or her world outside of school.

3. Access to a wider range of social and activity reinforcers provided by parents.

4. Increased opportunities to reinforce appropriate behaviors in both school and home settings.

5. Feedback from parents as to changes in behavior that can be used to improve programs being implemented by professionals and parents.

6. The ability to comply with legislation mandating continuing parental input to the educational process.

A productive parent-professional relationship provides parents with:

1. Greater understanding of the needs of their child and the objectives of the teacher.

2. Information on their rights and responsibilities as parents of an exceptional child.

3. Specific information about their child's school program and how they can become involved.

4. Specific ways to extend positive effects of school programming into the home. 
5. Increased skills in helping their child learn functional behaviors that are appropriate for the home environment.

6. Access to additional important resources (current and future) for their child.

And of most importance, a productive parent-professional relationship provides the child with:

1. Greater consistency in her two most important environments.

2. Increased opportunities for learning and growth.

3. Access to expanded resources and services.

Turnbull and Turnbull advocated that family-professional partnerships were empowering to both parties and "benefited the child in a relationship that can prevent or minimize conflict” (p. 117).

Dunst and Paget's (1991) work also supports the premise that solid parent-school partnerships are founded on the concept of cooperation, or the ability to work together voluntarily to reach a common goal. Dunst and Paget reasoned that a simple partnership is defined by two or more people working together on a common task. True collaboration only occurs when people work cooperatively over a period of time on a common task. Dunst and Paget stressed that effective parent-school partnerships are collaborative in nature: both parties acknowledge that each partner brings certain traits and skills to the relationship that benefits the partnership. Given that schools provide FAPE to students with disabilities for up to twenty-one years, the development of a collaborative parent-school partnership over time is essential for the student with disabilities to benefit from his education. 
Blue-Banning, et al. (2004) investigated the question, "What specific indicators of professional behavior do parents and professionals identify as indicative of collaborative partnerships?” (p. 169). Qualitative analysis of data generated by diverse focus groups and individual interviews concerning specific behaviors and attitudes of professionals necessary for positive partnership permitted Blue-Banning, et al. (2004) to identify indicators of professional behavior facilitative of collaborative partnerships. The indicators were grouped into six main categories of behaviors: communication, commitment, equality, skills, trust, and respect. The authors found that both parents and professionals agreed that when the perception of these behaviors was present, a successful parent-school relationship was likely to occur. They also pointed out "that common sense and ordinary human decency are at the heart of positive partnerships between family and professionals service children with disabilities” (p. 181).

\section{Conflict and the IDEA}

Due Process Hearings. The U.S. Congress also acknowledged that conflict between people is inevitable and that the parent-school partnership visualized in IDEA can break down. Therefore, Congress outlined specific regulations regarding conflict resolution in the IDEA. The primary mode of dispute resolution in the IDEA is arbitration through the use of a due process hearing. A due process hearing is modeled after a court proceeding, and the hearing participants have many of the legal rights associated with a regular court trial. Both the school district and the parent have the right to be represented by an attorney, examine the opposing party's records, call and cross examine witnesses, and appeal adverse decisions in civil court (Goldberg \& Kuriloff, 1991). Goldberg and Huefner (1995) wrote that Congress deliberately chose an 
adversarial system for resolving disputes, believing it was the best way to ensure that both parties would receive equal opportunity to present their case. Although the federal regulations regarding due process hearings are specific, they allow each state to adopt their own procedure for administering the hearing process. However, the state may not alter the federal law requirements and must ensure the students have access to the same or better protections outlined in the IDEA. The purpose of a due process hearing is to have an impartial third party hear both sides of a dispute, weigh the evidence as presented by the parties and render a unilateral, impartial decision based on the facts heard.

Unfortunately, the adversarial due process system currently in place does not accomplish the goal of complete dispute resolution as envisioned by Congress because the due process hearing procedure is too expensive, time consuming, adversarial, and emotionally draining for all parties involved (Goldberg \& Kuriloff, 1991). Hearings can create a huge fiscal burden on the LEA; "the average cost of a hearing in California is \$42,000.00” (Nash \& Perras, 1996, p. 5-6); the cost of special education due process hearings continues to increase (Wilson, 1997). Although hearing officers do not have the power to award legal fees, if the parent prevails in the hearing the parent may file a separate court action for the reimbursement of attorney fees, which could add thousands of dollars onto the price tag of the hearing.

Special education litigation is also emotionally demanding because of the adversarial nature of the proceedings (Gallant, 1982). As each side tries to win its case, hearings often become contentious as witnesses are examined and cross-examined. Feelings are often hurt, and it is difficult to mend the damaged relationships between parents and school personnel. The U.S. $9^{\text {th }}$ Circuit Court of Appeals emphasized in a 
notably adversarial case that the interests of all parties involved would better be served by compromise and cooperation rather than through adversarial posturing. (Clyde K. v. Puyallup, 1994).

Special education litigation is a legal paradox: once the legal battle between the parties is over, they must continue to work with each other to provide a FAPE to the student (Keith, 1999, p. 34). Goldberg and Kuriloff (1991) reported that many school personnel and parents who had been through a due process hearing felt it was not worth the cost and emotional trauma. Given an alternative, they would opt not to go through a due process hearing again. However, LEAs are concerned that if they do not go forward with a due process hearing, they might be compelled to provide services to a student beyond what is required by law; the services may even be inappropriate for the student. Parents are concerned that if they do not go to due process to try to force the school district to provide the requested services, their child will only receive minimal services, not a FAPE. (Reusch, 1996, p. 41).

Mediation. Care must be taken to ensure the special needs student does not get lost in a dispute between the parent and LEA. Given the IDEA's zero reject concept and the unique fact that the parties must continue to work with each other to provide a FAPE to the student after the resolution of a dispute, it stands to reason that utilizing methods for parents and school personnel to resolve conflicts in a peaceful and thoughtful manner is in the best interest of the parties, and most importantly, to the student (Gallant, 1982, p. 20). In the 1997 Amendments to IDEA, the US Congress tried to alleviate what many felt to be an adversarial dispute resolution system by incorporating strong language to support the option of voluntary participation of parents and school personnel in non- 
adversarial mediation prior to a due process hearing. Dobbs, Primm and Primm (1991) define mediation as a dispute-resolution and collaborative problem solving process in which a trained impartial party facilitates a negotiation process between parties who have reached an impasse. "The role of the mediator is to facilitate discussion, encourage open exchange of information, assist the involved parties in understanding each other's viewpoints, and help the parties to reach mutually agreeable solutions” (Yell, 1996, p. 278). The focus of mediation should be negotiation and resolution, not legal process, settlement or “win/lose.” The IDEA outlines the following mediation process:

1. LEAs shall ensure procedures are established and implemented to allow parties to resolve disputes through a mediation process;

2. Mediation will be available at a minimum when a request for due process is made;

3. Mediation will be voluntary;

4. Mediation will not be used to deny or delay a due process hearing;

5. Mediation will be conducted by a qualified and impartial mediator;

6. The mediator has no decision-making powers;

7. LEAs can require parents who do not wish to mediate to meet with a disinterested party to explain the benefits of mediation;

8. The state will bear the cost of mediation;

9. The state will maintain a list of qualified mediators;

10. Mediation will be scheduled in a timely manner and be held in a location convenient to the parties;

11. Any agreement reached by the parties will be set forth in writing; 
12. Discussions that occur during mediation are confidential and cannot be used in a due process hearing. The parties will be asked prior to the commencement of mediation to sign a confidentiality oath.

13. The code is silent regarding the presence or absence of attorneys during mediation (IDEA, 20 U.S.C. Sec 1415 (e), 1997).

Because IDEA calls for mediation as an alternative to due process, states are moving towards using more alternative dispute resolution (ADR) processes. Girard and Koch (1996) define alternative dispute resolution (ADR) as a "spectrum of processes that employ communication skills and creative thinking to develop voluntary solutions acceptable to those concerned in the dispute” (p. 77). Schrag (1996) performed a study that reviewed various forms of ADR, including mediation, and found that ADR can be effective in resolving disputes if there is mutual commitment and openness to reach an agreement, the mediators are skilled/trained, mediation seeks to reduce the impact of perceived power imbalances between the parties, mediation is a voluntary process, including the preservation of self-determination and, agreements are implemented promptly (pp. 19-28). Schrag also found that school districts planning mediation or alternative dispute resolution procedures and implementing them early in the disagreement prevented many small disagreements from escalating to large-scale battles. In addition, good alternative dispute resolution encourages cooperative school/community cultures. Goldberg (1995) supports the move toward state and school district ADR training because parents would feel more supported as they communicate with the school district, and the school district would become less adversarial if disputes were resolved in a positive manner. Although ADR seems to bring about dispute 
resolution in a less contentious manner, Wilson indicates that "alternative dispute resolution is not living up to its’ promise as a process in which parents are able to rebuild the trust with administration that has been lost as a result of conflict over a child's educational program” (Wilson, 1997, p. 102).

Barbara M. Morton (2000) indicated that there are several basic components that should be included in the training of ADR facilitators, regardless of the ADR program used, in order to ensure a positive, productive outcome. For example, the facilitator must be cognizant of the fact that change is inevitable, but growth is optional. One of the facilitator's roles would be to present growth as one of the goals to be attained by the dispute resolution. Another salient training need is allowing for a paradigm shift with regard to conflict. In the training, conflict should be defined, negative and positive consequences of conflict should be discussed, the facilitator should be made aware that conflict is inevitable; it is neither good nor bad; it can be constructive and cause positive system change. Training in basic human needs should also be provided, as well as training in anger management. Finally, communication training is essential to ensure the positive outcome of any dispute resolution attempt.

There are advantages to participating in mediation as outlined above: mediation reduces costs to both parties; it is informal and more conducive to open discussion and trust building; mediation is less time-consuming than a due process hearing (Dobbs, Primm \& Primm, 1991). A survey conducted in 1993 indicated that 99\% of school personnel and $90 \%$ of parents that had been through mediation would recommend the process to others (Dobbs, Primm \& Primm, 1993). 
However, mediation as stipulated in the IDEA has its drawbacks. Most importantly, by the time mediation is enacted via state procedures, which is often simultaneous to filing for a due process hearing, communication has all but ceased between the parties and both parties often view the issue as irreconcilable. Also, mediation as set forth by the IDEA is not designed to improve the relationship between the parties; it is designed to gain a settlement. The mediator, although a neutral, knowledgeable third party, is often an attorney, schooled in the ways of legal arbitration. Therefore, the mediator usually communicates "around" the parties, moving between them, pressuring each to come to an agreement. The agreement, if any, which is reached may or may not be satisfactory to one or both parties or be in the best interest of the student. (Shaw, 1999). Also, even if a settlement is reached, a parental request for attorney fees, if an attorney was used, could be forthcoming. In addition, without distinct language added to the settlement agreement, there is no way "to prevent parents from asserting the same or new claims with regard to a subsequent school year or with respect to a different educational program or IEP” (Ruesch, 1996, p. 5:1).

Although mediation is the primary tool for alternative dispute resolution, there are other viable means of resolving conflict. Perhaps the most widely accepted is the use of "third party" school district administrators as dispute mediators. When a dispute materializes, it is most often at the school level. If the school and parent cannot resolve the dispute, a call goes out petitioning a district level administrator to promptly come and mediate. If the administrator has been trained in dispute resolution methods, this often works well. However, the parent may feel besieged by the presence of yet another school 
administrator. Also, it could be stated that the school district administrator is not impartial.

It is current practice for due process hearing officers, state and federal judges to first ask if mediation has been considered or has occurred. Federal judges have ordered mediation prior to their ruling with regard to hearing or dismissing a case. (MCBOE $v$. J.J., 1999). The legal prohibitions against sharing information generated during mediation create a formidable obstacle regarding the objective examination of alternative dispute resolution effectiveness. As discussed above, the Individuals with Disabilities Education Act of 1997 mandates that the parties sign a confidentiality oath prior to the commencement of any mediation to ensure that discussions occurring during mediation remain confidential. Also, since the contents of the discussions held in mediation (other than the written agreement) cannot be used in any legal forum, it is not known how many legal actions alternative dispute resolution has prevented or precipitated. Therefore, other than simply counting the number of mediations requested during a specific period of time and ascertaining if the outcome of each mediation resulted in a written agreement (this information is kept by each state department of education), there is no established way to document whether or not a mediation was truly successful on all fronts.

Administrative and Judicial Findings. IDEA and its regulations stipulate unequivocally that its purpose is to assure that all children with disabilities have available to them a Free, Appropriate, Public Education (FAPE). Special education laws obligate the school district to protect disabled students from intransigent parents as well as provide FAPE (Murphy v. Timberlane, 1992). To date, no administrative or judicial decision has been issued that terminates a school district's responsibility of providing an 
identified disabled student a FAPE due to the breakdown of the parent-school relationship. There have been a handful of judicial or administrative decisions that touch on the issue of the breakdown of the parent-school partnership and how that interferes with a student with disabilities' access to a FAPE. The following statements from judges and AHOs make it apparent that a breakdown in the parent-school relationship is of serious concern:

“A hostile and suspicious attitude is counterproductive to [the child's] educational progress” (Grapevine, 1994).

"Under IDEA...our concern is not rewarding or punishing the parents. The appropriate concern is finding a program which will be of educational benefit to the child” (Oberti v. BOE, 1993).

“Trust - or lack thereof - has been an overreaching theme from the beginning...litigation tends to poison relationships, destroying channels for constructive dialogue that may have existed before litigation began... when combat lines are drawn, the child's interests often are damaged in the ensuing struggle” (Clyde K. v. Payallup, 1994).

Impact of Conflict on Parent-School Partnerships

Dunst, Johanson, Rounds, Trivette, and Hamby (1992) identified 26 variables that influenced collaboration, with mutual respect and trust in each other being the strongest indicators of the perception of a strong parent-school partnership. Dinnebeil and Rule (1994) also identified indicators that were indicative of a strong parent-school partnership: communication skills, follow-through behaviors and interpersonal characteristics like cheerful demeanor, outgoing personality and a positive attitude 
toward children and families. Dinnebeil, Rule and Fox (1996) followed up with a qualitative study that sought to isolate variables that either enhanced or interfered with the collaborative partnership. They found that "Relationships between parents and professionals form the basis of all early intervention services provided to infants and toddlers with special needs and their families” (p. 1); professionals "must possess a balance of personality traits, values and skills that enable them to be effective collaborators” (p. 16). The authors suggested variables such as disposition, personal characteristics, philosophical beliefs, values, and others "act interdependently to enhance relationships with others" (p. 10). Dinnebeil and Hale (1996) also noted that "conflict or disagreement between parent and service coordinators detracted from collaboration” (p. 4).

Blue-Banning, et al. (2004) identified 39 indicators as powerful predictors of a positive parent-school partnership. The authors organized these indicators into six broad themes: communication, commitment, equality, skills, trust and respect. As the data was interpreted, it was found that "both positive and negative examples of the same concept were presented” (p. 173) that substantiated the perception of positive parent-school partnerships. In this study, positive examples of the themes listed above highlighted how parent and professional perceptions of the existence of these themes improved parentschool partnerships. Negative examples described in this study highlighted how parent and professional perceptions of the absence of these themes undermine parent-school relations. The authors wrote:

...the study participants repeatedly emphasized that for them the quality of their partnerships with service providers was a critical element of their overall quality 
of life. Time and again, these participants referred to the stress and exhaustion caused by the perceived necessity to fight for services, cope with humiliating or disrespectful regulations or provider attitudes, or otherwise deal with breakdowns in their relationships with professionals (p. 182).

Lake and Billingsley (2000) conducted a study whose purpose was “to identify factors that escalate and deescalate parent-school conflict in special education” (p. 242). The authors adapted Deutsch's conflict resolution model to reflect the point of conflict and visually outline the conflict escalation or de-escalation process (Figure 1). The authors interviewed a total of 44 participants in Massachusetts: six mediators, 16 school officials (principals or special education directors), and 22 parents of students with disabilities. All participants had participated in mediation, due process, or both in an effort to resolve a perceived educational conflict. The authors interviewed the participants an average of 45 minutes and asked six primary, open ended questions:

1. What were the critical incidents that led to the request for mediation?

2. Are there things that you or the school could have done to decrease the conflict?

3. Were there factors that contributed to the conflict other than the actual issues of disagreement?

4. Why do you think the conflict was not resolved at the school level?

5. Are there things you wish you had done differently at the first sign of conflict or in the midst of a parent-school conflict?

6. What other actions could be taken to help parents and schools resolve special education conflicts? 


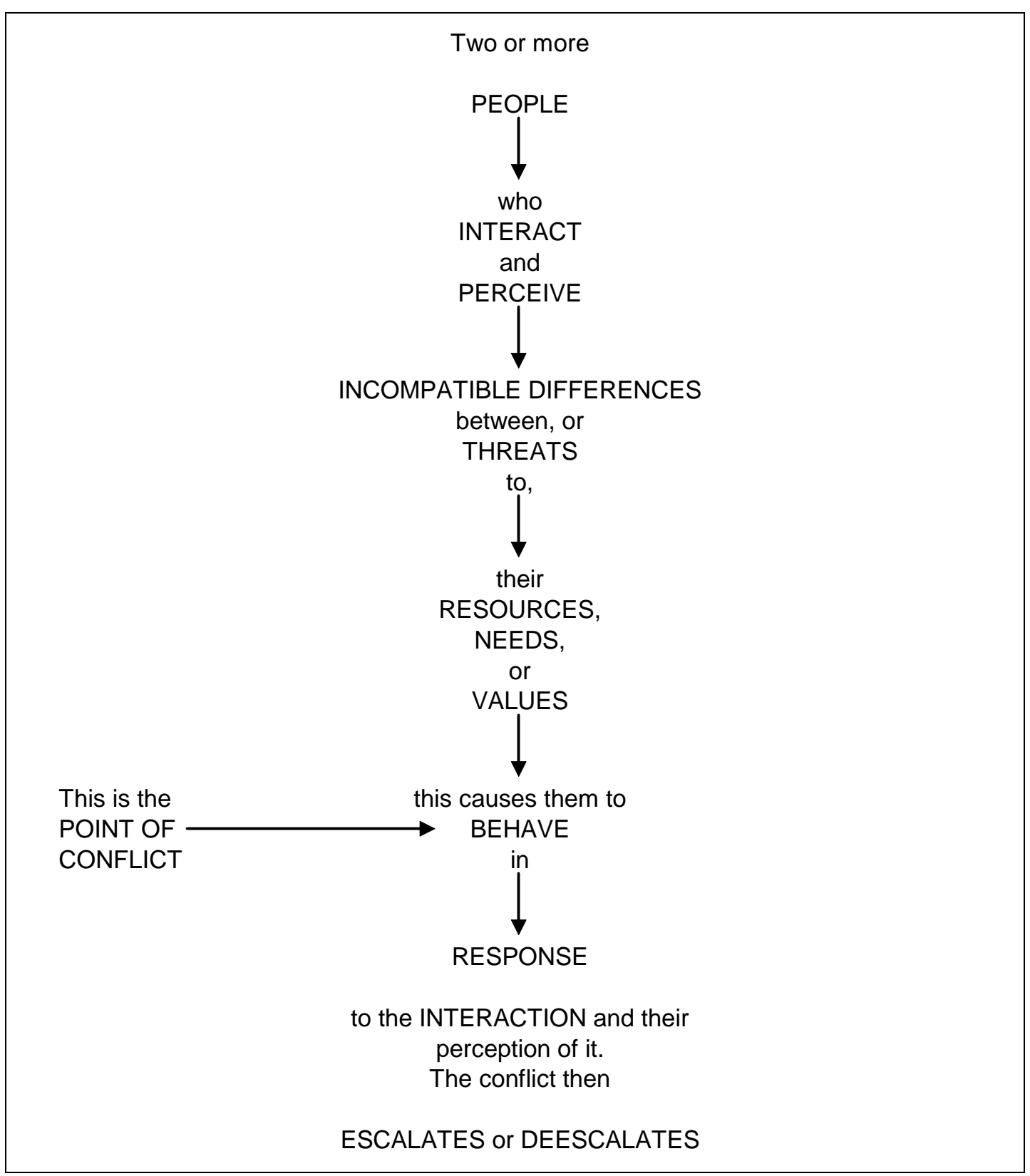

Figure 1. Development of conflict. Note. From “An Analysis of Factors that Contribute to Parent-School Conflict in Special Education,” by J. Lake and B. Billingsley, 2000, Remedial and Special Education, 21(4), p. 244. Adapted from The Resolution of Conflict (pp. 5-8, 350-353), by M. Deutsch, 1973, New Haven, CT: Yale University Press. Copyright 1973 by Yale University Press. Reprinted with permission. 
The data was analyzed using an emergent, grounded theory approach, including open, axial and selective coding, as well as the use of an interrater reliability process. Lake and Billingsley found eight categories of factors that escalate or de-escalate conflict, with corresponding indicators. The authors contend that these eight factors are not mutually exclusive; “in any given conflict situation many factors from various categories may operate simultaneously to escalate, de-escalate or contain a conflict” (p. 244). The researchers hold that the following are factors that escalate, deescalate or contain a conflict (Figure 2):

1. Discrepant views of a child or a child's needs;

2. Knowledge - imbalance, judgment, legal, problem solving;

3. Service delivery - nature of services, length of services, program options;

4. Constraints - fiscal, personnel, time, team functioning;

5. Valuation - issues of human worth;

6. Reciprocal power - action-inaction, intimidation, tenacity;

7. Communication - frequency, quality, distancing, clarifying;

8. Trust - conciliatory attitudes, parental tolerance.

In $90 \%$ of the interviews, Lake and Billingsley found that differences in the parents' and schools' view of the child either initiated or escalated conflict. The authors assert that conflict arises because parents and school professionals look at the child through different lenses; different parent and school perspectives of the child's abilities can become a barrier to a positive parent-school relationship. The findings also pointed out that parents and professionals’ lack of knowledge of how to identify and deescalate conflicts, and an imbalance of knowledge between parents and professionals regarding 


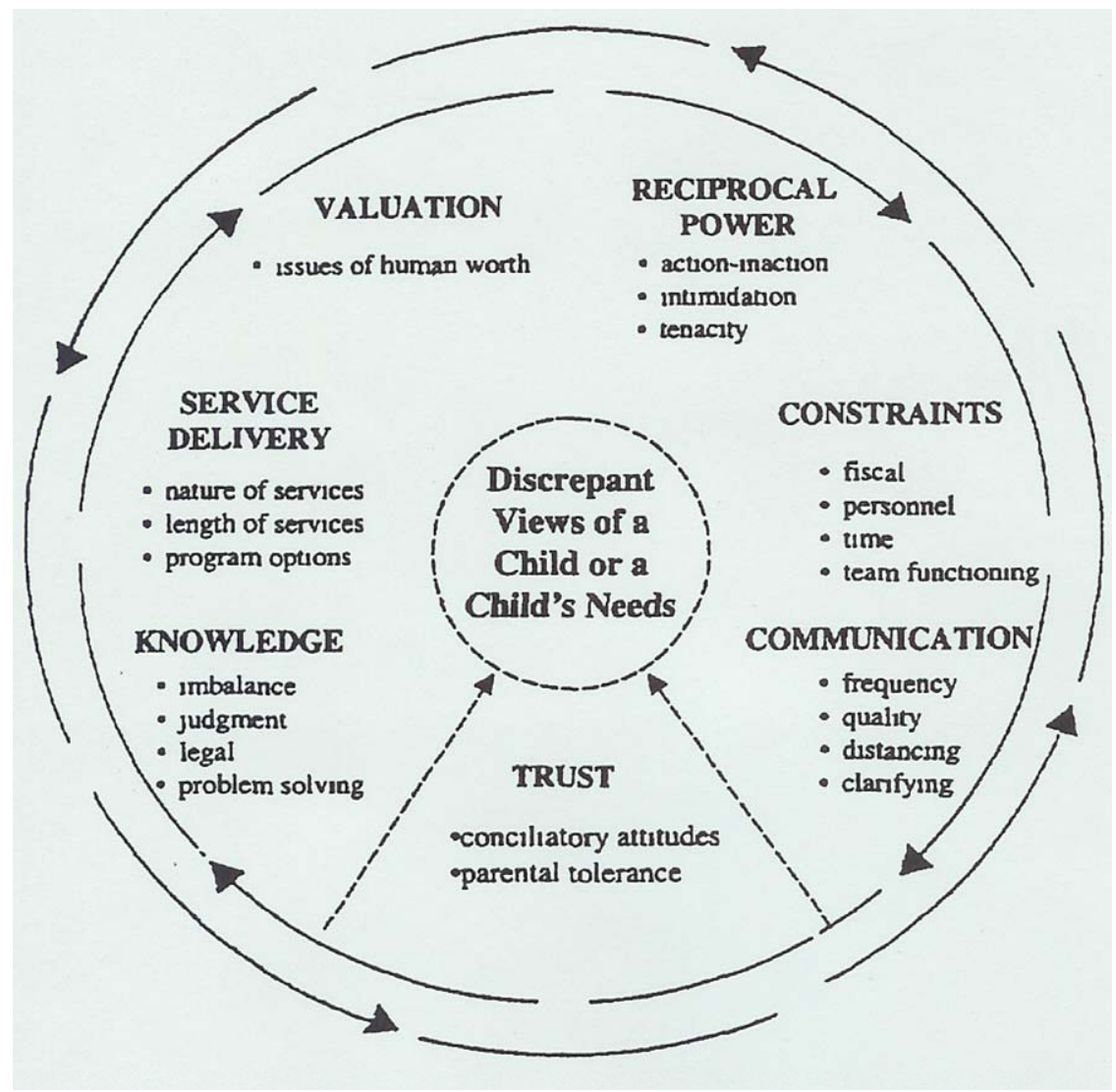

Figure 2. Factors that escalate and deescalate conflict. Note. From "An Analysis of Factors that Contribute to Parent-School Conflict in Special Education,” by J. Lake and B. Billingsley, 2000, Remedial and Special Education, 21(4), p. 244. Copyright 2000 by Remedial and Special Education. Reprinted with permission. 
the special education process had the capacity to escalate conflicts. Parent perception of how services are delivered to their children, the availability of programs they believe are necessary for their child’s FAPE, as well as parent and professional perception of lack of resources materials, time, money and personnel were all identified as escalating factors of conflict. Lake and Billingsley wrote:

Because no one could truthfully state that lack of services was due to lack of funds, other reasons were offered to parents. In some cases, parents became suspicious that the reasons stated were not the real reasons for denying services for their children (p. 246).

The authors also discussed valuation as a factor in conflict escalation. They defined valuation as "who and what people care for and about” (p. 246). The data supported the notion that when all parties value one another's feelings and opinions, conflict de-escalates. Examples of stakeholders' perception of devaluation included feeling lied to, that information was being withheld or that they were being treated in a condescending manner. They iterate "Learning to disagree without devaluing the opposing party is essential if working relationships are to survive” (p. 250).

In addition, Lake and Billingsley’s data demonstrated that conflict escalation occurred when parents and schools perceived the other party's tenacity as a power play to get what they want. "Parents, schools officials and mediators recognized the human costs of the consequences of such conflicts and uses of power” (p. 248).

Trust, or lack thereof, was identified as a "foundational element” in parent-school conflict. Lake and Billingsley indicated that if parents believed the element of trust was present in the parent-school relationship, they were more willing to work with school 
officials to remediate a perceived conflict. If parents perceived the trust element to be missing from the relationship, break down in the parent-school partnership was evident. Lake and Billingsley believe:

Parents in broken-trust relationships lacked the confidence to fully accept school personnel's demonstration of good-faith efforts. After a point, they no longer maintained hope that the parent-school relationship had value in and of itself or provided benefit to the child....The consequences of broken trust resulted in widening discrepant views between parents and schools, and resulted in an unwillingness to take the risks necessary to continue communicating about the needs of children (p. 248-249).

\section{Chapter Summary}

In this chapter, information and research was reviewed related to the foundations of special education, the Individuals with Disabilities Education Act (IDEA) and its provisions for parent-school collaboration and conflict resolution, and the impact of perceived conflict on parent-school partnerships. Blue-Banning, et al. (2004) pointed out that "The significance of partnerships in educational planning is evident in public policy, research, and federal legislation” (p. 167). However, the literature illustrates the disparity between the knowledge that strong parent-school partnerships are integral to planning and implementing a special needs student's individual educational program (IEP) and the ability of parents and school personnel to identify and deescalate conflict when it occurs. Conflict escalation has a crippling effect on parent-school relationships; when parentschool relationships are impaired by conflict escalation, providing FAPE to the special needs student becomes difficult or impossible. Several studies acknowledged factors that 
helped build and maintain strong parent-school collaboration or identified factors that escalated or de-escalated parent conflict. Lake and Billingsley studied the perceptions of parents of special needs children, school administrators and mediators during conflict; they identified factors that escalate and deescalate conflict between parents and schools. The research is relatively silent regarding the impact of points of impasse between parents and schools on conflict escalation during the conflict resolution process.

Lake and Billingsley quoted a parent's oral description of the impact of her experience with points of impasse that led to conflict escalation, which summarizes the spirit of the present study:

No matter how angry I got, the angrier they got back. The angrier I got, the worse the response was. I'm sure I was very annoying to them,...but they're very good at wearing you down. And I was worn down a number of times. It was fighting, all the time. It was like pushing back the water. No matter where you pushed, you were met with resistance everywhere (p. 247). 


\section{CHAPTER 3}

\section{RESEARCH METHODS AND PROCEDURES}

Marshall and Rossman (1989) acknowledged four purposes of research: exploration, explanation, description, and prediction. They pointed out "exploratory research can serve to identify important variables for subsequent explanatory or predictive research” (p. 15). Through their exploratory and descriptive study, Lake and Billingsley (2000) identified eight factors that have an effect on conflict escalation or deescalation between parents and schools. My goal was to discover and describe the impact of points of impasse between parents and school professionals on conflict escalation during the conflict resolution process set forth in the Individuals with Disabilities Education Act (IDEA). This chapter outlines and explains the research methods that were employed in this study, including design choice, case selection, and data collection, storage and analysis.

Yin (1984) wrote "A case study is an empirical inquiry that:

- Investigates a contemporary phenomenon within its real-life context; when

- The boundaries between phenomenon and context are not clearly evident; and in which

- Multiple sources of evidence are used" (p. 23).

Patton (1990) also believed that when there is a need to understand a unique situation in great depth, and where one can identify a case that is rich in information about the phenomenon in question, case studies are quite useful. Using an archival case study approach, this investigation endeavored to identify those tacit, often hidden aspects of the 
parent-school relationship that occur during IDEA's conflict resolution process. This research design permitted me to discover answers to the following research question using content analysis of a complete archived record: What is the impact of points of impasse between parents and schools on conflict escalation during the conflict resolution process? The choice of a qualitative, document analysis was logical because the question above required deep exploration with the aim to describe and explain the documented relationship between parents and school district that rendered this notable case.

\section{Selection of the Case}

Patton (1990) believes "Cases are selected for study because they are of particular interest given the study's purpose” (p. 53). To get a close-up view of the phenomenon to be studied, this investigator chose to focus in depth on one single, extreme case. "The logic of extreme case sampling is that lessons may be learned about unusual conditions or extreme outcomes that are relevant to improving more typical programs...logical generalizations can often be made from the weight of evidence produced from studying a single, critical case” (Patton, 1990, pp. 170, 175). The selection criteria for the unit of study were as follows:

1. The parents and school district (parties) must have been involved in the Individuals with Disabilities Education Act (IDEA) conflict resolution process;

2. The parties must have exhausted the entire IDEA conflict resolution process, terminating in the U.S. Supreme Court;

3. The break down of the parent-school partnership must have been a primary factor in the administrative hearing officers' (AHOs) and judges' decision at each point of impasse. 
Selection criteria number two was used to access the most points of impasse allowable by law. The subunits of study were the parents, the school district professionals directly involved in the conflict resolution process, the AHOs and judges, and all pertinent witnesses.

To find an appropriate case that met the criteria listed above, legal research was required to locate all cases pertinent to this investigation. "Legal research is concerned with document search and interpretation. It is concerned not with the discovery of 'scientific fact' but rather with correspondence with human made norms and behaviors” (Different Strokes, n.d.). I consulted a licensed attorney in West Virginia. A Westlaw search was completed given the above criteria. The Westlaw search reviewed all pertinent, reported case law recorded in law reports. Law reports consist "only of those cases that raise significant points of law or expand on the understanding of the law... Law reports are published for the purpose of being used as precedent (Law Reports, 2004). Precedent is defined in Black's Law Dictionary as:

An adjudged case or decision of a court, considered as furnishing an example or authority for an identical or similar case afterwards arising or a similar question of law. Courts attempt to decide cases on the basis of principles established in prior cases. Prior cases which are close in facts or legal principles to the case under consideration are called precedents; a rule of law established for the first time by a court for a particular type of case and thereafter referred to in deciding similar cases; a course of conduct once followed which may serve as a guide for future conduct (Garner, 1990, p. 1195). 
The Westlaw search identified only one case that met the selection criteria: The Board of Education of Community Consolidated School District No. 21 v. Illinois State Board of Education (BOE v. ILL). BOE v. ILL. is the only case involving conflict escalation to the point of irreconcilable differences that has been appealed to the U.S. Supreme Court (cert denied); it is also recognized as the pivotal, landmark decision in the area of parent-school conflict (N. W. Brown, personal communication, January 11, 2002). These inimitable attributes and the fact that this case met the selection criteria ensured that this documented case of parent-school conflict was purposive and not random. Also, due to the plethora of archived records, documents and exhibits in this case, $B O E v$. ILL. lent itself to a depth and breadth of interpretation in non-legal ways. For purposes of this study, I interpreted the archived information from a semiotic point of view, looking for meanings which are not the ones a lawyer or judge would normally expect to find in such documentation. Interpretation of this nature, called hermeneutics, espoused the study of meaningful communication, such as the stakeholders' language and narrative structure (Mohr, 2004). This analysis drew attention to people’s words or actions in a cultural way that fostered a different meaning from the one explicitly provided in AHO's or judge's decision. However, my use of a semiotic point of view to interpret the data might place limitations on this study. It must be recognized that trust between people is a negotiated thing; each party in a relationship experiences trust from their own point of view, which may or may not be experienced similarly by the other party in the relationship, or other "third” parties. The parties' experiences may or may not have been reflected in the record in such a way that the embedded meanings sifted 
from the documents mirror the experiences between the parties regarding trust in this case.

\section{Data Collection}

The data examined for this study was directly related to the focus of inquiry: the data was provided via archived documentary evidence. Maycut \& Morehouse (1994) believe that qualitative research can be done using documents as a primary source of data. Quoting Harbert, et al. (1992), Maycut \& Morehouse also accept as true that "It is possible to conduct a qualitative study using only documents...” (p. 112). Merriam (1990) details the rationale for utilizing documents as a primary source of information in an investigation:

Documents... are produced for reasons other than research and therefore are not subject to the same limitations. They are, in fact, a ready-made source of data easily accessible to the imaginative and resourceful investigator (p. 104).

The data found in documents can be used in the same manner as data from interviews or observations. The data can furnish descriptive information, verify emerging hypotheses, advance new categories and hypotheses, offer historical understanding, track change and development, and so on (p. 108).

One of the greatest advantages in using documentary material is its stability. Unlike interviewing and observation, the investigator does not alter what is being studied by his or her presence. Documentary data are 'objective' sources of data compared to other forms. Such data have been called 'unobtrusive’ (p. 108-109). Documents...should be used when it appears they will yield better data, more data, or data at less cost than other methods (p. 108). 
Because documents exist independent of a research agenda, they are non-reactive - that is, unaffected by the research process. They are a product of the context in which they were produced and therefore grounded in the real world (p. 109). Lincoln and Guba (1985) differentiate records and documents. Records are created to memorialize a formal transaction, such as marriage certificates, court transcripts, and banking statements; documents are created for personal reasons, such as letters, memos, and diaries. Working with two law firms in West Virginia, a written request for a photocopy of all public records and accompanying documents of The Board of Education of Community Consolidated School District No. 21 v. Illinois State Board of Education (BOE v. ILL.) was mailed to the U.S. $7^{\text {th }}$ Circuit Court of Appeals. The photocopies were paid for and delivered to this investigator (Appendix A). The public records and accompanying documents included all court dockets, due process hearing and trial transcripts, motions and pleadings of the parties, and all exhibits. These records and documents were a valuable data source because they could be acquired in a practical, yet systematic manner, and they contained comprehensive information relevant to the research question.

Merriam (1990) wrote "Determining the authenticity and accuracy of documents is part of the research process” (p. 107). Merriam provided a framework for ensuring authenticity of the records and documents that include the questions below:

- What is the history of the document?

- How did it come into my hands?

- What guarantee is there that it is what it pretends to be?

- Is the document complete, as originally constructed? 
- Has it been tampered with or edited?

- If the document is genuine, under what circumstances and for what purposes was it produced?

- Who was/is the author?

- What was he trying to accomplish? For whom is the document intended?

- What were the maker's sources of information?

- Does the document represent eyewitness account, a secondhand account, a reconstruction of an event long prior to the writing, an interpretation?

- What was or is the maker's bias?

- To what extent was the writer likely to tell the truth?

- Do other documents exist that might shed additional light on the same story, event, project, program, context? If so, are they available, accessible? Who holds them? (p. 107).

Each record or document was reviewed to determine if it is authentic prior to content analysis (Figure 3).

\section{Recording and Storing Data}

The names of all parties involved are public record; confidentiality is not of issue. However, due to the sensitive nature of this case, all names of the participants were excluded and a descriptive moniker was conferred on each subject. For example, the student's name was not used; he was simply called "Son,” or "the student.” All records, documents, and detailed notes were kept in locked file cabinets in a secure area at all times. Only the researcher had access to the data. All committee members could access the data upon request. 
Name of Document:

Page Number:

Code:

\begin{tabular}{|c|c|c|c|}
\hline Question & Response & \multicolumn{2}{|c|}{ Authentication Determination } \\
\hline $\begin{array}{l}\text { What is the history of the } \\
\text { document? }\end{array}$ & & $\square$ Yes & Do \\
\hline How did it come into my hands? & & DYes & DNo \\
\hline $\begin{array}{l}\text { What guarantee is there that it is } \\
\text { what it pretends to be? }\end{array}$ & & $\square$ Yes & $\square$ No \\
\hline $\begin{array}{l}\text { Is the document complete, as } \\
\text { originally constructed? }\end{array}$ & & $\square$ Yes & $\square$ No \\
\hline $\begin{array}{l}\text { Has it been tampered with or } \\
\text { edited? }\end{array}$ & & $\square$ Yes & $\square$ No \\
\hline $\begin{array}{l}\text { If the document is genuine, under } \\
\text { what circumstances and for what } \\
\text { purposes was it produced? }\end{array}$ & & $\square$ Yes & No \\
\hline Who was/is the author? & & Q Yes & D No \\
\hline $\begin{array}{l}\text { What was he trying to accomplish? } \\
\text { For whom is the document } \\
\text { intended? }\end{array}$ & & $\square$ Yes & $\square$ No \\
\hline $\begin{array}{l}\text { What were the maker's sources of } \\
\text { information? }\end{array}$ & & $\square$ Yes & $\square$ No \\
\hline $\begin{array}{l}\text { Does the document represent } \\
\text { eyewitness account, a secondhand } \\
\text { account, a reconstruction of an } \\
\text { event long prior to the writing, an } \\
\text { interpretation? }\end{array}$ & & $\square$ Yes & $\square$ No \\
\hline What was or is the maker's bias? & & $\overline{D Y e s}$ & Q No \\
\hline $\begin{array}{l}\text { To what extent is the writing likely } \\
\text { to tell the truth? }\end{array}$ & & $\square$ Yes & $\square$ No \\
\hline $\begin{array}{l}\text { Do other documents exist that } \\
\text { might shed additional light on the } \\
\text { same story, event, project, } \\
\text { program, context? If so, are they } \\
\text { available, accessible? Who holds } \\
\text { them? }\end{array}$ & & $\square$ Yes & $\square$ No \\
\hline
\end{tabular}

Figure 3. Framework for authentication of records and documents. Note. Adapted from

Case study research in education: A qualitative approach (pp. 107-108), by S. B.

Merriam, 1990, San Francisco: Jossey-Bass. Copyright 1990 by Jossey-Bass. 


\section{Data Analysis}

“Qualitative studies ultimately aim to describe and explain a pattern of relationships, which can only be done with a set of conceptually specified analytic categories” (Michler, 1990, p.185, as cited in Denzin \& Lincoln, 1998). With this end in mind, an inductive, emergent approach to document analysis of the archived records of this case was utilized. Each page of the raw data was coded to ensure ease of identification. All records were coded by page and line number. All documents were coded by Bates stamp, a stamp that is placed on each document included as an exhibit in a court case by the proffering attorney. The few documents that did not have a Bates stamp were hand numbered. The data was then unitized: “The process of qualitative data analysis is one of culling meaning from the words or actions of the participants in the study, framed by the researcher's focus of inquiry” (Maycut \& Morehouse, 1994, p. 128). Maycut and Morehouse's constant comparative method was used to analyze collected data.

The initial coding categories were the eight factors that escalate or deescalate conflict between parents of students with disabilities and schools as identified by Lake and Billingsley (2000). These categories are listed below:

1. Discrepant views of a child or a child's needs;

2. Knowledge - imbalance, judgment, legal, problem solving;

3. Service Delivery - nature of services, length of services, program options;

4. Constraints - fiscal, personnel, time, team functioning;

5. Valuation - issues of human worth;

6. Reciprocal power - action-inaction, intimidation, tenacity; 
7. Communication - frequency, quality, distancing, clarifying;

8. Trust - conciliatory attitudes, parental tolerance.

Each unit of meaning was continually compared to data previously categorized; those that were similar were grouped together. If a unit of meaning did not easily group with a known category, the inductive design of this study allowed for refinement to occur by merging or omitting old categories and creating new categories, bringing about the discovery and exploration of new relationships and patterns. This was done by writing rules of inclusion, or identifying properties that each unit of meaning had in common, which were stated as propositions, a statement of fact grounded in the data (Maycut \& Morehouse, 1994). Each unit of meaning was then coded to its propositional category.

Once all units of meaning were appropriately categorized, this investigator closely examined all categories and propositions to uncover relationships and reveal emergent patterns. Exploration of this new information widened or narrowed the focus of inquiry, yielding a better understanding of the phenomenon of interest (Maycut \& Morehouse, 1994).

\section{Researcher Point of View}

This research was conducted by a central administrator of special education (CASE). From a CASE perspective, the school district's main goal is to provide the special needs student with FAPE as IDEA dictates. At times it seems impossible to do so because the parent-school partnership is jeopardized by the negative, emotional experiences of moving through the conflict resolution procedures. I "wear the hat" of a school administrator, which allowed a dual perspective: one, of the frustrations of all stakeholders involved in an escalating conflict; the other, the ability to discern the need 
for further examination of this event. Because of my role as a school administrator, I am sensitive to conflict escalation between parents and schools. My role as a school administrator and the experiences I have gained in this role bias my perspective as a researcher. However, my experiences have prompted me to ask this research question and to diligently search for answers. Because the answers are embedded in value systems such as my own, they are not objective measures. Therefore, there is a possibility that my interpretation of the data may be shaded by this point of view. To counter the possibility of researcher bias, chapter four was built to ensure the events in this case were described objectively. As a check against researcher bias, my doctoral committee chair conducted a detailed review of all content subsequently included in chapter four. 
Table 1.

Timetable for Conducting the Research

\begin{tabular}{|c|c|c|c|c|}
\hline 2004 & Week 1 & Week 2 & Week 3 & Week 4 \\
\hline $\begin{array}{c}\text { SEP } \\
- \\
\text { OCT }\end{array}$ & $\begin{array}{l}\text { Prospectus } \\
\text { preparation. }\end{array}$ & $\begin{array}{l}\text { Prospectus } \\
\text { preparation. }\end{array}$ & $\begin{array}{l}\text { Prospectus } \\
\text { preparation. }\end{array}$ & $\begin{array}{l}\text { Prospectus } \\
\text { preparation. }\end{array}$ \\
\hline $\begin{array}{c}\text { NOV } \\
- \\
\text { DEC }\end{array}$ & $\begin{array}{l}\text { Prospectus } \\
\text { preparation. }\end{array}$ & $\begin{array}{l}\text { Prospectus } \\
\text { preparation. }\end{array}$ & $\begin{array}{l}\text { Prospectus } \\
\text { preparation. }\end{array}$ & $\begin{array}{l}\text { Prospectus } \\
\text { preparation. }\end{array}$ \\
\hline 2005 & Week 1 & Week 2 & Week 3 & Week 4 \\
\hline $\begin{array}{c}\text { JAN } \\
- \\
\text { MAR }\end{array}$ & $\begin{array}{l}\text { Prospectus } \\
\text { preparation. }\end{array}$ & $\begin{array}{l}\text { Prospectus } \\
\text { preparation. }\end{array}$ & $\begin{array}{l}\text { Prospectus } \\
\text { preparation. }\end{array}$ & $\begin{array}{l}\text { Prospectus } \\
\text { preparation. }\end{array}$ \\
\hline APR & $\begin{array}{l}\text { Prospectus } \\
\text { examination. }\end{array}$ & Data collection. & $\begin{array}{l}\text { Unitize data, } \\
\text { construct coding } \\
\text { categories, write } \\
\text { case narratives. } \\
\text { Write. }\end{array}$ & $\begin{array}{l}\text { Data analysis: } \\
\text { constant } \\
\text { comparative } \\
\text { method. Write. }\end{array}$ \\
\hline MAY & $\begin{array}{l}\text { Data analysis: } \\
\text { constant } \\
\text { comparative } \\
\text { method: Write. }\end{array}$ & $\begin{array}{l}\text { Data analysis: } \\
\text { constant } \\
\text { comparative } \\
\text { method: Write. }\end{array}$ & $\begin{array}{l}\text { Schedule } \\
\text { Dissertation } \\
\text { Defense. Write. }\end{array}$ & $\begin{array}{l}\text { Defense } \\
\text { Preparation. }\end{array}$ \\
\hline JUN & $\begin{array}{l}\text { Defense } \\
\text { Preparation. }\end{array}$ & Final Defense. & $\begin{array}{l}\text { Revisions to } \\
\text { Dissertation. }\end{array}$ & $\begin{array}{l}\text { Revisions to } \\
\text { Dissertation. }\end{array}$ \\
\hline JUL & $\begin{array}{l}\text { ETD } \\
\text { Submissions. }\end{array}$ & & & \\
\hline AUG & $\begin{array}{l}\text { Degree } \\
\text { Conferred. }\end{array}$ & & & \\
\hline
\end{tabular}




\section{CHAPTER 4}

\section{THE CHRONICLE OF ONE FAMILY'S EDUCATIONAL ENCOUNTER}

The purpose of this study is to provide a rich description of the impact of points of impasse between parents and schools on conflict escalation during the conflict resolution process. This was accomplished by performing an in-depth document analysis of the archived records of one unique case: The Board of Education of Community Consolidated School District No. 21 v. Illinois State Board of Education (BOE v. ILL., 1991).

The first section of this chapter is an explanation of the process for locating and retrieving the archived records used in the document analysis. The second section describes the participants and their roles in the case. These descriptions are a composite sketch of the information presented in the archived records. The third section depicts a chronological portrayal of each participant's experiences with points of impasse and conflict escalation, as evidenced in Son's archived educational and legal records in this inimitable case.

\section{The Archived Record}

This investigator contacted an attorney in a law firm in West Virginia to inquire about locating and retrieving a copy of the public, archived record of the court case $B O E$ v. ILL. (1991). The West Virginia attorney informed this investigator that the most expedient way to gain access to the complete record was to request a copy of the record from one of the representing attorneys in the case. This investigator asked the West Virginia law firm to proceed with acquiring a copy of the complete record; the West 
Virginia law firm chose to identify, locate and make contact with the law firm that represented the school district. The West Virginia law firm then verbally requested a copy of the record. A follow-up request was also made via e-mail. The Illinois law firm agreed to locate, duplicate, and mail a copy of the complete archived record to the West Virginia law firm, noting that the record was quite voluminous. A contract was drawn up between this investigator's agent (the West Virginia law firm) and the Illinois law firm, stipulating the specific hourly rate at which the Illinois law firm would locate, duplicate and mail the record in its entirety to the West Virginia law firm. The contract was signed by both law firms. The documents were located, duplicated and mailed to the West Virginia law firm. The West Virginia law firm presented the duplicated copy of the complete, archived record to this researcher upon receipt of payment for the record. The record was reviewed by this researcher to ensure that all documents, transcripts and exhibits were accounted for per the docket sheet. All documents were reviewed for authenticity.

Once authenticated, the archived record was analyzed to identify and provide descriptions of the participants in this case.

\section{Meet the Participants}

\section{The Family}

The archived records produced the following descriptions of members of the family. These descriptions were provided by members of the family to professionals who were taking pertinent histories to gain historical background regarding Son’s family life:

The family consisted of Mom, Dad, Son, and Grandpa (Dad's father). They lived together in a single family dwelling in a working class neighborhood in a close suburb of 
Chicago, Illinois. English was the spoken language in the home. The family had several pets: a dog, a cat, and a goldfish.

Grandpa. Grandpa was born in 1903. He married, but Grandma passed away. Mom reported that Grandpa transitioned into the family in 1973 at the age of 70. Grandpa was 28 years old when Dad was born. Grandpa was a retired shoemaker and spent most or all of his day at home. Grandpa provided care for Son when needed and requested. Mom reported that Grandpa (her father-in-law) could “sometimes be gruff and mean,” so Mom didn’t ask Grandpa to care for Son very often.

Dad. Dad was born May 25, 1931 into a two-parent, one sibling household. His older brother died when Dad was four years old. Dad completed high school, and subsequently enlisted in the military, serving during the Korean Conflict. Dad was currently an electronic technician, working from 7:30 a.m. to 4:00 p.m. daily. Dad was seven years older than Mom. Dad was married to Mom for many years prior to having Son. Dad was 46 years old when Son was born. Son was Dad's only child. There was no record of any prior marriages. Dad's only remarkable, reported health history was an ulcerated leg that caused hospitalization at an unrecorded date after Son was born.

Mom. Mom was born on April 15, 1938. She was the oldest of three siblings. She completed high school and went to one year of college. Mom was currently a proofreader for an insurance company, and had worked in this capacity for 25 years. Her work hours were 7:30 a.m. to 3:30 p.m. daily. Mom and Dad were married for many years prior to having Son. Mom reported that although they tried to have children earlier in their marriage, “it wasn’t meant to be.” Mom and Dad were “surprised and happy” when they found out Mom was pregnant. Mom was 39 years old when Son was born. Son was 
Mom’s only child. Mom denied any prior marriages. The only significant medical history Mom reported was high blood pressure. Mom noted a family history of mental retardation; she indicated her brother's mental retardation was “injury related” and that he also had cerebral palsy. Mom also noted that she, her mother and her brother suffered from allergies.

Son. Mom reported no significant health related issues before pregnancy. Mom began prenatal care during her third month of pregnancy, seeing the doctor monthly thereafter, and weekly during the last month of pregnancy. Mom reported feeling "great" during pregnancy; she neither smoked, used alcohol nor drugs during pregnancy. Mom reported that the fetus kicked “a lot - I couldn’t sleep at night!” Mom conveyed that Son was born weighing seven pounds, 11 ounces on September 30, 1976 at St. Joseph’s Hospital in Chicago after 14.5 hours of labor. At that time, doctors informed Mom that a C-section was needed due to the transverse position of the fetus. Mom was placed under general anesthesia, and a routine C-section was performed; no complications ensued. Son cried immediately after birth, and there was no record of any injuries, defects or need for further medical support or intervention for Son while hospitalized. Mom and Son were discharged eight days later, upon Mom’s sufficient recovery from the C-section.

Mom reported Son’s developmental history as significant. She indicated that Son “never slept at night”, and that "he wouldn't take milk.” Mom conveyed that Son was "high strung, strong tempered and very independent, but loved to be cuddled." Son was toilet trained at 13 months, but could not feed himself until age two "because he couldn't hold a cup or fork right.” Mom stated Son’s developmental milestones were otherwise unremarkable, with the exception that Son never crawled; he simply began walking at 10 
months of age. Mom conveyed that Son's speech and language development was also within normal limits. Mom described Son's medical history stating that Son had a high fever at age 17 months; Son was hospitalized at that time for five days due to gastroenteritis and subsequent dehydration. He also had a mild case of the chicken pox, as well as recurring ear infections. Son was diagnosed with a hearing loss due to the ear infections at age five, and subsequently had surgery to remove his tonsils and adenoids and simultaneously had pressure equalization (PE) tubes placed in both ears. Mom described his hearing loss as “corrected, but he still gets ear infections every once in a while.”

Mom described Son’s preschool years as “spending most of his early childhood with adults, including his parents, grandmother and grandfather." She stated that "Son received lots of special attention before he started school and he found that very satisfying." Mom reported that Son attended nursery school at 2.5 years of age, but "he resented me going to work." Mom said that Son did not interact well with age appropriate peers. She conveyed that Son was "hard to get along with at school and would not share with other children; he would bang his head and chew the buttons off his shirt, and hit other children.” Mom also stated, “Son didn’t have to play with those other kids; we played with him at home anytime he wanted.” Mom again noted that Son had difficulty “with his motor - couldn’t color, cut and paste like the other kids... and it was almost like he could not see the board. He couldn't skip, either.” Son attended nursery school exhibiting similar behaviors until he enrolled in public Kindergarten.

Mom described Son’s physical attributes as being a “small boy, with beautiful dark, curly hair and sparkly eyes.” Mom described Son’s personality as “a real charmer - 
he can be real good and real bad." She noted that "Son is friendly, but sometimes gets his temper, but he can be reasoned with more now that he's past the 'terrible twos'. He can be really sensitive, and cries easily. He has a hard time sitting still.”

\section{The School District}

Community Consolidated School District No. 21 was a school district in a suburb on the outskirts of the Chicago city limits. The archived records produced the following self descriptions of the school district employees involved in this case:

Assistant Superintendent for Support Services. The assistant superintendent for support services (Asst. Supt.) had held this position for 15 years. He was also a teacher and junior high school principal in the same school district. The Asst. Supt. had been employed by the school district for 34 years. His current duties included administrating special education for the District. He held a master's degree in education, and Illinois state certificates for administrator and teacher.

Principal. The principal was asked only one question about himself. Principal was the principal at Watson Junior High, where Son attended.

Special Education Teacher 1. Special Education Teacher 1 (SpEd Teacher 1) was a teacher of students with behavior disorders (BD) at the junior high school Son attended; it was her first year at Watson Junior High. However, she worked for three years previously at an elementary school in the District. Prior to that she worked as a BD teacher for five years in another school district. She received her bachelor's degree in special education at Illinois State University in 1980, and her master's degree in education administration and supervision from the same institution in 1988. SpEd 
Teacher 1 held Illinois state certificates in learning disabled (LD), BD and mentally impaired (EMD). She was Son's teacher for approximately three months.

Special Education Teacher 2. Special Education Teacher 2 (SpEd Teacher 2) had been teaching LD and BD students in the school district for five years. This was her first year at Watson Junior High; previously she was at Key Elementary School for four years. Prior to working in District 21, SpEd Teacher 2 taught BD students in an alternative junior high school in another school district. She held Illinois state certification in LD and $\mathrm{BD}$, administration and supervision. She received her bachelor's degree in special education from Southern Illinois University in 1982 and her master’s degree from National College of Education in administration and supervision in 1988.

P.E. Teacher 1. P.E. Teacher 1 was the physical education teacher at Watson Junior High School, the junior high school Son attended.

P.E. Teacher 2. P.E. Teacher 2 taught P.E. at Robert Elementary School, where Son attended grades 1-4. She had Son for P.E. from first through fourth grade.

LD and BD Coordinator. LD and BD Coordinator was employed by the Northwest Suburban Special Education Organization (NSSEO) since 1977. This public organization provided support services to special education students in several school districts, including District 21. LD and BD Coordinator served District 21 exclusively from 1982 to 1989. Prior to that, he was employed as a special education teacher for other school districts and the Illinois Department of Corrections. LD and BD Coordinator received his bachelor's degree in history at Northern Illinois University in 1967. He received a master's degree in secondary education in 1968 from the same institution. LD and BD Coordinator received another master's degree in Special 
Education in 1974. He holds Illinois state certification in administration of special education, LD, BD, history and political science.

Special Education Teacher 3. Special education Teacher 3 (SpEd Teacher 3) had taught for ten years. She worked at Watson Junior High for seven years. She holds Illinois state certification in LD and BD. SpEd Teacher 3 was Son's Science teacher at Watson Junior High.

The Legal Staff

Both the parents and the school district hired attorneys to represent them throughout the IDEA conflict resolution process. Beginning with the first due process hearing, administrative hearing officers (AHOs) or judges presided over the hearings or civil suits, and, in turn, rendered decisions and orders. Based on the information provided in the archived records regarding these individuals, the following are descriptions of the officers of the court:

Family Attorney. The family attorney (FA) was born June 8, 1944 in Chicago, Illinois. He was married with two children. He graduated from Roosevelt University with a Bachelor of Art degree in 1969. He graduated from the Chicago Kent College of Law in 1973. FA worked from 1973 through 1979 in two different law firms in the Chicago area. In 1979, he began a solo practice as a plaintiff's attorney. FA held Illinois state certificates as a Level I and Level II Due Process Hearing Officer.

School District Attorney. The school district attorney (SDA) was a married, professional female. She worked as an associate attorney for a large defense firm with offices in four major U.S. cities, including Chicago. 
Administrative Hearing Officer 1. Administrative Hearing Officer 1 (AHO1) was a professional female. She completed her Bachelor of Art degree Cum Laude in Psychology, her Masters of Education Degree in Special Education, and was completing her Juris Doctorate in law for the duration of the due process hearing. She held Illinois state certification in Director of Special Education, Administration, and Level I Due Process Hearing Officer. She had 15 years of teaching experience, including teaching children with behavior disorders in a variety of settings including public schools, vocational programs and psychiatric hospitals. AHO1 was a full time student and worked as an independent educational consultant at the time of the due process hearing. She was mutually agreed upon by the parties as the hearing officer in this case.

Administrative Hearing Officer 2. Administrative Hearing Officer 2 (AHO2) was also mutually agreed upon by the parties to hear the Level II due process. AHO2 was a professional male who held an Illinois state certificate for Level I and Level II Due Process Hearing Officer.

Judge, United States District Court for the Northern District of Illinois, Eastern Division. The judge that heard this case was the Honorable George W. Lindberg. Judges, United States $7^{\text {th }}$ Circuit Court of Appeals. The Honorable Cummings, Wood, Jr. and Flaum heard this case. Judge Wood, Jr. dissented with the majority opinion in this case.

United States Supreme Court. William Suter, Clerk for the Supreme Court, was the U.S. Supreme Court's designated signatory and correspondent. He denied the request of the Board of Education of Consolidated School District No. 21 and the state of Illinois to be heard (writ of certiorari) in this case. 
Expert Witness. (Marcie Canel) Expert Witness was called to testify for the family. She was an education therapist and an LD and BD teacher. Expert Witness held an Illinois state certification in LD and BD. She received her bachelor's degree from the University of Illinois in 1973; she received her master's degree from National College of Education in 1987. She held various teaching positions in the past.

Son’s Educational History Unfolds

Kindergarten 1981-1982

Son attended kindergarten during the 1981-1982 school year at Meadow Elementary School, the school in his home attendance area. Son was transferred to Robert Elementary School to attend first grade for the 1982-1983 school year. The records are silent as to who initiated the transfer and the reason the transfer occurred. First Grade 1982-1983

On September 16, 1982 Son’s first grade teacher at Robert Elementary School referred Son to the Case Study Team. She noted that Son was "having a difficult time learning beginning sounds and is very disorganized in work habits." She wrote that "Son has been frustrated in doing beginning sound work \& will crumble papers or not turn them in.” The first grade teacher also listed the ways she tried to remedy the problem: use of picture identification dittos and oral presentation of words. She wrote, "Son is successful when he works one-on-one, one step at a time.” The first grade teacher wrote about her concerns for Son: "Son has a good personality - willing to work and a great desire to learn. He is a cooperative child but he is becoming very frustrated by his inability to achieve success in beginning reading.” It is not known if Mom and Dad were provided with this information. 
Mom and Dad were sent an unsigned, undated form letter from Asst. Supt. requesting permission to do a Case Study Evaluation of Son. This letter did not document any specific concerns regarding Son's current levels of educational performance, but did state that the parents would be "fully informed" of the evaluation results, and that Son would "continue in his current placement until the case study evaluation was completed." Mom signed on September 10, 1982, granting permission to evaluate.

The case study evaluations were completed within timelines. On September 15, 1982 an assessment of Son’s learning environment was done by the first grade teacher and the primary $\mathrm{LD}$ and $\mathrm{BD}$ teacher. When describing what kind of difficulty Son exhibited in the classroom, they wrote, "Son has difficulty listening \& paying attention; some trouble learning beginning sounds; disorganized work habits; difficulty performing paper pencil tasks; tires easily.” They wrote that these difficulties manifest themselves “in large group situations - easily distracted; seat work that is difficult.” They also noted Son’s areas of success: "oral language skills are good; good social skills; volunteers in large group situations; good memory.”

On September 17, 1982 the school nurse called Mom and took a family medical \& health history over the telephone. This was one of three in the record.

On October 7, 1982 the school psychologist did a comprehensive psychological evaluation. The psychologist summarized the first grade teacher's information in this way: "The first grade teacher related that Son is a cooperative boy who is becoming very frustrated by his inability to achieve.” Given the Weschler Intelligence SC-Revised (WISC-R: a formal psychological test battery that determines innate intelligence; the average scaled score on this test is 100), Son had a full scale score of 102, with a verbal 
score of 123 and a performance score of 81 . The psychologist described Son in this way in his report:

Son has overall potential in the above average to superior range. He has decided learning disabilities in the visual perceptual and visual motor channel. He has an excellent vocabulary and excellent judgment for a boy his age. Son appears to be a well adjusted boy and emotional factors do not appear to be relevant at this time. In summary, Son shows dramatic discrepancies between his high verbal skills and low visual perceptual and visual motor skills. He should receive the services of a learning disabilities resource room teacher to accommodate his visual perceptual and visual motor weaknesses.

On October 18, 1982 Son was made eligible for special education services under the exceptionality of specific learning disabilities, and an individualized education program (IEP) was developed for him. The principal, first grade teacher, LD and BD resource teacher, psychologist and Mom made up the IEP team. When writing the IEP, Son's skills were described as noted above with these additions: "Fine motor skills are poor. Has difficulty tying his shoes. He has trouble skipping. Socially immature; plays aggressively; good peer relationships; has difficulty following oral directions; difficulty attending; enjoys being helpful.” The IEP team determined that Son needed to be in a special education resource room for 2.5 hours per week for direct instruction in visual perception, motor, organization and integration skills. All members, including Mom, were in agreement.

On May 19, 1983, at the end of Son's first grade year, the IEP team met again to discuss Son's educational progress. It was noted that a decision had already been made 
to retain Son in first grade. Reason for retention was not noted. In the IEP, present levels of educational performance state:

Son works hard to complete seat work but doesn't always understand the work. He understands the basic concepts of addition, but has not yet memorized his facts to 10. Fine motor skills are poor, but there has been improvement this year. He has difficulty copying from the board, correctly spacing letters \& words, cutting. Son is very immature. He has trouble sitting for long periods of time; organizational skills are poor; he has good peer relationships but gets frustrated when things don’t go his way. He enjoys being helpful.

Son's time in the resource room was increased from 2.5 to three hours per week working on the same areas of weakness noted in his initial IEP. All members of the IEP team agreed, including Mom.

\section{First Grade Repeated 1983-1984}

On May 17, 1984, at the end of Son's repeated first grade year, the IEP team met again to discuss Son's present levels of educational performance:

Son has mastered all first grade criteria in arithmetic. His reading comprehension skills are good, but word attack skills and sight vocabulary still remain a little weak. Son's gross motor skills are average for his age. His fine motor skills are much better. He can write neatly \& legibly. Independent work does not always reflect this. Son does not always take pride in his work; he doesn't always put forth the effort he is capable of. He has good peer relationships.

The IEP team continued his placement in the LD resource room, but decreased his time to 2 hours per week. All IEP team members, including Mom, agreed. 
Second Grade 1984-1985

By the end of the first semester of his second grade year, Son had mastered many of the objectives on his current IEP. On January 31, 1985 the LD and BD resource teacher sent a notice form to Mom and Dad informing them that services would be decreased from two hours to one hour per week. Mom signed the notice on the same date and returned it to the teacher. However, Mom did not check whether she agreed or disagreed with this change in amount of services.

On May 16, 1985 an IEP meeting was held to again discuss Son's current levels of educational performance at the end of his second grade year. Present levels of educational performance included:

Son is reading on a second grade, second month level. All skills are good at this level. He is in a regular second grade spelling program. He averages $90 \%$ on word tests and $75 \%$ accuracy on dictation tests. Son is presently in a regular second grade math class and has mastered most of the second grade math concepts. He has had some difficulty memorizing basic facts $1-20$ and working with money. Son's gross motor skills are good; his fine motor skills are weak. When he puts forth effort, his handwriting is legible. Son does not write sentences with correct capitalization and punctuation. He gets along well with his peers. He is polite and considerate of other's needs. He seems to feel as if he must always achieve perfection. This inner pressure interferes with his performance. 
The IEP team again determined that during the 1985 - 1986 school year (third grade) Son would receive one hour per week of direct instruction in the resource room. All IEP members, including Mom, agreed.

Third Grade 1985-1986

On September 25, 1985, three weeks into Son’s third grade year, Mom signed consent to re-evaluate form, granting permission for District 21 to complete a triennial reevaluation of Son. This form stated that a psychologist, social worker and nurse would be involved in the evaluations. A notice of procedural safeguard for parents of students with disabilities was also sent at that time.

On September 26, 1985 a referral for triennial re-evaluation was completed by the $\mathrm{LD}$ and $\mathrm{BD}$ resource teacher and Son's third grade teacher. The referral indicated these present levels of performance: "reading and spelling on grade level in regular classroom. Has trouble completing written work.” The teachers wrote:

The biggest concern: Son's attitudes and behaviors in school. He is physically aggressive towards others. He is inattentive in class. He seems to have an attitude of failure before he starts so doesn't put forth as much effort as he probably could. He doesn’t listen to directions. He’s inattentive in class. He draws war pictures when he should be listening, he plays with things in desk. He is off his chair 3 times a day on average. He disturbs others. How much of his difficulty is due to visual perceptual difficulties and how much are emotional problems?

On October 9, 1985 the school nurse contacted Mom via telephone and updated Son's health history. No remarkable change was noted. However, it was stated that 
“Mom is concerned about Son's school work. He is having trouble with subtraction. She wonders if he needs a tutor.”

Also on October 9, 1985 the third grade teacher filled out an observation form, which provided the following information regarding Son’s performance in the regular classroom setting:

Son has difficulty coping with his frustrations and getting along with his classmates. Son appears capable of producing grade-level work. However, his poor work habits, listening skills and behavior interfere (these are in addition to his LD problem.) Son works best in small groups and a structured classroom. He has a tendency to display temper when he becomes frustrated. He also will day dream instead of staying on task when he feels overwhelmed. Son makes worthwhile contributions in class discussions. When concentrating, Son has done well on the math concepts that have been covered.

On October 21, 1985 Mom was contacted via telephone by a social worker for the purpose of updating Son's family and social history. On that date, Mom reported the following:

Mom felt “Son’s grades were improving.” She attributed the change to disciplinary measures implemented in the home i.e. "took away his karate lessons.” She also reported a change in his attitude toward homework: "He doesn’t resent it now because I don’t expect 100’s only 80’s.” Mom acknowledged that his frustration was her fault because of pressure to be perfect. She also believes that much of his school difficulty was related to an earlier ear problem which affected his hearing. 
The social worker noted that Son’s karate program “has given him a sense of false pride. He appears to use karate to compensate for a perceived inferiority - if he can dominate, he feels successful.” The social worker also wrote that "Mom does not acknowledge any serious difficulties. It would appear that she does need some interpretation and guidance to more adroitly meet Son’s developmental needs.”

On November 12, 1985 a comprehensive psychological evaluation was completed by a licensed psychologist. The results of the WISC-R showed a full scale score of 100, with a verbal score of 115 and a performance score of 84 . The visual perception and visual motor concerns exhibited in 1982 were confirmed in this report. The psychologist also discussed the following:

Son related that he enjoys playing football after school...Most of all, Son seemed enthusiastic about karate. He discussed with enthusiasm his karate lessons and his developing skills.

I asked Son if he was having any difficulties at school. He said, “I don’t get the work done really. I can’t really spell that great. I don't read that great, but its not that bad, either.” After discussing his concerns about his academic weaknesses, Son spontaneously discussed his relationships with others. He said, “I sometimes have trouble with other kids. I don’t hurt them, but I play around with them. I don’t really fight. I just play fight. But sometimes I’m mean. Sometimes they want to get out of it.” At this point, Son was ambivalent about whether or not the fighting he was doing was "play fights” or serious hostilities. When I asked him directly about this, he related, “I don’t really know if they fool around or not. They want to fight in a way, but they don’t really. Actually I don’t 
get along too well.” I then asked Son if he wanted to talk to someone about this and he responded that it "might be a good idea."...Son appears to have some anger which is expressed in passive ways, such as being obstructional, quietly uncooperative or resistant to adult direction. The frustration of the challenge of his academic assignments can easily make this worse. Son could benefit from counseling services...Son's emotional adjustment should be discussed with his parents and with the school social worker at a staff conference.

On November 12, 1985 the LD and BD resource teacher sent a notice to Mom and Dad informing them that Son's IEP would be amended to add 1.5 hours of service a week because he was not making adequate progress in phonics. Mom did not sign this form.

On January 9, 1986 a multidisciplinary staff meeting was held to review the reevaluation data described above. It was agreed by all members, including Mom, that Son should continue with his LD resource placement and add social work services.

Anecdotal notes were kept by the regular classroom teacher beginning February 5, 1986 through April 24, 1986. A synopsis of these notes follows:

Feb. 5/86 After second report card came out, Son left his at school when his parents picked him up from daycare. They drove back and got it. When Mom saw he had gotten a D on his report card, she grabbed him from behind and started to hit him in the head. This was observed by one of the day care teachers. Our school social worker reported the incident to D.C.F.A.

4/24/86 Gym teacher has had a continuing problem with Son trying to get him to keep his shoes tied. Everytime it becomes an issue. He will refuse to lace them. Teacher says not tied, no gym. Son replies, “I don’t care.” 
On April 23, 1986 a meeting notice was sent to Mom and Dad letting them know that there would be a multidisciplinary conference regarding Son on May 9, 1986. The notice stated, “The purpose of this meeting is to review his progress to determine what program is necessary for next year.” A notice of procedural safeguards for parents of children with disabilities was also sent.

On April 29, 1986 a social worker observed Son and reviewed his records. In his summary of observations the social worker wrote:

Son is a nine year old child who appears to be dealing with intense internal conflicts regarding aggressive impulses. This aggression becomes focused on himself at times in a destructive way...he will make comments about "killing" himself although he does not present an overt affect of depression.

Mom at times feels overwhelmed about how to best care for Son or react to his behaviors. She has on occasion hit him in view of school staff and frequently uses aggressive verbal references regarding Son (i.e. "he’s going to get it when he gets home" or "I'll beat it out of him"). She has little insight as to the nature of both Son’s or the family's problems and therefore, seeks simplified solutions to complex issues. Despite discussion regarding help for Son, the parents are unable to organize themselves sufficiently to follow up on recommendations. Son's behavior seems partially related to the very inconsistent boundaries within the family structure. His parents can be extremely generous at times and then emotionally unavailable to Son. Son's internal conflicts compound his already established learning difficulties and need to be addressed 
specifically in the context of his education.... a more intensive educational program would be beneficial in addition to individual counseling.

On May 12, 1986 (not May 9, 1986 as the meeting notice advised) the professional staff, with Mom in attendance, had a staff conference regarding Son's educational progress: "The feeling is that Son is not succeeding in class, because of several behavioral and emotional problems. Our intermediate LD/BD program would not be able to give Son the services that he needs next year.”

Also in May, 1986 (day not noted) a BD Criteria Documentation Form was filled out by professional staff. Son met BD criteria in the following areas: adaptive behavior (aggressive, few peer relationships), classroom difficulties (off task, puts forth little or no effort), personal characteristics (self destructive at times), and academic performance (performance does not reflect ability; affects a non-caring attitude about his work; work is illegible even though he can write legibly). Anecdotal notes on this form state: "It's as if he has tried so hard for so long and can't meet his parents' expectations that he has just given up" and "Parent over reacts. Becomes aggressive towards child. Will talk about hitting Son. Has unrealistic expectations for child.”

On May 22, 1986 an IEP meeting was held at the end of Son's third grade year to discuss his present levels of educational performance. All pertinent personnel were in attendance, including Mom. On that date, Son was reading on third grade, second month level. His spelling was on the third grade level. His spelling tests averaged 95\% but "he does poorly on applying skills.” Son had a grade equivalent of third grade, seventh month in math. Written language skills included the ability to write a complete sentence; he knew the rules for capitalization and punctuation "but is careless in applying them." 
Son's fine motor skills continued to be weak. "Son is aggressive towards his peers, has anger issues, and is resistant to adult direction.”

At this IEP meeting, there was discussion about where to best educate Son given his academic and behavioral needs. The options discussed were: Student Support Center at Key Elementary School, regular classroom, and LD resource program. The IEP team “recommended Student Support Center - Parents denied permission. Placed Learning Disabilities Resource Program Intermediate.” It was agreed Son would continue with LD services at Robert Elementary School in the amount of 2.5 hours per week. No behavioral goals or objectives were written into the fourth grade IEP for Son, or any other related service support.

Fourth Grade 1986-1987

On November 25, 1986 a BD evaluation form was filled out by LD and BD Coordinator. LD and BD Coordinator observed Son on three different occasions, as well as interviewed staff, reviewed Son’s IEP and case study, and teachers’ documentation. $\mathrm{BD}$ and LD Coordinator concluded:

There appears to be only two recommendations: Actively pursue with parents, once again, placement in Student Support Center, which was recommended in May; BD criteria documentation is complete. Or, if Student Support Center placement is not forthcoming, Robert Elementary staff must meet and develop a comprehensive plan to attempt to support Son’s needs.

Sometime in January, 1987 Son was transferred back to Meadow Elementary School. This transfer was not facilitated by District 21. Son’s May 22, 1986 IEP was 
continued at Meadow Elementary School. Within one month, Mom contacted Asst. Supt. and asked that Son be placed in the Student Support Center at Key Elementary School.

On February 16, 1987 an IEP meeting was held to review Son's educational placement. SpEd Teacher 2 was the only professional in attendance. Both parents were in attendance. Son's placement was changed to the Student Support Center, and Son was transferred to Key Elementary. The May 22, 1986 IEP continued to be in effect. Also at this meeting, the parents informed SpEd Teacher 2 that Son would be seen by a private therapist at Mom and Dad's expense. Mom and Dad requested that Son's records be released to Private Therapist.

On April 30, 1987 an IEP meeting was held at the end of Son's fourth grade year to review his current levels of educational performance. All pertinent personnel were in attendance, including Mom. Son was reading on the fourth grade level. Spelling was on the third grade level, with difficulty noted in applying learned skills. Son was using a fourth grade math book, but performance was so inconsistent due to lack of motivation and refusal to complete tasks that grade level could not be assessed. Son still had difficulty with his handwriting, but "I feel he can do better than he shows.” Son’s "behavior is somewhat impulsive and aggressive towards peers. Son seems to be very, very angry about something. Son seems to have trouble concentrating and doing his assignments because he is angry.” The IEP team, including Mom, agreed to continue Son's placement in the Student Support Center at Key Elementary School. His time in special education was increased from 2.5 hours per day to four hours per day. Social work services were added as a related service one hour per week. Goals and objectives to support Son’s behavioral needs were also added. 
Fifth Grade 1987-1988

On April 12, 1988 SpEd Teacher 2 wrote a note to document that she had seen Son threaten another child on three occasions with a softball bat he had brought from home. Subsequently, she took the bat from Son.

On April 26, 1988 an IEP meeting was held to discuss Son's levels of educational performance during his fifth grade year. Both Mom and Dad were in attendance, as well as the principal, SpEd Teacher 2, and the social worker. It was documented that Son was reading on a 5.0 grade level; spelling was on a 4.0 grade level, but Son didn’t apply rules to his daily work; Math was a 4.5 grade level, but "is difficult for Son. How well he does depends on his attitude and motivation.” Son had poor sentence structure and was careless with punctuation and capitalization. Fine motor skills were weak. "Son is very impulsive and aggressive both in class and out. Will hit and fight with peers regardless of the consequences. Verbally abusive to others. Has difficulty concentrating and sitting still at times.” The IEP team referred Son for a vision-muscle balance screening. All team members, including Mom and Dad, were in agreement to continue with the Student Support Center at Key Elementary School and to decrease Son's time in the special education environment from four hours to 3.5 hours, while increasing social work services from one to three hours per week. It was also agreed that Son would continue seeing Private Therapist.

Also during this meeting, Dad brought up the fact that Private Therapist "thought it would be a good idea” for Son to receive a gun as a gift from Dad. All professional personnel in attendance agreed that this would feed into Son's anger and violent temper. 
Dad added they could only use the gun for target practice at Private Therapist's farm.

“Mom doesn't seem to like the idea but seems to go along with Dad.”

On May 17, 1988 SpEd Teacher 2 wrote the following anecdotal record:

Son broke the front window in the school today with his baseball bat. He was chasing another student and threw the bat meaning to hit the student but instead hit the window. Principal approached Son and discussed it with him. Son came back in the room, sat down, then got up and began to stomp around, crying. The first thing he said was, “Now I’m not going to get my 22!”

On May 24, 1988 SpEd Teacher 2 noted that Son again made reference to a gun: “Son said to the janitor, 'I'm glad that lady shot all those kids'.” Again on June 1, 1988 SpEd Teacher 2 wrote, "Son has made threats against other children.”

On June 3, 1988 SpEd Teacher 2 spoke with Private Therapist via telephone regarding Son’s progress and her concern about Son having access to a weapon. There was no evidence of a release allowing the school district to speak with Private Therapist. The following is SpEd Teacher 2's description of her interaction with Private Therapist: According to him - Son's talking more, acting out less. He felt the situation at Robert Elementary had something to do with the Jewish faith. He believes Son had $\underline{\text { NO }}$ sense of masculine identity at beginning of treatment, so Private Therapist feels his extreme aggressiveness is okay. (He needs to know more present day happenings w/ Son’s behaviors) - OBVIOUSLY! W/Gun. Private Therapist feels it will be another outlet for Son to "vent out” in; will give Son \& his Dad more time together. I told him I disagreed. Agreed that Mom is 
definitely a Borderline Personality Disorder - very serious - so he feels Son is doing quite well considering that fact combined w/ a weak, passive father.

Sixth Grade 1988 - 1989

The Keys Elementary School principal sent an undated form to Mom and Dad requesting parent permission to conduct a triennial review of Son. A copy of the procedural safeguards for parents of children with disabilities was simultaneously sent to Mom and Dad. Mom signed permission for District 21 to conduct a comprehensive reevaluation on October 12, 1988.

On October 26, 1988 the school nurse contacted Mom via telephone and updated Son's health status. Son weighed 68 pounds and was 54.5 inches tall. Son had a hearing and vision screening on this same date. He passed the hearing screening, but failed the vision screening and was referred for a vision-muscle balance test. Mom indicated that Son currently received allergy shots two times a week, and might have food allergies. She was considering a blood work-up. The nurse reported no other health concerns that would interfere with learning at that time.

On November 1, 1988 a conference was held between Mom, Dad and SpEd Teacher 2. SpEd Teacher 2 documented her discussion with Mom:

Discussed: staying in area - office, etc. Problems in unstructured situations. Bathroom, hallways. Specials. Making noises, stomping, hanging on doors, standing on toilets. Lunch room - sitting at table touching other people's stuff. Bus - Telling other kids to spit and hit. Doesn't mind other authority figures in building. Doesn’t accept responsibility for behaviors. Antagonizing others. 2 
fights in room; 1 playground. Have to number papers in folder so Son won't throw out papers.

Discussed Son's problems and laid groundwork for Rome-Behavior Education Center (BEC). Discussed how Son will have a tough time at Clinton. Still considering Watson and now Rome-BEC. Parents want Son to go to Clinton. They don't like the violence at Watson. Parents weren't receptive to Rome-BEC but didn’t get upset when it was brought up. Will initiate new intervention: daily sheet communicating to parents Son's behavior.

On November 2, $1988 \mathrm{SpEd}$ Teacher 2 wrote a short note to Mom stating that it was reported by the parent-volunteer bus monitor that Son was fighting with another boy on the bus and would not stay in his seat.

On November 3, 1988 it was reported by the parent-volunteer bus monitor that she was "struck by Son in the face with his fist." SpEd Teacher 2 wrote that the bus monitor reported that Son was running up and down the bus aisles, fighting with students. When asked to be seated, Son would not comply. The bus monitor then grabbed Son's arm and attempted to place him in a seat. He hit her in the face with his fist, while yelling, “You fucking bitch, I don’t have to do what you say!” This note was sent home for a parent signature. Mom signed and returned to SpEd Teacher 2.

On November 11, 1988 a social developmental study was completed by a school district social worker. The social worker interviewed Mom and described her findings in this manner:

Mom is pleased with Son's progress in the school program. She feels that having him leave Robert Elementary School was a great decision and regrets she 
originally opposed the idea. She felt something happened to Son; what happened he won’t tell them. She feels his behavior has improved over the years.

Much of the family routine revolves around Son’s karate practice. Son has been successful and greatly enjoys karate. The family, for recreation, also spends time target shooting. Son has a gun and is hoping to get a second one. The family sometimes goes to the farm owned by Private Therapist for target practice. Mom reports Son is quite skilled in firing a gun.

Mom reports Son's relationships with his parents are sometimes good and sometimes not so good. She says it depends on his mood. His relationship with his grandfather is also inconsistent. Mom states her father-in-law can be difficult to get along with as he has a "mean streak" and a selective memory. The family does not spend too much time with their extended family as there are conflicts.

Mom describes Son as very affectionate and that he is good with young children. She says that at home, Son's behavior can be very good or he can be very bad. She feels he intentionally tries to "get her goat." She says he can be very nasty at times. In terms of discipline, Mom feels that withdrawing privileges is the most effective means. Mom says that they are going to take away his gun, but Son "has hid it" to make this impossible right now.

Mom states that Son relates well to his peers. She currently likes all of his friends except one. She says he has a nice group of friends from karate. He does fight sometimes with other boys. Mom feels that his grandfather glorifies fighting too much. 
The social worker also observed and interviewed Son and described her observations and interaction with Son in this way:

Son is a very energetic youth who can be very charming and engaging with adults. In a group situation with peers, Son can be verbally and physically aggressive and intimidating. He insults other children but is loyal to his friends. His best friend is John. Son enjoys guns and karate. Son is a very angry youth who feels frustrated in school. He has shown poor impulse control. Son appears to loathe weakness of any kind and expressed hatred for students in his class that are overweight or have handicaps. He has good self-help and hygiene skills; he is very concerned about his appearance.

In school Son relates poorly with peers. He is viewed as a bully. He is mean to other students. Son needs constant adult supervision. He responds to limits set by his classroom teacher, but this is not generalized to other adult school personnel.

At the present time, Son is being cabbed to and from school as his behavior was uncontrollable on the bus. He hit a parent riding the bus when she tried to prevent his hitting another child.

Although Son has improved his behavior since entering the program, his behavior remains problematic. A major concern with Son is his obsession with power and strength. He talks continually about his gun and his desire for more guns. It is felt by this worker and other school personnel that due to Son's anger and poor impulse control, it is very dangerous for Son to have contact with firearms or any other weapons. 
The social worker recommended Son continue with individual and group social work services and that Son not have access to firearms. She also recommended that Mom and Dad consider "child guidance counseling to assist them in setting firm and consistent limits” on Son’s behavior at home.

On November 23, 1988 SpEd Teacher 2 wrote a letter to Mom:

I know these are difficult times for you right now having to cope with Son going to and from school in a cab. I just wanted to write you a note to let you know that I, too, am concerned about Son. I also think it's important for you to realize that it's a situation which is no longer in my control.

There's nothing I can do to alter the situation.

I would really like to continue to work with you and your husband on other school related issues as we always have been able to do. I am Son’s teacher; I am not responsible for transportation.

I am always willing to discuss Son’s problems or progress as it relates to school as well as hold conferences with you. Please note the following time slots, which are the only times I can be reached during the day...

Please do no call me at home as it is inconvenient and difficult for me to be reached.

Thank you for your cooperation. Sincerely, SpEd Teacher 2

On that same day, SpEd Teacher 2 wrote the daily communication sheet to Mom and Dad. SpEd Teacher wrote, "Bothering others in bathroom.” Mom wrote underneath this statement, “I am sure that there others that Due that.” SpEd Teacher 2 also wrote, 
“Inappropriate language used in classroom. Son said, 'Beat the F-U-C-K out of him..” Mom wrote underneath this statement:

Who was the Remark made about, write me a note. Do Not use Son as a Scape Goat. That what it sounds like. Even on the Bus when he got kicked OFF. I am sure other kids Do thing on the Bus. Don’t Push us to far. We will stick up for him my husband and I.

This was returned to SpEd Teacher 2 by Son the following day, November 24, 1988.

On November 24, 1988 Mom also wrote a note to SpEd Teacher 2, which was delivered to her by Son. Mom responded to SpEd Teacher 2's letter in this manner: “I can not call you During those hours. I cannot Leave my Desk I have a Job. Just see that Son take his homework Home Son Does not Like Principal. I can’t blame him. Mom”.

On December 5 and 8, 1988 a psychological report was completed by a school district psychologist. The psychologist observed that "Son is a good looking boy with dark, curly hair. He appears shorter than usual for his age and he is slightly built.” The WISC-R was administered to Son. Results indicated a full scale score of 100, with a verbal score of 112 and a performance score of 87 . This discrepancy between scores continued to substantiate the diagnosed learning disability in the visual-perceptual-motor area. The psychologist confirmed that educational achievement is "significantly below expectancy based on his age, grade and ability.” When asked to respond to pictures that were shown to him, 'Son was very, very verbal....and introduced violent themes to even the most innocuous, peaceful pictures...At no time was there any sign of remorse or need for his characters to face the consequence of their behavior.” The psychologist described Son in this way: 
Son is a boy with significant behavior and learning problems. Intellectual functioning is intact and he continues to display superior verbal reasoning powers. The learning disability diagnosed in the early grades is still present. Son displays evidence of Attention Deficit problems that are manifested in difficulties of staying on task, concentrating and completing school work. However, of even more significance at the present time is the significant behavioral problems that are interfering significantly with relationships with peers and authority figures. His anger and acting out behaviors make it difficult for him to function in a regular school setting. He needs a very structured school setting designed for children with behavioral difficulties. He needs to begin assuming responsibility for his own behavior...Continued social work services will be needed to help Son deal with his behavior and its consequences.

On December 15, 1988 SpEd Teacher 2 sent the daily communication home to Mom and Dad per their agreement. She wrote, "Son had trouble lining up today after lunch. Pushing in line. Principal sent him to the back of the line and Son called Principal an asshole. Keeping you informed.” Mom signed, and returned the communication with this note on the bottom: "The Next Time Principal touches him I will call the Police. I mean it Tell him hands of my child or any other child.”

On January 24, 1989 a notification of conference form was sent to Mom and Dad informing them of a February 8, 1989 conference date to review the reevaluation information to determine if Son remained eligible for special education.

On February 6, 1989 SpEd Teacher 1 observed Son in his learning environment and indicated that Son needed constant monitoring, needed to have math assignments and 
pencil paper tasks modified. She stated that Son had good verbal communication skills especially with adults, and was extremely mature for his age. However, "He exhibits much anger. Pounds on desks, talks to himself, gets out seat, constant movement. Verbally aggressive if angry with adults. Needs a strict routine, much structure; one on one with all assignments (or a group of 2 or 3).”

On February 8, 1989 a multidisciplinary conference was held. The multidisciplinary team (MDT) consisted of all professionals who evaluated or observed Son. Mom was also in attendance. All information described above was shared with the parents and noted on a conference summary report. Son continued to be eligible for special education. He met the criteria for behavior disorder, which was determined to be his primary disability. He also continued to meet the criteria for learning disability, which became his secondary disability. The MDT reported the following supporting information:

Son's parents are pleased with his current educational placement and feel he has made progress. They say that his behavior at home is inconsistent. He can be nasty or pleasant. He doesn’t usually tell his parents what's on his mind. Son hates school and is often angry at the school personnel...Allergic to bacteria in milk - cannot eat...Son is unable to practice self-control and requires external control to be provided within the school setting. He is unable to accept responsibility for his behavior and projects blame onto others. He doesn't take consequences seriously. These behavioral factors seriously impede Son's academic functioning...Behavior significantly interferes with learning/educational functioning. 
The MDT reviewed four least restrictive environment options. The first option they considered was mainstream with consultation, and the MDT, including Mom, agreed that this was not structured enough for Son to succeed. The second option considered was the Robert Elementary School LD and BD resource room. This was also unanimously vetoed for the same reason. The third learning environment considered was the Student Support Center at Key Elementary School. Mom preferred this placement. All other team members felt this placement could not provide enough support given Son's current academic and behavioral needs. The school district strongly recommended the Behavior Education Center (BEC) at Rome School. (This was an alternative learning school for severely behaviorally involved youth.) Mom refused this option. It was then agreed that Son would continue in his current special education placement: the Student Support Center at Key Elementary School for the remainder of the sixth grade.

On February 21, 1989 a bus conduct report was filled out by Son’s bus driver and Principal stating that Son had engaged in "excessive mischief” on the bus. The form also noted that previous reports of Son’s “excessive mischief” had been sent home, and any further incidents of this nature would mean that Son would be suspended from the bus.

On February 23, 1989 another bus conduct report was filled out by Son’s bus driver and principal stating that Son violated safety procedures, was rude, discourteous and annoying, was fighting, pushing and tripping other students, and was "running up and down the aisle, and hitting child in seat behind him.” Son was suspended from the bus. Mom and Dad were contacted by telephone, and arrangements were made to transport Son to and from school in a cab. 
On May 8, 1989 SpEd Teacher 2 sent a form to Mom and Dad stating that an IEP meeting would be held on May 30, 1989 to review Son’s progress and determine if any changes needed to be made in Son’s education program for seventh grade.

On May 30, 1989 an IEP meeting was held to discuss Son's levels of educational performance during his sixth grade year. The IEP team consisted of all appropriate personnel, including Mom. There was no significant change in Son’s academic performance since the February 8, 1989 meeting. Son continued to have significant behaviors that interfered with the learning of himself and others. "Cannot handle unstructured settings, image of a troublemaker, aggressive toward peers, frequent fights. Maintained a ' $C$ ' average in academic classes in $6^{\text {th }}$ grade. Poor fine motor skills.” Goals and objectives were written to support Son's areas of weakness in this manner: “Son does not have age appropriate coping skills; Son does not have many positive social interactions with peers; Son does not take responsibility for own behavior.” The IEP team also listed specific supports Son would need to benefit from his education:

Small structured classrooms for all academic areas, consistent behavioral expectations in all school environments, immediate and appropriate consequences for behavior, specially trained adult supervision, availability of therapeutic services on a daily basis, availability of immediate crisis intervention resources, availability of on-going parent support, availability of trained staff to build a cooperative, consistent effort between home and school.

Because Son would be transitioning to the junior high school for seventh grade, two placement options were presented by the school district. The first option considered was the Student Support Center at Watson Junior High. Given the nature and severity of 
Son's behavioral issues, the school district felt that Watson Junior High could not provide enough support in the Student Support Center to ensure Son could make progress towards mastering the goals and objectives on his IEP. The school district then recommended the Behavior Education Center at Rome School (Rome-BEC.) Mom refused both placements. She felt that Watson was full of "gangs" and Rome-BEC was a school for "bad boys". Instead, Mom requested that Son go to his home school, Clinton Junior High. This was instantly rejected by the school district because of lack of appropriate BD and related services at Clinton Junior High to support Son's current IEP as written. The school district acquiesced to Son's placement occurring at Watson Junior High’s Student Support Center, although all professional staff felt the best placement for Son would be at Rome-BEC. Mom left the IEP meeting without agreeing to this placement.

Also on May 30, 1989 a disposition of placement form was sent to Mom and Dad, indicating the IEP team's decision to place Son at the Watson Junior High Student Support Center effective August 28, 1989 and informing them of their right to request a due process hearing if they did not agree to this placement.

Seventh Grade 1989 - 1990

In August, 1989 Mom and Dad enrolled Son at Watson Junior High. The May 30, 1989 IEP was put into place via the Student Support Center. Beginning on September 6, 1989, detailed anecdotal records were kept by all teachers regarding Son's behavior. A phone contact log was also kept.

On October 5, 1989 a parent conference was held to “examine Son’s progress at Watson to date...” Principal discussed with Mom that Son was suspended from school 
for three days for swearing at a teacher. Mom and Dad were provided with a written student suspension form outlining the offense that same day.

On October 6, 1989 a letter was written to Mom and Dad by Principal memorializing the conference. Principal explained that Son was suspended from school because he directed abusive language at a teacher. He explained that suspension from school was not the preferred method of discipline for this infraction; detention before or after school was the norm for such offenses. "Unfortunately, due to conflicts with home and after school activities, we have been unable to implement.” Principal reported that Mom had now agreed to allow Son to be kept after school until 5:15 the same day misbehavior occurred. "In addition, the following plan was also adopted":

1. We would notify Mom any day Son would have to be kept until 5:15. Son can ride the 5:15 bus home daily, except on Wednesdays when Mom will pick him up at 5:00 for Karate lessons.

2. We will do our best to discipline Son within our school setting. However, should his misbehavior warrant suspension, we will continue to suspend him from school.

3. Mom indicated she would be contacting Son's pediatrician as well as Omni House. She also indicated that she would consider the Omni "Big Brother" program.

4. We also talked about Son's use of a gun as a means of releasing energy and agreed that this indeed was inappropriate and we strongly encouraged Mom to seek out an alternative recreation. 
5. We agreed to meet again next Thursday, October 26 (or sooner if needed) at 1:30 to discuss the progress being made.

6. We also agreed to reserve our decision about Rome-BEC placement but did indicate it was an option we must consider.

On October 23, 1989 Principal sent a notification of conference form to Mom and Dad stating an IEP meeting would be held on November 1, 1989 to review Son's progress and determine if any changes were necessary in Son's education program. A copy of procedural safeguards for parents of students with disabilities was also sent.

On October 23, 1989 SpEd Teacher 1 also sent home a parental notification of IEP change form specifying a change in special education teacher (from SpEd Teacher 1 to SpEd teacher 2), as well as a change in math and reading objectives.

On November 1, 1989 Principal sent another notification of conference, with procedural safeguards, to Mom and Dad stating an IEP meeting would be held on November 7, 1989 to review Son's progress and determine if any changes were necessary in Son's education program. On the bottom of this form, Principal wrote, "In the event that our initial meeting date was not convenient for you, we have scheduled this second conference date in the hope that you can attend.”

On November 3, 1989 Son was again suspended for one day from Watson Junior High for “obscene gestures and gross disrespect to a teacher.” A written notice outlining the offense was sent to Mom and Dad.

On November 6, 1989 Asst. Supt. wrote a letter to Mom and Dad stating that a copy of Son’s special education file, of which Mom had requested a copy, was enclosed. 
On November 7, 1989 an IEP meeting was held to review Son’s IEP and discuss his educational placement. All pertinent personnel were in attendance, including the LD and BD Coordinator as the school district representative, and the Rome-BEC representative. Mom, Dad and Son were also present. It was noted that Son had not made progress in his behavioral goals since he was in sixth grade. "Son has been suspended 4 days this year for injurious and disruptive behavior. Son is currently placed in a BD classroom for the maximum time offered at Watson, for $60 \%$ of his day.” The IEP team considered allowing Son to remain at Watson Junior High, but the District rejected this because he could not progress in his goal areas given the current programming offered at Watson Junior High, nor could Son's needs as listed in his IEP be supported at Watson Junior High. The IEP team then considered the Rome-BEC. “Mom and Dad rejected the reports of Son's behavior and the placement suggestions offered. They want him to remain at Watson Junior High.” The family was informed of their legal rights and given a copy of procedural safeguards for parents of disabled students. "The due process hearing process was explained to the family." The RomeBEC representative explained the program to the family. The final portion of the IEP meeting was described in this way:

Mom and Dad will not agree to the Dist. 21 placement recommendation. Dist. 21 believes that only the Rome-BEC can meet his needs. Therefore, the family is afforded 10 days to consider this recommendation (Nov. 17, 1989.) Dist. 21 will file for due process in order to meet Son's needs if Mom and Dad reject the placement. 
On November 7, 1989 a disposition of placement form was sent to Mom and Dad stating that a change of placement had been made; Son would be attending Rome-BEC. This was signed by the local education agency 's (LEA) representative, LD and BD Coordinator.

On November 9, 1989 Asst. Supt. sent a letter via certified mail to Mom and Dad. Enclosed was a copy of the IEP and meeting notes from the November 7, 1989 meeting, as well as a disposition of placement form dated November 7, 1989 stating that a change of placement had been made; Son would be attending Rome-BEC. Asst Supt. wrote, “I would urge you, as I have in the past, to be open-minded about a placement at Rome. I do not, and never have, viewed Rome as a place for bad boys, but rather, as a facility providing the necessary staff ratio and structure to help students avail themselves of an educational program.” Asst. Supt. also wrote that it was the intention of District 21 to file for due process if the parents did not agree to the Rome-BEC placement by November 17, 1989.

The IDEA Conflict Resolution Process Is Invoked

On November 20, 1989 of Son's seventh grade year, a letter was written to Mom and Dad by Asst. Supt. informing them that District 21 filed a due process hearing request, a copy of which was enclosed. This letter was sent certified and regular mail because "we have also had some difficulty reaching you with certified mail, since a letter previously sent to you was returned to me on November 20, 1989 after three attempts to deliver it.” Asst. Supt. reminded Mom and Dad that the District "remains open for any discussion concerning the proposed placement” during the due process procedure. 
School District 21's request for a due process hearing was received by the Illinois State Department of Education (ISDE) on November 27, 1989. Pursuant to the state’s rules for administrative hearing officer selection for a due process hearing, ISDE provided to both parties a list of five due process hearing officers sanctioned by ISDE on November 30, 1989. According to the rules, each party would take turns, beginning with the parent, "striking”, or eliminating, the names of administrative hearing officers until one was left. This process was to take no longer than five days. The District had the responsibility of reporting the chosen hearing officer to ISDE. The ISDE would then appoint the chosen hearing officer to hear the case.

On December 5, 1989 Asst. Supt. sent a copy of this information to Mom and Dad: “If you have any questions regarding this procedure, please don’t hesitate to call me.” In response to that letter, Mom contacted Asst. Supt. via telephone on December 8, 1989 and informed him that the family "would be seeking legal assistance” and she would contact him when that had been done.

On December 11, 1989 Asst. Supt. wrote Mom and Dad reminding them of their responsibility to assist in selecting a hearing officer, as the timeline had past and he had not heard from the family. Asst. Supt. wrote that he had contacted ISDE:

They advised me that I should inform you that you have a few extra days to jointly select a hearing officer, and if you do not comply with that request, the District should proceed to select the hearing officer...Consequently, if I do not hear from you by the morning of Thursday, December 14, the District will select a hearing officer from the list provided by the state. 
On December 15, 1989, family attorney (FA) wrote a letter to Asst. Supt. informing him that FA “objects to the list of hearing officers” provided by the state. FA also requested that "District 21 conduct an immediate evaluation of Son, at its expense, through the Northwest Suburban Special Education Organization (NSSEO).

On that same date, FA wrote a letter to the Illinois State Department of Education objecting to the list of proposed hearing officers provided by ISDE. FA wrote that he objected because two of the proposed hearing officers "were employed by or administratively connected to a school district.”

On December 21, 1989 ISDE wrote to FA explaining that "neither of [the hearing officers] is employed by or administratively connected with public school districts.” ISDE informed FA that the ISDE rejected FA's request for a new list of hearing officers.

On December 26, 1989 FA wrote a letter to Asst. Supt. stating that in light of the fact that a new or revised hearing officer list would not be forthcoming from ISDE, he would participate in the choosing of a hearing officer when Asst. Supt. returned from the holidays.

On January 3, 1990 Asst. Supt. wrote a letter to FA, enclosing the Hearing Officer Selection Report and requested he obtain parent signatures and then return to Asst. Supt. Asst. Supt. would then keep a copy and forward the original to the state.

On January 8, 1990 Asst. Supt. wrote a letter to FA:

This is to confirm our telephone conversation of January 8, 1990, in which District 21 agreed to contract with NSSEO to do an independent evaluation of Son. The components that NSSEO would be responsible for would be a psychological evaluation, a social history update, and a psychoeducational 
evaluation. I enclose the NSSEO parent permission form. When signed, please return the form to me so that I may make a formal referral to NSSEO.

On January 12, 1990 Mom signed permission to allow NSSEO to do the evaluations noted above.

On January 17, 1990 the administrative hearing officer (AHO1) was notified by ISDE that she had been appointed as AHO in this case. AHO1 contacted both parties and set up the hearing on the mutually agreeable date of February 23, 1990.

NSSEO completed all evaluations and on February 1, 1990 a notification of conference was sent to Mom and Dad, letting them know that on February 8, 1990 all appropriate parties, including attorneys, NSSEO and school district staff, would meet to review “your child's recent case study and determine eligibility or continued eligibility for special education programs and services and recommend placement, if necessary.” A copy of the district's procedural safeguards for parents of students with disabilities was also sent to Mom and Dad.

On February 1, 1990 the NSSEO licensed social worker completed a social history. She reviewed all social histories already in Son’s file, as well as interviewed Mom. The social worker reported:

Much of the family routine revolves around Son's participation in karate lessons. Mom reports that Son has been very successful in karate and greatly enjoys the sport. He has been involved in Karate since age $6 \frac{1}{2} 2$. In addition to taking Karate lessons, Son currently assists in teaching Karate to younger children on a weekly basis. 
In April 1989, Mom's mother died of pneumonia/heart attack in Son’s bed. Mom reported that Son was the first one to find her after she died. Son became very upset. Mom stated that since his maternal grandmother's death, Son has chosen to sleep on the living room couch.

Mom reported Son was involved in private counseling on a weekly basis in $5^{\text {th }}$ and $6^{\text {th }}$ grade. She feels Son did benefit from the counseling and stated "Son is more open to communicating”.

Mom said that sometimes Son lies. He likes to get his own way. Mom stated that “once in a while Son swears or argues when he does not get his own way." She stated Son's behavior has improved at home; she said she “can reason with him now."

Mom stated Math has always been a weak area for Son. She is concerned about reading this year; she noted that previous years Son did well in reading but this year he is failing. Mom is concerned that he is failing all of his academic classes this year. Mom reported when frustrated in school, Son tends to act out, swear, make noises in class. He has very good school attendance.

Mom said, "Sometimes Son tries to be a leader." Mom reported Son is well liked, has a group of friends, has a best friend, plays sports with his friends and gets along with peers at school.

Mom explained that the school has recommended Rome-BEC. She voiced negative feelings of the prospect of Son's placement there. She is especially concerned about the negative influence of the peer group at BEC. Mom would 
like Son enrolled in regular education classes with assistance from LD teacher only when needed.

On February 1, 1990 Mom also completed a Vineland Adaptive Behavior Inventory. This instrument reveals a child's functional developmental age level in three areas: communication skills, daily living skills, and socialization skills. Mom indicated that Son was moderately low functioning in communication and socialization skills, and low functioning in daily living skills. Overall, Mom rated Son’s adaptive behavior as "moderately low for his age."

Also on February 1, 1990 Mom was interviewed to update Son’s medical history. No new issues were raised: "No illness or accidents reported; Son is in good health." Son was also interviewed on February 1, 1990 by the NSSEO psychologist and social worker. Son self-reported the following information:

Talks back to his parents, swears at them sometimes. He does what he wants to do. Grounded once for a $1 \frac{1}{2}$ hour by his mother. Ususally gets what he wants. Tells parents everything, but sometimes lies. He reports being in three different schools in $4^{\text {th }}$ grade: Robert, Meadow for one month, and Key where he "was in an LD program all day.” He went to Key because he “didn’t like it at Meadow and they didn’t have a student support center.” He said, “4 ${ }^{\text {th }}$ grade wasn’t my best year." In $5^{\text {th }}$ grade, he "went out for some classes the second half of the year." He said reading is his strongest subject and math is his weakest. He says this year getting A's on tests; he said he does not study but memorizes information when reading it the first time. Failed classes first semester $7^{\text {th }}$ grade except for physical education. One time accused of stealing money from teacher within the last year; 
he reported he did not do it. Work is easy, so gets frustrated; he said he hates taking time to do work. Talks out in class sometimes. Gets time-outs at school. When mad at teachers, he swears at them. Has gotten into fights at school this year. Feels he is popular and part of a popular crowd. Likes girls. Reports parties with teenagers where beer is present. He reported drinking 1/3 cup beer daily as a "blood thinner". Wants to be a pediatrician and/or work for the CIA. He wants regular class with help for math; he wants elective classes i.e. home economics. Wants to go to Clinton where friends from last year attend. He thinks he can change his behavior and thinks if he is in "normal classes" he will do the work. He does not want to go to Rome-BEC because “druggies go there.” Reported he “does not have a good temper” but does with little kids.

On February 5, 1990 the WISC-R was administered by an NSSEO school psychologist. Son’s full scale score was 89, verbal scale score was 97 and performance scale score was 82. Testing confirmed a significant discrepancy between verbal comprehension and perceptual organization skills. Also, a significant drop in the verbal comprehension area was noted as compared to the 1988 WISC-R results. Son expressed anti-social attitudes, and "appeared to enjoy introducing subjects of shock value. He was adamant in dislike of Watson Junior High, its staff and school work.” Son also reported "less self-dissatisfactions than average for a school aged child.” Academic achievement results indicated Son was currently functioning at a 4.9 grade level in math, and 5.5 grade level in reading and spelling.

On February 8, 1990 all information above was reviewed by the eligibility committee. Mom was in attendance as a member of the eligibility committee. All were in 
agreement that Son continued to meet eligibility criteria for primary BD and secondary

LD. NSSEO professionals made the following educational recommendations to support Son’s needs:

Specially trained adult supervision; small group instruction; consistent plan for behavioral expectations and consequences; adult monitoring of progress; direct instruction of problem-solving techniques; held accountable for behavior and academic expectations; given realistic praise/reinforcement; availability of social skills training; opportunity to discuss problematic situations; direct instruction in cognitive and compensatory strategies, and study skills; visual cues for oral directions; step-by-step instruction, especially in math.

Based on all of the above, educational options were again considered. The team's recommendation follows:

District 21 recommendation is that special day school (Rome-BEC) can meet Son's needs \& the self-contained BD program at Watson Junior High cannot meet Son's needs. The student could not be educated in the regular education school building with supplementary aids and services because needs are too severe. Parent rejects this option.

Level One Due Process Hearing: Day One. The first day of the Level I due process hearing was held on Friday, February 23, 1990. Administrative Hearing Officer 1 (AHO1) began the hearing by going on the record, stating Son's name and asking what the primary handicapping condition of Son was. BD and LD Coordinator answered, “BD.” AHO1 then introduced herself and said that the timelines for resolving this matter could not be met because of the dispute regarding the names on the ISDE hearing officer 
list. She asked if either party had a concern with her appointment as the hearing officer. Both attorneys stated that the issue had been settled. AHO1 proceeded to ask all parties to introduce themselves. There were 13 people in the hearing room, including AHO1: Mom, Dad, Son, FA, FA’s paralegal, Social Worker, Principal, Asst. Supt., School District Attorney (SDA), LD and BD Coordinator, SpEd Teacher 1, and SpEd Teacher 2. AHO1 reviewed the pre-hearing rights of the parties: both parties were represented by counsel; both parties had the right to inspect and review all school records pertaining to the student, which must be disclosed to all parties, including the hearing officer, at least five days prior to the hearing. FA said he had a stack of records that he had received "last night” from Mom. AHO1 asked Mom, "Where did you get them?” Mom replied, "Through the mail that this woman, SpEd Teacher 2 sent.” AHO1 stated she did not have a copy of these records and asked SDA if she was given a copy. SDA said, "No.” SDA also said:

They did not come from the school district. They came from a classroom teacher to the parent. So they were not a part of the school district submissions as such, and they are not—-they have not been disclosed to the district by the parents as documents upon which they intend to rely in accordance with the applicable regulations. So we do object to their being introduced because of the five-day rule.

FA argued that these additional documents were "prepared by an employee of the school district, a teacher. These were mailed to the parents. These documents are certainly relevant to the issues since they were current daily performance sheets regarding Son prepared by SpEd Teacher 2." AHO1 ruled that the "records were out because they 
were not disclosed to all parties and to this hearing officer, nor was I provided copies of them to this point. They are not to be used during the hearing.” FA objected and asked if they could be made part of the record as an offer of proof. AHO1 said, “They are excluded.” FA again argued to have these documents put into the record as an offer of proof and attempted to read the document dates into the record. AHO1 stopped the court reporter, stating, “I’m not putting that on record, because I have excluded these documents, and they need to be removed from this area. I don’t want them referenced again.”

AHO1 continued to review the pre-hearing rights of the parties. She stated that both parties had the right to request an independent evaluation, which had already taken place. Also, each party could compel the attendance of any school district employee or other person who had knowledge of the student. Both sides acknowledged their witness lists and agreed that the witnesses would be present to testify.

AHO1 stated that the placement of Son would not change pending completion of the Level I Hearing (Stay Put). She asked if Son was still in the last placement agreed upon by the parents and school district, to which SDA answered, "Yes.”

AHO1 asked Mom and Dad if they wanted a closed or open hearing. FA said, “Closed.” AHO1 acknowledged that Son was present and said, “The parents have the right to have the child present. If the hearing officer determines that attendance by the child will be detrimental to the child, the parents' request shall be denied.”

AHO1 said that she would like each side to present their case with no interruptions "while the other side is presenting." The burden of proof "is with the school district to establish that what they are proposing is appropriate.” She defined the standard 
of proof as " 51 percent of the evidence in support of the school district's position.” The parent has "no burden of proof, other than they can present evidence on any issue.” AHO1 then outlined the order of the hearing:

- Opening statements from the District, then parents;

- District presents witnesses, testimony, direct evidence;

- Parents cross-examine the District's direct testimony;

- Parents do their uninterrupted presentation;

- $\quad$ The District can cross-examine;

- The hearing officer will ask questions whenever necessary;

- $\quad$ Short closing statements from the District, then the parents.

AHO1 stated the reason this hearing was being held was because the parents rejected the proposed placement of Son at Rome-BEC. SDA clarified by saying, "I believe the issue is whether the proposed change of placement is appropriate, and I should add the change of placement seeks more restrictive placement.” AHO1 asked if that was FA's understanding, and he said, “My understanding of the issue is that the district is seeking a more restrictive placement.”

FA made a motion to "exclude all witnesses, other than those who are testifying or those that are parties to the action.” SDA opposed the motion, saying:

That is a formality of an adversarial proceeding that I think is not such a proceeding today...I don't believe that this is strictly an adversarial proceeding in which there can be claims, some prejudice, that witnesses are present; and in the way FA has formed his motion to allow parties to be present would be significantly unfair to the 
district because it would allow each person sitting on his side of the table to remain, and all of the individuals sitting at my side of the table to leave...

To which FA responded:

Now, certainly this is supposed to be a non-adversarial proceeding. I think that if it was truly a non-adversarial in nature, the SDA on behalf of the District would have stipulated to my offer of proof, Defendant's exhibit No. 1, records prepared by a district employee...Certainly also it would be unfair and prejudicial to allow witnesses who are going to testify on behalf of a party to sit there and listen to all the other testimony that comes in and formulate things for their own testimony... AHO1 ruled that each side could designate three people to stay at the table during the hearing; all others would be excluded. "Once someone has testified, they are free to stay. Everyone can stay for opening statements.”

Opening Statements. SDA gave the opening statement for the District. She said that "District 21 requested a hearing to resolve a question of change of placement for Son.” Son was 13 years old, enrolled at Watson Junior High and was in the $7^{\text {th }}$ grade. Son had disabilities in BD and LD, with BD being the primary disability. Both in February 1989 and again in May 1989 the District proposed that the most appropriate placement for Son given his current needs would be Rome-BEC. Parents objected. As a second choice, the parents and District agreed on Watson Junior High in a partial selfcontained BD class. Son attended that placement. "According to the professionals that have worked with Son, it has been highly unsuccessful in delivering the services necessary for him. He needs constant and close supervision in order to be kept on task and to receive an appropriate academic instruction.” SDA continued by saying: 
His behavior, in addition to class disruptions, has over the past year been observed and documented as bizarre and highly unusual for student of his age, even within a behavior disordered category...We believe that all the observations, all of the evaluations, all of the evidence strongly supports—overwhelmingly supports the need for this student to receive the therapeutic services available at the Rome-BEC placement.”

FA gave the family’s opening statement. He began by discussing Son's birth via C-section, "terrible” ear infections, and that Son had fallen down a flight of stairs when he was around two. He went on to say:

It is the parents' position that District 21 missed the boat with Son. The restrictive environment that they wish to place Son in is not appropriate. The reason it's not appropriate is because Son’s primary handicap as determined by all of the records that go way back to his early school is learning disabilities. They were not appropriately treated by the school district. Also, the school district has been derelict in its duty to provide Son with a medical evaluation, and has consistently refused to have a neurological evaluation of Son when the same was primarily indicated....

I think that the evidence will show that what's happened is the school district became frustrated with its inability to deal with Son's learning disabilities appropriately. Son started to have behavior disorders, which I think is not uncommon. Behavior disorders then became the primary concern of the school district. And somewhere along the line, all of the resources, all of the skills of the school district, all of the evaluators failed to recognize that the learning 
disabilities must be the primary concern of the school district, and they must give primary attention to this in order for Son's behavior disabilities to subside. Son certainly may need a contained class in a less restrictive school in order to have his learning disabilities attended to. And certainly they have not been attended to. The records reflect that. The testimony of the defense expert will establish that the school district has just missed the boat with Son by not meeting the primary need, that is teaching him to learn despite the learning disabilities.

AHO1 then asked the District to put on its presentation.

School District Direct Examination - Asst. Supt. SDA called Asst. Supt. as her first witness. SDA asked Asst. Supt. to identify himself and explain his current role with the school district. She asked if the Asst. Supt. was the superintendent's designee as "keeper of the records." Asst. Supt. stated that he was the designated keeper of the records for special education students. SDA asked Asst. Supt. to "summarize the background of Son's special education services and placements briefly for purpose of simply establishing the background for the hearing officer." FA objected "to the narrative.” At this time AHO1 stated that the District was allowed to present its case without interruption. FA clarified by asking AHO1 if "there will be no objection that will be heard?” AHO1 clarified by saying, "Right.” FA took exception to this because objections could not be preserved for the record.

Asst. Supt. was asked when Son came to his attention. He responded, “September, 1982, when he was in $1^{\text {st }}$ grade at Robert Elementary School.” Upon request, Asst. Supt. proceeded with a narrative of Son's educational background, referring to the documents as he went. During Asst. Supt.'s narrative, SDA asked several 
questions for clarification, such as "How does the school district determine eligibility for BD services?”, “And there is a BD criteria form?”, and, “Could you explain what a student support center is?” He responded to each question, and continued his narrative, which included statements such as:

As I say, my next contact with Son was in Watson Jr. High in student support center where continuing problems, fairly severe problems, were seen. SpEd Teacher 1 documented all of the different incidents, contact with the parents, various explanations of the problems that were going on, attempts to remediate them. Principal and SpEd Teacher 1, as I say, were not happy that things were not working out well for Son. We had a meeting with the parents to kind of discuss where we were with the problem. Basically, that was an attempt to get some co-operation in having Son see the consequence of his actions, and we were not getting any cooperation from the parents at this time.

SDA asked Asst. Supt. pertinent questions with regard to the reason this due process hearing was requested by the District. Asst. Supt. responded, "It was our responsibility as an agency, if we thought Son was not in an appropriate placement, it was our responsibility to then go to hearing if parents refused placement.”

SDA's final questions attempted to provide support to the following District arguments:

- Rome-BEC was the appropriate placement for Son given the information provided in the record: "Was the reclassification of Son as primary behavior disorder disputed by the parents?” “No.”

- Son’s primary disability was BD, his secondary disability was LD; 
- No one, including the parents, believed there was ever a need for a neurological evaluation of Son: "Was there ever a request made by any member of the district team to or suggestion that a neurological examination would be appropriate to identify this child's needs?” "No.”

SDA stated she had no further questions for this witness.

Parent Cross Examination - Asst. Supt. FA's first interchange with a school district witness began in this way:

FA: $\quad$ You said you were aware of Son since $3^{\text {rd }}$ grade?

Asst. Supt.: $\quad 1^{\text {st }}$ grade, September 1982.

FA: $\quad$ You said the school district has BD criteria. Could you tell us what that criteria is?

Asst. Supt.: I'd have to refer to the document perhaps.

FA: I'd like to see if you could exhaust your memory first.

Asst. Supt.: I don’t think this is a memory test.

FA: $\quad$ The question, sir, is can you without referring to the document tell us what the BD criteria is?

Asst. Supt.: The basic criteria is our form of criteria on that behavior education scale, and whatever reference to his behavior or emotional status from the psychological and observation.

FA: $\quad$ Are there different components that make up the criteria that the school district uses to determine whether someone is behaviorally disordered?

Asst. Supt.: Maybe you might clarify components. 
SDA: $\quad$ Miss Hearing Officer, is there a reason that the witness can’t refer to the document, which he's already referred to as the BD criteria form?

AHO1: $\quad$ I allowed the district to go through a long narrative with fairly leading questions, and I'll let him continue a bit further, although I realize if he wants to refresh his memory, he has every right to do that. But at this point, I'm not going to interrupt FA.

FA's questioning of Asst. Supt. continued in this same manner throughout cross examination. FA's questions attempted to provide support to the following arguments:

- The placement designated by the IEP team was not the least restrictive environment for Son, as other schools could implement the IEP as written: “Isn’t it correct that teachers with both LD and BD certification can be made available to students at Watson?" "Yes..."

- The IEP, as written, was not appropriate, as Son was primarily LD with behaviors and not BD with a learning disability: “Isn’t it true that sometimes learning disabled students who become frustrated develop behavioral disorders?” “Yes.”

- The school district did not complete appropriate evaluations that would have shed light on Son’s learning difficulties: "Do the records indicate that the parents were ever advised that the neurological evaluation might be necessary in order to determine what appropriate education would be for Son?” “No.”

- The school district did not provide appropriate support for Son's behavioral concerns, but punished him for those behaviors: "Sir, can you tell me if you believe it would be appropriate to punish a student for behavior a student could not control?” “No.” 
Hearing Officer Examination - Asst. Supt. AHO1 asked several questions to clarify Asst. Supt.'s current role and professional credentials. AHO1 then asked Asst. Supt. "to review for me the District continuum of services." Asst. Supt. answered in this way:

We have behavior disorder resource in all of our elementary buildings and in both junior highs, and the next more restrictive placement would be the student support center, and that can be to whatever degree we feel a student needs. But at that point, we'd consider moving to a more restrictive placement than next restrictive placement, which would be Behavior Education Center at Rome to the extent that we would feel being all day self contained at the junior high level even more restrictive. If he were at the BEC, he could be in other classes because there would be appropriate people being able to give him the classes in music and art, industrial arts, and he just wouldn't be available of those things in our junior high if he was self contained.

AHO1 asked if Asst. Supt. believed that Rome-BEC was less restrictive than a fully self contained program at the junior high, to which he responded, "It's less restrictive because it could be more - a more natural junior high developmental setting.” AHO1 confirmed that Rome-BEC only served BD students, then asked Asst. Supt. if any students went to Rome-BEC part day and returned to the junior high part day. Asst. Supt. answered, “Quite a few.” AHO1 also asked, "Do you have any students placed in private day schools or residential facilities or is that an option?” Asst. Supt. responded that the District did have students in residential facilities. Finally, AHO1 asked about parent cooperation: 
AHO1: $\quad$ You described no parent cooperation. Can you give me specific instances of what you meant when you said that?

Asst. Supt.: Okay. Probably the largest one particularly at Watson was not allowing the teachers to follow through with one of the normal consequences with staying for resource, staying after school for detention, those kind of things. Our meeting in November with Principal and the others was primarily to try to find some way to do that, allowing Son to participate in his karate lessons, which were very important to him.

AHO1 completed her questioning by clarifying the specific timelines that Son was identified as LD and BD, as well as asking Asst. Supt. to define what constituted permanent and anecdotal records. AHO1 then dismissed the witness.

AHO1, FA and SDA discussed whether or not the hearing could be concluded by the end of the day. SDA stated, “ I'm very pessimistic about being able to finish today.” It was agreed that two more witnesses would testify and then the hearing would be continued for another day.

School District Direct Examination - SpEd Teacher 1. SDA questioned SpEd Teacher 1 about her current professional credentials and her role within the school district. In response to questioning, SpEd Teacher 1 said she had known Son for three and a half years. She indicated she knew Son from Key Elementary School, where Son had been placed in the student support center. As part of behavioral reinforcement, Son was allowed to peer tutor younger students in SpEd Teacher 1's special education classroom in 1988. SpEd Teacher 1 transferred to Watson Junior High the same year Son 
matriculated to Watson as a seventh grader. SpEd Teacher 1 testified that she was Son's primary teacher, or case manager, for the first two months of the school year. SDA asked, “And for what reason was his case manager changed?” SpEd Teacher 1 answered, "His case manager was changed due to a request from parents that there be a change."

SDA then asked questions regarding the services and behavioral supports Son was provided this school year at Watson. SpEd Teacher 1 said she worked with SpEd Teacher 2 to develop positive intervention strategies to be used with Son, and reviewed some of these strategies, such as a "success ladder", and a "100 square grid" as means of positive reinforcement.

SDA asked SpEd Teacher 1 if she also supported Son's academics due to his learning disabilities. She answered that she had Son for math and addressed his learning disability in this area by "utilizing flashcards to help basic recall, modified assignments so that Son was not required to do so many problems, and requiring less written output from Son.”

SDA asked SpEd Teacher 1 if Son attended all classes with teachers who had LD certification; she said all but two: P.E. and reading. SDA also asked if Son's IEP called for social work services and was he receiving them, to which SpEd Teacher 1 responded that the parents requested in writing that the services be terminated. SpEd Teacher 1 was then asked to read aloud the note Mom sent demanding that the social work services be stopped immediately.

SDA went on to ask about Son's participation in "time out", and after school detentions. SpEd Teacher 1 described time out and detentions, but indicated that parents also revoked permission for these strategies to be utilized. SpEd Teacher 1 said: 
I would be certain to notify Mom that particular day that Son would need to stay. And at times we'd set up a schedule if I knew the time he would have to stay. Repeatedly, there were requests made by Mom to not keep him even after we developed a schedule. And at some point, I received a letter asking that he not stay past 3:00 at any time.

SDA asked SpEd Teacher 1 about her anecdotal records, especially her phone contact log. SDA and SpEd Teacher 1 reviewed the phone contact log which documented the numerous times Mom was contacted to request Son stay for after school detention, then discussed the notes Mom would write asking that he not serve the detention. SpEd Teacher 1 testified that to her knowledge, Son never made up detention when he missed it.

SDA then questioned SpEd Teacher 1 about Son’s behaviors at school. SpEd Teacher 1 gave lengthy testimony outlining various types of non-compliant, inappropriate, and in some cases, dangerous behavior. The following is an example of what SpEd Teacher 1 said about Son's behavior:

I recall on one occasion Son saying that he could kill me. He could just do it with his gun. On some occasions, he would make reference to me going to jail hoping that I would like bread and water, I was going to be sued for child abuse. SDA asked SpEd Teacher 1 if she had spoken to Mom regarding these incidents; she replied she had. SDA followed up by asking if SpEd Teacher 1 “found Mom's attitude to be supportive of your efforts for Son?” SpEd Teacher 1 answered:

No, I did not. Mom expressed concern that I was physical with Son, that I needed to stop pushing him, and that I was not handling him properly. I explained to her 
that I had never handled him physically. Her reaction was that she really didn't believe that I hadn’t touched him.”

Finally, SDA asked SpEd Teacher 1 if she thought Son's current placement was working out. She answered with the following statement:

Because Son was exhibiting the behaviors on such a regular basis that they were so consistent, frequent and severe, and that he wasn't responding to interventions or strategies. It seemed clear to me that this wasn't appropriate, that we couldn't meet his needs.

SDA had no more questions of this witness.

Parent Cross Examination - SpEd Teacher 1. FA began his questioning by referring to SpEd Teacher 1's phone contact logs and asking, “Didn’t there come a point when Son was serving detentions every afternoon?” SpEd Teacher 1 replied, “I don’t think we reached that point. I would have to disagree with that.” FA followed with questions such as: How did you support Son’s learning disability? Why were your anecdotal records incomplete? Why did you punish Son by not letting him go to the bathroom? Was Son's behavior similar to others you have had in class in previous years? SpEd Teacher 1 responded by answering all of FA's questions, indicating she appropriately supported Son’s learning disability, she had never kept comprehensive anecdotal notes on her students, she always let Son go to the bathroom when he asked, and Son's behaviors, as a whole, were more severe than any other student she had had in the past.

Finally, FA asked if SpEd Teacher 1 knew what Tourette's Syndrome was. SDA objected. AHO1 interjected that there was no mention of Tourette's in the record and the 
witness was not a medical doctor and could not render a medical opinion. FA dropped this line of questioning, and had no more questions for this witness.

At that time, AHO1, FA and SDA held a discussion regarding the most expedient use of their remaining time. They mutually agreed to take witnesses out of order to accommodate the parents' expert witness (Expert Witness), who had arrived and was waiting to testify.

Parent Direct Examination - Expert Witness. FA began questioning Expert Witness regarding her educational background and subsequent professional work history to qualify her as an expert witness. FA then asked Expert Witness if she had reviewed all of Son’s educational documents. She replied, “Yes, I have.” FA asked if Expert Witness had spoken with Son, Mom and Dad. She answered that she had spoken with all of them, and spent about an hour with Son. FA asked, given her interview and review of the documents, "have you reached certain opinions in this matter?” Expert witness said, "Yes." She opined that she believed that Son had a learning disability and was behavior disordered. Expert Witness's answer to a question about the frequency of after school detentions was, "My opinion is that many of the punishments were not deemed, and he was being punished for his disability.” When FA asked if she had an opinion about whether or not Rome-BEC was the appropriate placement for Son, she answered, "I believe at this point it would not be an appropriate placement because based on less restrictive environment, all interventions have not been authorized appropriately.” When asked if Son currently had an appropriate IEP, and whether or not more evaluations needed to be completed, Expert Witness answered in this way: 
The opinion is Son has severe learning disabilities, that they were looked over, they were not addressed appropriately, and that out of frustration that this child had due to the practices that were put in place, he manifested behavior disorder...I think Son should certainly be tested for ADD and have a neurological, as some of the manifestations of his behavior may, in fact, be biochemical, and this fact should be looked at.

FA had no more questions for this witness.

School District Cross Examination - Expert Witness. SDA introduced herself, and asked Expert Witness to explain how she came to the conclusion that Son was severely learning disabled versus mild or moderately learning disabled. Expert Witness answered, “...it’s obvious that the learning problems were not being addressed.” SDA then asked if Expert Witness had ever observed Son in his classroom. She responded, “No, I did not.” SDA then asked several questions regarding how Expert Witness could opine that she disagreed with BD as Son's primary handicapping condition when she had not been a part of the EC or IEP meetings, and had not observed Son in the classroom. She answered:

What I am saying is that I believe that it's a two prong problem, and one is not necessarily more primary than the other one...My feeling is that if the team had addressed more directly and more therapeutically and more effectively the preferred practices for learning disabilities, that Son would not be acting out as he is at this time.

SDA proceeded to question Expert Witness about her interview with Son. Expert Witness noted that Son was very cooperative, did everything she asked him to do, but had 
trouble focusing eye contact. SDA then put forth a "what would you do next with a child who did not respond to your behavior interventions” scenario, and asked Expert Witness to share her thoughts. She shared them in this way:

What I saw in the placement was that he was not succeeding, and it wasn't being looked at as to why he wasn’t. So if a child is being mainstreamed, for example, in a class, and is behavior disordered, and he's frustrating easily, what is it in particular that's frustrating him. And I saw no interventions that were being used. I saw more reports that they were letting the child fail as opposed to succeed. Goals were being set up way too high for any achievement. My opinion is that the treatment was inappropriate. We could sit and argue the point of LD/BD probably from here until doomsday, and on each side of the argument, it would come up; but the fact of the matter is that the learning disability wasn’t addressed appropriately or treated appropriately, so the one manifested the other.

SDA had no more questions for this witness.

Hearing Officer Examination - Expert Witness. AHO1 asked Expert Witness if she had seen any of the correspondence between attorneys or had reviewed Son's medical records, to which she responded, “No.” AHO1 asked several questions soliciting Expert Witness's opinion regarding types of behaviors that would result in the placement of a student at an alternative school such as Rome-BEC. Expert Witness answered:

Very severe behaviors, totally uncontrollable, difficulty with authority, police involvement, kids that have severe ED problems, kids that have problems with 
schizophrenia, they're substance abusing. It's kind of like getting into Yale or Harvard, but only the other end of the stick.

AHO1 then asked Expert Witness what a classroom would look like at an alternative school and what interventions would be used. Expert Witness described the need for social work services, psychiatric evaluations, behavior modification to earn privileges, and close one on one supervision and therapeutic support in a class of up to eight students with two adults. Finally, AHO1 asked Expert Witness's opinion regarding Son’s current educational needs. Expert Witness responded with this statement:

I believe Son would need small self-contained classroom, that he should not be mainstreamed right now, that he needs to have therapeutic intervention, social work, classroom where the behaviors are dealt with and where the learning problems are dealt with so that he can break down the tasks, approach the tasks and complete the tasks, he needs to work on issues of self esteem.

AHO1 had no further questions for Expert Witness.

Parent Direct Examination - PE Teacher 1. FA asked PE Teacher 1 to clarify her role in the District and with regard to Son. PE Teacher 1 said she was currently a physical education teacher at Watson Junior High and had Son in her class for three or four weeks. FA then asked, "Would you deem it appropriate for a gym teacher to discipline a child who has fine motor co-ordination problems because the student could not tie his shoe laces?” PE Teacher 1 responded, “No.” FA had no more questions for this witness.

School District Cross Examination - PE Teacher 1. SDA had no questions for this witness. 
Parent Direct Examination - PE Teacher 2. FA asked PE Teacher 2 to clarify her role in the District and with regard to Son. PE Teacher 2 said she was the physical education teacher at Robert Elementary, where she had Son from first through fourth grades. FA asked PE Teacher 2 if she recalled once punishing Son because he was unable to tie his shoes. She answered, "I have a rule in my gym class for safety reasons that they have to have their shoes tied in order to participate in gym. So if he didn't he didn’t get to take gym.” FA had no more questions for this witness.

School District Cross Examination - PE Teacher 2. SDA asked PE Teacher 2 to refer to a document which stated that the gym teacher was having "a continuing problem with Son trying to get him to keep his shoes tied.” SDA said that the document referred to Son's refusal to lace his shoes, and asked PE Teacher 2 if she knew if Son could tie his shoes. PE Teacher 2 responded that Son could tie his shoes with no problem in first, second and third grade. When SDA asked PE Teacher 2 if her exclusion of Son from PE class was because he refused to tie his shoes, not because he could not tie his shoes, PE Teacher 2 responded, “Correct.” SDA had no further questions of this witness.

School District Direct Examination - SpEd Teacher 2. SDA began questioning SpEd Teacher 2 about her educational background, professional history and current role and responsibilities within District 21. SpEd Teacher 2 testified that she had been a BD teacher for seven years. The first two years she taught BD students in an alternative junior high, then four years at Key Elementary and this school year at Watson Junior High in District 21. SDA then asked SpEd Teacher 2 to compare the Key Elementary student support center to the Watson Junior High student support center. SpEd Teacher 2 pointed out that she and her aide were able to follow and support the same group of 
students through grades three, four and five at Key Elementary, teaching most of their academic subjects, while supporting the students in the mainstream more and more each year because "they would be expected to move around a lot more at junior high.” At Watson Junior High, the day was broken into periods and the students saw more than one special education teacher for their services. SpEd Teacher 2 said she currently had seven students, with the support of an aide during certain periods. SDA asked SpEd Teacher 2 if she was Son's teacher upon his enrollment at Key, in February of his fourth grade year. She said, "Yes.” SpEd Teacher 2 explained that Son came with an IEP already written for learning disabilities, and she implemented that IEP. At the request of SDA, SpEd Teacher 2 reviewed some of the direct instruction, accommodations and modifications made by SpEd Teacher 2 to support Son’s academic needs. SDA also asked SpEd Teacher 2 what Son's behavior was like when he came to Key and for the remainder of his fourth grade year. SpEd Teacher 2 recounted, "Son was very withdrawn, angry, very quiet, self abusive - would bang his head on the desk. He was physically aggressive on the playground, hallways, lunch room unstructured settings.”

SDA then asked a series of questions concerning Son's progress during his fifth and sixth grade years. SpEd Teacher 2 explained that Son "did improve in ways within the student support center in fifth grade.” She reported Son was mainstreamed for one class, Social Studies, and his grades were average across the board during his fifth grade year. She went on to explain that during Son's sixth grade year he continued to have difficulty in unstructured settings, especially on the bus, and that Son began obsessing about guns. "He would make comments about wanting to kill people or shoot people, make gun noises.” At SDA's request, SpEd Teacher 2 described her conversation with 
the school's social worker, who had a conversation with Private Social Worker about Son and the concern that he would have access to a gun.

SDA asked questions about the documentation SpEd Teacher 2 kept regarding certain incidents regarding Son’s behavior. SpEd Teacher 2 explained Son's behavior in this way:

Son had to sit next to me for each and every assembly. It was very hard for him to control himself...how difficult it was for him to conduct himself in the lunch room that year...He would just walk up to other students. It's a very unstructured time, and he would walk up to students and just, you know - verbally antagonize them, shove them on the arm, start some type of altercation either coming into the lunch room, he would also do this in the lunch line... We discussed this in a conference with Son's parents. We recommended that they not purchase a gun, that it would feed into Son’s anger and violent temper, and we strongly discouraged it, the social worker and myself.

SDA then asked SpEd Teacher 2 to share her observations of specific behavioral incidents that had occurred. She described an incident where Son, in trying to hit another student with a baseball bat, broke the front window of the school. Another incident she described was when the janitor approached her and told her that he overheard Son remark that Son "was happy that a lady shot all those kids.”

SDA asked SpEd Teacher 2 if she ever tried to conference with the parents regarding Son’s behaviors. She answered, "Yes, I did.” She continued by saying she had several conferences at school with Mom to discuss Son’s behavior. When asked if Mom and Dad were supportive of her efforts, SpEd Teacher 2 answered: 
To a certain degree. My relationship with the parents in the three years was not that bad of a relationship. I had difficulties when Son would do something at school, sometimes Mom would call me back and say that Son had given her a different version of the story and generally they would believe Son.

SDA asked whether Mom would call SpEd Teacher 2 "a lot” and, if so, where Mom would call. SpEd Teacher 2 responded that Mom called her “At my home.” SDA asked if SpEd Teacher asked Mom not to contact her at home. SpEd Teacher 2 said, "Yes” SDA followed up by asking, “And did she?” SpEd Teacher replied, "No, she did not.”

SDA switched tacks and asked about SpEd Teacher 2's involvement in drafting the seventh grade IEP. She stated she was involved, and was one of the primary educational experts who believed Son could not get the support he needed at Watson Junior High; that the proper placement would be Rome-BEC. SpEd Teacher 2 relayed that her reasons for believing Rome-BEC was the appropriate placement for Son included Son's inability to make improvement in his behaviors given the current services in the student support center, and the amount of daily monitoring Son would need at Watson. She went on to testify that she tried to talk with the parents about the Rome-BEC program, but "there was no agreement. We recommended if-They were in disagreement with Rome-BEC placement, so we recommended that he go to Watson and try to continue in the student support center at Watson.”

SDA then asked SpEd Teacher 2 about Son's educational progress at the beginning of this, his seventh grade year. SpEd Teacher 2 said that she took over as Son's case manager in November at the parents' request. She testified that at that time, 
Son's behaviors continued to deteriorate; she had a conference in November with the parents to let them know this was the case:

I had a conversation with Mom regarding my observations from having Son, having taken over as his case manager from SpEd Teacher 1. I shared with her the difficulties that I was experiencing with him, his progress. I shared with her my grade book and explained to her that he was currently failing his courses with me, had low scores, wasn’t turning in assignments. And then I tried to explain to her this was all occurring in his other classes that he was being serviced in also. SDA then asked SpEd Teacher 2 to describe Son's behavioral and academic progress as of this date. SpEd Teacher 2 described it in this way:

My observations about Son's behavior for the current school year were that he was totally out of control, was unable to conduct himself at all, even at times with me - you know - one on one situation, or small group within the support center, bizarre behaviors. He would make references to killing, shooting, bombing the school, make noises, total refusal. He could not conduct himself appropriately on a consistent basis.

SDA asked if Son assumes responsibility for any of his behavior, shows any remorse, or has been responsive to any effort to modify his behavior. SpEd Teacher 2 answered, “No, he has not” to each question.

Finally, SDA asked SpEd Teacher 2 if she were aware that Son had failed a vision re-evaluation screening given by the school nurse in the $6^{\text {th }}$ grade. She answered, Yes.” When asked if she were “aware of any follow up work done as a result of that”, SpEd Teacher 2 said that the school nurse sent a couple of notes home to the parent, which was 
customary whenever a deficit area was noted that a physician had to follow up on. SDA had no more questions for this witness. Because it was getting late, AHO1 agreed that parent cross-examination would occur on the next scheduled day of the due process hearing.

Hearing Officer Examination - SpEd Teacher 2. AHO1 asked several questions of SpEd Teacher 2, including whether or not there were physical injuries to the students with which Son fought, and whether or not she had actually seen the gun mentioned in her testimony. SpEd Teacher 2 testified that the students were, at times, bruised by Son's physical aggression towards them, and that although SpEd Teacher 2 had not seen the gun, it was indeed a reality per the discussion with Private Social Worker. AHO1 had no more questions for this witness.

SpEd Teacher 2 was admonished not to speak to anyone regarding her testimony, as she would complete her testimony when the hearing reconvened on February 28, 1990. AHO1 adjourned the hearing at 6:00 P.M.

Level One Due Process Hearing: Day Two. AHO1 reconvened the hearing on February 28, 1990 at 10:30 a.m. After a few housekeeping clarifications, she asked FA to begin his cross examination of SpEd Teacher 2.

Parent Cross Examination - SpEd Teacher 2. FA asked SpEd Teacher 2 about the amount of time she spent instructing Son. She answered that it depended on the subject, but the majority of the time she was with Son she spent instructing him in academics. FA verified that SpEd Teacher 2 was familiar with Son's educational records and his motor problems, and concurred that Son had a learning disability. FA asked why Son’s May 30, 1989 IEP had goals and objectives that addressed behavioral disorders, 
but did not have goals and objectives that addressed his visual and spatial perceptual concerns. SpEd Teacher 2 answered that Son's LD issues were addressed in the academic portion of their instructional day; it was ongoing. When asked if SpEd Teacher 2 provided Son with positive behavior strategies to decrease his inappropriate behaviors, she answered, “This year Son has not engaged in any behavior modification techniques that I have tried to implement with him.” FA asked SpEd Teacher 2 if her anecdotal records were more comprehensive this year than in past years, to which she answered, "Yes."

FA changed tacks and asked SpEd Teacher 2 if it were normal for a special education teacher to have a student for three years in a row. She responded that it happens "not infrequently” in elementary school. FA asked if Son had ever had a personality conflict with her, to which she responded, “No.” FA then asked if all adolescent males had an infatuation with guns, “almost a sexual issue.” SpEd Teacher 2 responded, “I don’t know.”

FA asked SpEd Teacher to refer to her anecdotal notes from November 8 through January 10, which was not part of the official record. He asked questions to discern what she noted and why she did or did not note certain things, such as time of the behavioral incident. She said she noted things that she believed were relevant, and did not note others. When asked if she charted Son's behaviors based on her data, she stated she did not develop a chart.

FA asked why, if unstructured settings were difficult for Son, they were allowed. SpEd Teacher 2 stated that unstructured settings included hallways, bathrooms, recess, assemblies, and lunchroom. FA did not follow up on this line of questioning. 
FA asked SpEd Teacher 2 if she was sure that Mom and Dad received the notice stating that the case manager had changed from SpEd Teacher 1 to herself, SpEd teacher 2: "Is it customary for the school district to pop a parental notification of an IEP change in the mail without certifying it, or without requiring a parent to come in and receive a copy?” She responded that is was common practice to mail the form home via regular US mail. When asked if she knew whether or not the parents actually received it, SpEd Teacher 2 said, “No.”

FA then said, “You told Son’s mother not to call you anymore, correct?” SpEd Teacher 2 said she asked Mom not to call her at home. FA stated, "When you tell a parent not to call anymore, is that like telling a parent, 'I don't care'?” SpEd Teacher 2 responded that she did not think so; she did not give mixed signals to the parent.

FA proceeded with questions about how "silent lunch” was used, and asked for an explanation of its therapeutic ability. SpEd Teacher 2 said that silent lunch was given to Son by her and other teachers when Son did not complete his homework; it was a consequence, not a therapeutic intervention.

FA completed his cross examination with in-depth questioning that called into question SpEd Teacher 2's knowledge and ability to follow through with appropriate instructional and behavioral strategies that would have allowed Son to benefit from his education. Following that line of questioning, FA had no more questions of this witness. District Redirect Examination - SpEd Teacher 2. SDA asked if SpEd Teacher 2 knew whether or not, when the parents requested that the case manager be changed from SpEd Teacher 1 to her, they requested her specifically? SpEd Teacher 2 said, “They requested, specifically, me.” SDA followed up by saying SpEd Teacher 2 had testified 
that she had requested Mom not call her at home. SDA asked, "Did she continue to call you at home?” SpEd Teacher 2 responded, "Yes. Then I had to get an unlisted number.” SDA asked why Son was asked to have silent lunches, when he could have stayed at other times, such as after school. SpEd Teacher 2 said Son's parents would not allow that to occur. Finally, SDA asked where Son's needs could best be met. She responded, “Rome-BEC.” SDA had no more questions for this witness.

Hearing Officer Examination - SpEd Teacher 2. AHO1 asked several clarifying questions of SpEd Teacher 2, including how did Son function in a group setting and how many periods of the day did she have him for instruction? SpEd Teacher 2 said Son did not interact well at all in any group scenario, and that she had Son for five of 11 periods daily. AHO1 had no more questions for this witness. AHO1 then broke the hearing for lunch.

Upon return from lunch, AHO1 asked the District to call their next witness. District Direct Examination - BD and LD Coordinator. SDA began her questioning by confirming BD and LD Coordinator's credentials and current job duties within the District. She asked BD and LD Coordinator to describe the findings of his classroom observation of Son. He said, "I indicated that he had poor work habits, and oppositional behavior, and appeared to be moody. There was some history of self abusive behavior. Generally did not comply with classroom requirements, was my overall impression.” SDA also asked BD and LD Coordinator to define a behavior disorder as it is used in the district. BD and LD Coordinator said:

It encompasses both state and federal guidelines, but a little more specific because it refers to behavior disorders as problems demonstrated in the school setting that 
significantly interfere with the youngster's educational functioning or performance. Those behaviors resist the effort of regular education to intervene. And they are longstanding, and they are not due to a single incident, nor are they detrimental in nature... When we observe those behaviors over time, and we apply our best intervention efforts, and that fails, that helps us crystallize the diagnosis, along with the rest of the case study pattern.

SDA asked BD and LD Coordinator if he was aware that Son had a learning disability and that all IEPs except the most recent one had LD goals and objectives on it. He said, "Yes.” BD and LD Coordinator was then asked to define a learning disability. He responded in this way:

Learning disabilities are disorders in psychological processing of information that significantly interferes with the youngster's acquisition of curriculum. And that, at present, despite below average, to above average intelligence, are not caused, primarily, by other extenuating circumstances...for example, mental retardation, sensory impairments, physically handicapped.

SDA then asked if a student had both a learning disability and is behavior disordered, "at which point does the student primarily become classified as behavior disordered rather than learning disabled?” BD and LD Coordinator answered, “One way often used is to determine how much special education or service would be appropriate for each disability." SDA then asked what the origin of a behavior disorder is. BD and LD Coordinator answered, "From my experience, the origins of behavior disorder would stem from family issues, many times, also compounded by school experiences, as well as 
that great unknown, something innate within the child, which appears to be the million dollar question, diagnostically.”

SDA began a new line of questioning regarding Son’s current placement. BD and LD Coordinator described Son's placement as much more restrictive than the average BD student at Watson Junior High. “It’s almost completely self contained with special education services, with the exception of physical education.” SDA had BD and LD Coordinator describe the continuum of services provided by District 21. BD and LD Coordinator noted that the next more restrictive placement after the self contained program at Watson Junior High was a special day school, Rome-BEC. The most restrictive setting would be a residential setting. SDA asked if the special day school was within the District's boundaries, to which he answered, "Yes."

SDA asked BD and LD Coordinator why the team felt Son should attend a special day school at this time. BD and LD Coordinator said that a list of educational needs and behavioral supports was generated prior to the November IEP meeting. It was explained to Mom that given this list of needs and supports, Son would have to attend Rome-BEC. SDA asked if BD and LD Coordinator believed that Son's learning disability was severe. He responded, “Not at all.” When asked if Son's LD needs could be met at Rome-BEC, he responded, "Yes."

BD and LD Coordinator was then asked to describe the Rome-BEC setting, and also asked how students who attended Rome-BEC could matriculate back to their home school. He said:

Students are mainstreamed out of the BEC back to their home school on the basis of the development of appropriate behaviors. Those behaviors don't have to be 
perfect, but they have to improve to a certain level as determined by the staff before mainstreaming is considered....25\% of students are mainstreamed.

When asked if he concurred with the recommendation that Son should be placed at Rome-BEC because other, less restrictive placements have been tried and failed, BD and LD Coordinator said, "Yes." SDA had no more questions for this witness.

Parent Cross Examination - BD and LD Coordinator. FA asked BD and LD Coordinator how many times over the years he had observed Son in SpEd Teacher 2's classroom. He responded, “At least a dozen.” FA then asked if he had ever made any recommendations to SpEd Teacher 2 about "how she should be addressing Son's learning disability". BD and LD Coordinator answered, "I felt SpEd Teacher 2 was addressing the specific learning disability of Son in her classroom functions and instructional techniques.” Upon request, BD and LD Coordinator explained some of the methodologies he saw used with Son, such as lining up paper for math problems to offset his visual perceptual issues.

FA questioned $\mathrm{BD}$ and LD Coordinator regarding the learning disability being present prior to the behavior disorder. BD and LD Coordinator disagreed, stating that it had been identified before the behavior disorder, not that the learning disability fostered the behavior disorder. When FA asked if $\mathrm{LD}$ and $\mathrm{BD}$ Coordinator believed that behavior disorders can sometimes be due to the frustration of learning disability problems that are not being adequately or properly addressed, he said, "No, that's not true. That can never be the case."

FA asked if attention deficit disorder or visual balance problems were learning disabilities. BD and LD Coordinator replied, "No, they are not.” When asked if they 
could cause difficulties with learning, BD and LD Coordinator replied, “They could.” When asked if the EC meeting held in November of 1989 covered both LD and BD, the Coordinator said it only covered BD at that time, but the parents could have asked for the LD portion to be covered if they had wished.

Hearing Officer Examination - BD and LD Coordinator. AHO1 followed up by asking BD and LD Coordinator if there were any other placements through NSSEO besides Rome-BEC that were available, to which LD and BD Coordinator responded, “For hearing impaired - a very low incidence group...NSSEO also has a facility that is for primarily LD - it's referred to as the Miner LD Center, and it's located in Arlington Heights.” He went on to state that this center did not have the therapeutic and behavioral supports needed by Son. AHO1 asked, given a psychological report that suggested Son might have ADD, if ADD had been ruled out. BD and LD Coordinator said, "No.”

SDA said, “This closes our case in chief. I am reserving the right to call a witness in rebuttal.”

Parent Direct Examination - Science Teacher. FA asked Science Teacher for her name, address, and current position in the District, which she recounted. When asked if Science Teacher was LD and BD certified, and if she was Son's current science teacher, she replied, “Yes.” FA asked what Son's grades were in science. Science Teacher recounted that he had a B minus first semester, and right now had “up to a D. He received an F for mid quarter, but completed a few assignments yesterday, day before.” FA asked if Son “does his work in class as you assign it.” Science Teacher said, "No.” FA asked what she does when Son does not do his work. Science Teacher responded in this way: 
Since he is unable to come, for whatever reason, to class, on a prepared basis, all of his work is self-contained in the class. I keep it all for him. When he comes in, I hand him his work. Some days he's able to participate; other days, he’s not. It's all on a day to day basis. I keep it all for him: his books, his work. Because whenever it's left, it does not come back. We realize the best way for him to be successful with me is for him to keep his books with me.

FA then asked Science Teacher if she had ever given Son a silent lunch. She said, "Yes, for various reasons: ranging from failure to complete academics, coming late to class, inappropriate behavior, assigned by another teacher.” FA had no more questions for this witness. SDA had no questions for this witness; AHO1 excused the witness.

Parent Direct Examination - Dad. FA asked Dad to state his relationship with Son, and he did so. FA then asked, "Does Son have any access whatsoever to any weapons?” Dad replied, “No more. They're all gone. No weapons in the house whatsoever."

FA then asked Dad if Son was still seeing Private Social Worker. Dad answered, "No. He stopped seeing him a year or so ago.” FA asked if Dad has watched Son in Karate. Dad responded in this manner:

Yes I have, and as of now, he works fine. When he started Karate, he had a very bad problem: when everybody would be left, he would be right. When everybody was on the right hand, he'd be on the left hand. We talked to the instructors, and they said, "We will work with him.” And they did. And they did work with him. They stood right there. When he was wrong, they instructed him. Yes, they did. They didn't give him any silent lunches. They didn't yell at him. They didn’t push him. They never yelled at 
him for biting a pencil. Like you do! It took about maybe a year and a half, maybe two years, before he started to straighten himself out. And if you like, we would bring the Sensei up here, to let you people hear it. Right now, as of this time, he’s considered one of the best in his class. You people will probably see him at the Olympics in 1992, in Barcelona.

FA asked Dad if Son teaches Karate. Dad said that Son has been teaching the beginning kids for about a year and a half. FA asked if Son finds Karate a "rewarding hobby.” Dad said, "Yes, he does."

District Cross Examination - Dad. SDA asked Dad when Son began Karate lessons. Dad said when Son was six and a half. When SDA asked if he had been doing “it for approximately seven years”, Dad responded, “Okay, whatever.” SDA had no further questions for this witness.

Hearing Officer Examination - Dad. AHO1 asked Dad if the left - right problem was gone within two years, then that meant Dad did not see it as a problem after Son was eight and a half years old. Dad answered that Son still had a problem once in a while, but self-corrected immediately. AHO1 asked how often Son takes Karate lessons. Dad said that Son takes lessons six days a week, one hour each time, and teaches two lessons each week. AHO1 asked Dad if the instructors at Karate ever told him that Dad and Mom should get a medical evaluation because of Son’s left - right difficulties. Dad said, “No, because they're not medical people; they're just teachers.”

AHO1 asked Dad why they requested that Son's teacher be changed from SpEd Teacher 1 to SpEd Teacher 2 in November. Dad responded: 
Because we thought SpEd Teacher 1 was not doing her job properly. She was pushing, shoving, silent lunches, silent dinners, staying after school. She made him walk home in the rain because she slammed the door on him; he knocked on the door and they wouldn't let him in. He had to walk home two miles in the rain, because they made him stay after school, and they held him after the bus had left. And that's one of the reasons why we sort of cut down on after school.

AHO1 had no more questions. She asked Dad to step down.

Parent Direct Examination - Mom. FA asked Mom if she was Son's mother. She said, "Yes, I am.” FA asked Mom what happened to Son when he was 10 months old. Mom recounted that Son fell down a flight of 12 stairs, had to go to the hospital, but recovered. She said Son had to go to the hospital for dehydration when he was 17 months old, and that he had recurring ear infections to this day.

FA then asked Mom if she had ever observed Son in his classroom. Mom said, “Yes, I did.” She explained her experience on February 8, 1990 in this way:

I observed Son and saw a very frustrated child in that room, and saw SpEd Teacher 2 putting on an act, because I know she does not spend that much time with him - from what Son tells me - every day. And what I can see, I would say no, because she has other kids. Son was acting out, singing, put his foot up on the chair. And he was just plain nervous. He’s a hyper child.

FA said, “Throughout this hearing, you have seen Son sitting here, relaxed, not fidgeting, behaving himself. Mom said, "He can be like this at home, yes. If you are nice to him. But if someone pushes or grabs him all day long, no. Those two teachers here, no.” 
FA asked Mom if they punish Son when he does something “not good.” Mom listed several punishments, including not being allowed to go outside, not allowed to watch TV or play with his Nintendo; if it is something really bad, he cannot go to Karate. FA then asked Mom if she received a note from SpEd Teacher 2 asking her not to call her at home anymore. Mom memorialized her experience in this way:

I felt she didn't want me to have anything to do with her anymore; that's the way she wrote it. Then she wrote down her hours, and my hours conflicted with her hours. I have a job; they keep harassing me at work, calling me until my boss told me I was getting so excitable; she says, “I don’t want those calls here anymore.” And Principal was another one who harassed me quite often starting in November. Son not doing his work; he’s fighting or swearing, or he’s doing all these things. I'm at work, I've got a job. I get these calls and my boss sees me getting so excited that she doesn’t know what to do. Now, I need this job. If they're going to keep calling me, and I'm going to lose my job, that's not going to be good for anybody. That's what they're going to be causing if they keep calling.

FA then asked Mom how often Son had to stay after school. Mom said two or three times a week, so she "put a stop to it." FA asked Mom why she asked that the school social worker stop seeing Son. She said:

I didn't think it was for our benefit. I think it was for their benefit. If I need someone, I will get my own; I don't need them. The school is never for the child; it's always for the school district...At the meeting, my husband and I were there, and I said, "No way. You are going to be for the school and never for my child.”; 
he was stuck up. “I don’t want you on this case. I want someone there for us, not for them.” I want my own, that I have confidence and would never give it out to anybody.

District Cross Examination - Mom. SDA asked Mom if she called the police a lot. Mom responded, “No, I don’t. I called them once, on my son, when he wasn’t home. If you were listening, lady: he wasn’t home, they kept him in.” At this time, AHO1 directed FA to ensure "there's courtesy." FA asked to go off the record. Back on the record, SDA asked Mom if she had shared Son’s medical history with the school district. She answered, “No, they have not been shared with—I didn’t think it was their business to know. They never asked me for any records.” SDA asked Mom if she assisted the school nurse fill out several health histories for Son. Mom said she did, but they never asked her about anything.

SDA then asked Mom if Son could have a "different version of the facts" than she does at times. Mom said, "Correct." SDA followed up with, "And sometimes he has a different version of the facts than the teachers have, is that correct?" Mom said, "I disagree. I know both of these teachers. I have been in the school a number of times at Key, so I know a little bit more different. I believe him more than I believe them.”

SDA then focused on Mom's observations of Son in SpEd Teacher 2's classroom in February, 1990. She confirmed that Mom saw Son’s disruptive behavior. Mom said yes, but it was caused by "frustrations." SDA then asked Mom if Principal told Mom that Son was actually having a good day that day. Mom said, "That was the first time; that was the first nice words he's ever said to me. And the only words.” 
SDA asked if Mom agreed with the four suspensions Son had had this school year. She said, "I disagreed. He should have been made to sit in a corner, and not suspensions where he can’t learn.” SDA had no further questions for this witness.

Hearing Officer Examination - Mom. AHO1 asked Mom what supports she thought Son should have at school to decrease his 'acting out.” Mom said, "I think they could talk to him and work with him on a one-on-one basis. He should have a teacher that's just for him if he’s having that much difficulty. She can't handle him and go to all of the other ones. He needs one person until he can get the thing together.” AHO1 asked Mom what punishments she thought would be good at school. Mom said, "Make him sit in the back of the room and in a corner by himself, away from everybody. That would be great punishment.” AHO1 had no further questions.

At this time, Mom asked if she could say something important. "I don’t know if it is going to hurt two people, but I believe it's going to hurt two people in this room.” AHO1 asked FA to determine if Mom's statements were relevant to the case. Mom said, "I want it to be known." After going off the record and consulting with Mom, FA told AHO1 that the remarks were unrelated to the case. Mom retorted, "I can't say that? It is irrelevant to the case; but what I observed should not have been observed.” AHO1 heard Mom’s remarks in camera, then stated, “That’s not going on the record.”

AHO1 asked Mom to define a silent lunch. Mom said, “A silent lunch is where, if he doesn’t have lunch, they don’t let him buy lunch. AHO1 clarified by asking Mom if she thought Son was not allowed to eat lunch. Mom answered, “Correct. They don’t let him. SpEd Teacher 1 doesn’t let him. SpEd Teacher 2 didn’t, and Science Teacher didn’t let him.” AHO1 had no more questions for this witness, and she was excused. 
FA stated he did not have any more witnesses. This concluded the family's presentation.

District Direct Examination - Principal. SDA asked Principal to state his name and his current position. SDA asked Principal to describe what a silent lunch is. Principal explained that silent lunch is when students who have had a minor disciplinary issue eat in a classroom with a teacher rather than in the main cafeteria. He said that food was never withheld from students for any reason.

SDA asked Principal if he had observed Son in various classrooms, in the hallways, and in the lunchroom. If so, did he concur with the teachers that Son had inappropriate behaviors? Principal stated he had observed Son in all of those environments and concurred that Son consistently behaved inappropriately.

SDA asked Principal if he had difficulty dealing with Mom. Principal answered, “Yes.” When asked to characterize Mom’s relationship with him, Principal replied, “I would characterize her relationship as being one that's held a position that she believes in strongly, but has gone into conflict with what we need to be doing in our school." SDA had no further questions for this witness.

Parent Cross Examination - Principal. FA asked Principal if Son's teachers were providing appropriate methods to support Son’s behavior. He replied, "His teachers, sure.” FA asked Principal if he had any training in behavior disorders. He answered, “No."

FA asked Principal to describe the LD and BD programs currently offered at Watson Junior High. Principal described the support services, which encompassed four LD and BD teachers who provided resource support through self-contained placements. 
FA asked Principal if the District could add one more classroom to support students that were both LD and BD. Principal said they were already doing that.

FA had no further questions for this witness. AHO1 excused the witness.

District Closing Argument. SDA summarized the District's case by making the following points:

- The School District cannot meet the needs of Son in his current program at Watson Junior High;

- The School District can meet son's needs in the more restrictive placement of Rome-BEC;

- Testimony and evidence supports this change in placement;

- Expert Witness was not credible because she did not observe Son in class and did not review all of Son's records, but only those given to her by FA;

- Testimony and evidence also supports the fact that Son is primarily BD and secondarily LD.

Parent Closing Argument. FA summarized the family's argument by making the following points:

- The parents did not consent to a change in placement;

- The parents contend that Son is LD, which caused the behavioral concerns. Because of parents' "limited abilities”, they did not understand this change from primary LD to BD when it happened, or they would have objected then;

- The School District failed to meet its burden of proof that Son needs all of these behavior interventions, and that he no longer needs LD strategies; 
- All evaluations that should have been done were not done. Specifically, a neurological evaluation to rule out ADD should have been done;

- Change of placement to Rome-BEC cannot occur because it will not meet Son's LD needs and it is not currently known if Son is ADD.

AHO1 closed the hearing, stating, "I would like to thank you the participants of the hearing. It has been a long two days.” Level One Due Process Hearing Decision and Order. AHO1 issued the Due Process Hearing Decision and Order via certified mail to all parties on March 8, 1990. In the decision, AHO1 answered the five questions below:

1. If the child has needs which require special education: AHO1 indicated all records and testimony substantiated Son's eligibility for special education in the areas of behavior disorder and learning disability.

2. If the evaluation procedures utilized have been appropriate in nature and degree: "The evaluation procedures utilized have been appropriate in nature and degree in this particular case...The documentation clearly tracks the impact of the child's handicapping condition on his educational social behaviors.” AHO1 wrote that the parents or their attorney could have requested neurological or medical evaluations be completed prior to the hearing, and did not do so.

3. If the child's diagnostic profile is substantially verified: AHO1 indicated all records substantially verified the presence of a behavior disorder and a learning disability. "Any placement the child will attend must provide a program model with individualized strategies for addressing the multiple needs of the child.” 
4. If the special education placement and related services are directly related to the child's needs: AHO1 wrote:

The current placement at Watson Junior High is not directly related to the child's needs and the District is correct in seeking a more restrictive placement that will allow the child to achieve success and halt his current pattern of failure in school. The issue of what constitutes an appropriate program specifically individualized for this child is a critical issue which requires comprehensive examination of the underlying problems the child has either experienced directly in the academic setting or which have occurred outside school but have impacted negatively in the educational setting.

a. Parents have refused support services from District-employed staff, such as social workers. Parent stated that "if I need one I'll get my own.” She also said she wanted confidences kept, that information should not be shared among school staff. However, she could not give an instance when any confidences were violated. When asked if prior medical history had been shared with the District, she responded, "No, it is none of their business”, although she had specific information regarding pediatric exams and discussion (but not prescription) of medication. The existence of this secreted information reflects negatively on parents' current request that the District conduct a medical exam.

b. Parents recognize that the child's version of facts is often different than that of the staff but stated that they believe the child more than the teacher. 
c. Parents do not want after school detention or quiet lunches used as intervention strategies, but when asked what strategies might be used, the parent suggested a lunch study hall and described the quiet lunch used by the school but to which the parents were vehemently opposed. Parents also felt that talking to him, 1-1 teaching and physically modifying the classroom would be successful, but these strategies have already been tried without success by the staff. Parents further described consequences they use at home for the child's inappropriate behavior. These strategies include no TV, staying in after school, no Nintendo, no Karate.

d. Approximately two years ago, the child had been promised and given a gun as a reward. It has since been taken away.

e. The child is not permitted to stay after school because he is responsible for giving his grandfather his medication.

f. There appears to be no boundaries between the child and the parents. The result, as clearly demonstrated in the hearing, is that the parents share their negative opinions about the school and staff with the child; he also realizes that parents believe his statements to be more credible than those of all the professionals. Further, he has been privy to derogatory statements made about the staff, ill-advised statements that cannot help but sabotage and undermine whatever educational program the District develops.

The parents have what appear to be irreconcilable differences with the District. It is questionable if even minimal success for the child will result from any except the most restrictive placement which can provide the most comprehensive 
structured program with immediate consequences, at all times. Given the immediate need for this child to be allowed to be a child, to be treated as a child and not an adult, a flexible positive peer culture program model would be a therapeutic model likely to provide a comprehensive approach to meeting both the behavioral and learning needs of the child. The LD/BD Coordinator pointed out legitimate concerns regarding positive peer culture, and his input would be important. The child needs to develop appropriate behavior patterns, personal responsibility and care and concern for himself and others. His manipulative behaviors must be channeled into positive experiences.

5. If the child's rights have been fully observed: “The District has exhibited good faith in all its dealings in this case. Any procedural errors, should any have occurred, are de minimus, given the history of refusals of service by the parents...the child's rights have been fully observed by the District.” The following is a synopsis of AHO1's written Order:

1. The District shall refer the child for placement at Placid Shore Residential Education Facility. This will allow Son the opportunity to continue to participate in Karate when staff-designated behavioral criteria are met. An IEP meeting will be held to write an appropriate IEP, which must include weekly participation by the parents.

2. This placement may be delayed due to a waiting list at Placid Shore.

3. In the interim, Son will attend Rome-BEC. An interim IEP will occur within 10 days and will include specific behavior guidelines, a level system to encourage adherence to the guidelines, a coordinated communication system that provides 
daily feedback to the parents. Parents shall "separate the child from adult decision making.” Parents will implement the same level system at home that is used at Rome-BEC. Staff will assist parents in development of this plan. If parents agree, Expert Witness can review Son’s entire educational file and make appropriate recommendations that would be integrated into the IEP. The IEP will also address Son's LD needs as well as identify any other related services, such as social work, counseling, etc. that is deemed necessary.

4. Parents and child shall visit Placid Shore and Rome-BEC.

5. The interim IEP shall be reviewed, and modified as needed, every three weeks.

6. Parents will allow communication between Son's pediatrician and District staff.

7. "The District shall follow Honig v. Doe should removal of the child from school be necessary during the timeline for appeal and for the conclusion of any appeal, should one be filed."

On March 16, 1990 FA appealed AHO1’s Decision and Order to the Illinois State Board of Education (ISBE), requesting a Level Two Due Process Hearing to "vacate the order of the Level I hearing officer in its entirety.” All parties received a copy of the motion on March 19, 1990 via certified mail.

\section{Level Two Due Process Hearing}

On March 21, 1990 the Illinois State Department of Education (ISDE) presented the parties with a list of names of possible hearing officers. The parties went through the striking process, and on March 30, 1990 SDA notified ISDE via certified mail of the selected hearing officer. On that same day, ISDE notified AHO2 by letter of his appointment as hearing officer in this case. On April 3, 1990 AHO2 accepted the 
appointment as hearing officer and requested all Level I hearing documentation be forwarded to him for his review. On April 5, 1990 AHO2 contacted FA to set a mutually agreeable hearing date for oral arguments on April 16, 1990. Although AHO2 attempted to contact SDA, she was on vacation and could not be reached.

FA filed a motion for default judgment on April 3, 1990. The motion stated that FA had not been given "a true and complete set of the administrative record”; he had not been provided a copy of the transcripts of the testimony in the Level I due process hearing. Also, FA requested an independent evaluation of Son at the District's expense. On April 11, 1990 SDA responded, stating that all relief requested should be denied on the basis that the transcripts were not delivered to the District until April 2, 1990. The transcripts were subsequently copied and delivered to FA on that same afternoon. SDA also wrote that independent evaluations could only be requested in writing by the parents if they disagreed with an evaluation previously completed by the District; no such written disagreement had been received. Finally, SDA indicated that she had been on vacation from April 2 through 7, 1990. Therefore, she was not party to the choosing of the hearing date, and April 16 would not work for the District because all employees were on spring break.

Parent Memorandum in Support of their Appeal. On April 11, 1990 FA submitted a memorandum in support of the parents' appeal. FA argued that the District did not have the appropriate personnel observe Son in the classroom, and therefore this "tainted the evaluation" the AHO1 relied on to make her decision. FA also argued that AHO1 "had no right” not to allow him to offer other documents as proof, and that AHO1 would not allow objections to be made during the hearing. According to FA, both issues caused 
“severe prejudice” to the parents' case, "violating their procedural and substantive due process rights.” FA also argued that the District punished Son for his disability, did not give proper weight to Expert Witness's testimony, and could not sustain its burden of proof for a change in Son's educational placement. FA concluded with the statement that a residential facility could be appropriate if implemented on a day placement basis, but "Watson Junior High has an adequate LD/BD program. His IEP at Watson can be tailored to meet his special needs and at the same time, maintain him in the least restrictive environment with an appropriate education.” School District Brief to Affirm AHO1's Order. On April 11, 1990 SDA submitted a brief to support the District's request to affirm AHO1's Order. In her brief, SDA reviewed the nature of the dispute, recapped Son's educational history and the District's reasoning to change Son's educational placement. SDA referred to the testimony given in the Level I Due Process Hearing. She wrote, "Instruction has been and will continue to be modified to incorporate and address his learning disability. However, because his behavior has interfered significantly with his ability to learn, his behavior problems need to be addressed in a more intensive program.” SDA went on to argue that a special day school such as Rome-BEC continued to be the appropriate placement and least restrictive environment in which Son could benefit from his education.

SDA then described the parents' position, indicating that Mom “openly admitted her failure to cooperate with the School District based upon her mistrust of the individuals and officials therein.” SDA wrote:

The parents' position at the Level I Hearing was that Son's behavior in school is precipitated by his learning disability and that he should be placed in a regular 
education classroom with support services for learning disabilities. The discrepancy between the parent's perception of the child's problem and the schools’ perception could best be described as a 180 degree difference. SDA continued with discussion of the Level I decision, indicating that the Hearing Officer's Order was "clearly more restrictive than the placement sought by the School District.” SDA wrote that the District did not appeal this decision because the District believes residential placement is appropriate:

...the parents failure to place consistent limitations on the child and to communicate mixed messages of their support of the discipline procedures imposed and implemented by the school, created greater confusion and disorientation within Son than would occur should he be removed from the family home and placed for education purposes in a residential facility.

SDA wrote that this is an unusual case in that case law suggests that most residential placements are requested by the parents, not the District. However, SDA argued that the District and the Hearing Officer can request a more restrictive placement if that is the least restrictive environment in which the child can benefit from his education. SDA wrote, “Son’s continually belligerent and noncompliant behavior...indicates a more restrictive environment is required to ensure that Son will learn to conform his behavior in such a manner as to allow delivery of academic instruction.”

SDA argued against the parents' position of Son attending the residential facility as a day placement, indicating that the transportation situation would be next to impossible. SDA also wrote: 
This position overlooks the obvious component which the Hearing Officer perceived. That is, the education of the student can only be effectuated if the parents are not involved on a continuous basis in second guessing and undermining the disciplinary efforts of the educators.

SDA concluded her brief by stating that Son has been appropriately evaluated, and the testimony and supporting documentation "amply supports" a more restrictive environment such as the one AHO1 has ordered. Therefore, SDA requested that AHO1's Order of a more restrictive placement be affirmed.

Level Two Due Process Hearing - Day One. On April 16, 1990 AHO2 went on the record to discuss preliminary matters. AHO2 identified all of the participants in the room, including FA, Mom, Dad, Son, SDA, Asst. Supt, Principal, and LD and BD Coordinator. AHO2 clarified that he did not live in School District 21 or its feeder high school district, District 214. However, AHO2 stated that his wife worked as a high school teacher in the adjacent high school district. SDA had no objection with AHO2 hearing the case; FA made a motion that AHO2 recuse himself. AHO2 asked if both parties could make a motion and agree to an extension of time so that another hearing officer could be appointed. FA made this motion, and SDA opposed, stating that, due to the "Stay Put" provisions under IDEA, Son was currently receiving his education at Watson Junior High and continued to make no progress there. Therefore, a motion to extend the time for a decision in this case would be detrimental to Son's education. "At the very least, the District would urge that the interim placement ordered by AHO1 be implemented if additional extension of time is being sought by the parents.” AHO2 denied the motion to recuse himself. 
AHO2 then asked FA to discuss his motion for default judgment. FA expounded on the fact that he was not adequately prepared for today's hearing because he did not receive the transcript from the District in a timely fashion. He also said that although he had requested a neurological evaluation in the first hearing, one was not ordered and subsequently had not been done. It was the parents' belief that this medical evaluation might shed light on Son's educational needs. FA also said that a neurological evaluation was necessary to ensure that Son's placement was in the least restrictive environment.

SDA responded that FA actually received the transcripts three days prior to herself, as she was on vacation when they arrived. The transcripts were delivered late by the transcriptionist. SDA told AHO2 that she had contacted FA and requested that they mutually agree to request an extension of time, and he refused. As of this date, FA has made no motion to extend. SDA also told AHO2 that she had ensured the District employees who might need to testify were available, even though it interrupted their spring vacation. SDA stated that at no time during the Level I Due Process Hearing up until this moment, had she seen or been provided a copy of the records FA wanted to offer as proof. Therefore, the five-day disclosure rule would again prohibit their entry into the record. Finally, SDA said that a neurological evaluation was not required to determine if Son needed a more restrictive placement.

AHO2 responded by saying that he could continue the hearing for seven days and get around the five-day rule. He also said that the District acted in bad faith by not getting the transcripts to FA in a timely manner, even though it was the transcriptionist's error. AHO2 also said he believed a neurological evaluation might be helpful to diagnose ADD, if it existed in Son. AHO2 asked SDA to provide the parents with a list of three 
board certified pediatric neurologists and ensure that one of them could see Son within seven days and provide a short report that stated whether or not Son has ADD. AHO2 said:

My concern is simply the restrictiveness. Not that on its face that the - that the presently posed situation for this child would be inappropriate, given the background, but rather that it may be wholly inappropriate if we are dealing with something other than what the supposition is at this point.

SDA proposed that a recess be granted so that she and FA could review the documents he wanted to offer as proof. She also suggested that to save time, AHO2 could hear whatever he deemed appropriate on this day, and all other information, including the neurological results, could be discussed at the continuation of the hearing. AHO2 agreed, and a recess was granted.

AHO2 came back on the record and granted the parents' motion for a continuance, based on the fact that FA was not provided the records in a timely fashion. He also said this would allow time to get the neurological evaluation completed. AHO2 said it was his understanding that FA modified his motion to offer the records as substantive evidence, not as an offer of proof. SDA did not object, so AHO2 admitted the records into evidence.

SDA then stated that if the continuance was granted, this would mean the ISDE timelines for completion of a hearing could not be met. Therefore, SDA requested the opportunity to present testimony that would support the District's intention to "seek application from the State Superintendent or his designee, as to the implementation of the interim placement ordered by the Level I Hearing Officer.” SDA argued that given the 
fact that the State Superintendent might choose AHO2 as his designee in making this decision, it would be expeditious to hear the witnesses because they were already here. AHO2 agreed.

District Direct Examination - Principal. SDA asked Principal to state his name and confirm that he was currently the principal at Watson Junior High. SDA tried to ask several questions of Principal, but FA continually objected, stating that these questions and answers could be found in the Level I Due Process Hearing transcript. SDA argued that she was trying to "set forth the basis of his knowledge and opinion that a change in placement was necessary.” AHO2 overruled FA's objections, then immediately said:

Excuse me. I have so far tolerated it. I don't need a cheering section here ma'am, and if you cannot control yourself - If you cannot control yourself within the conducts of this hearing, I have the right and prerogative to exclude anyone from this hearing. It's a public hearing. We can walk people in off the street, but I don’t have to put up with any unusual conduct or pushing of glasses or responding to any ruling that you may not agree with. So are we clear?

Mom responded, "I'm clear.” There was nothing in the record that shed light on the cause of AHO2's retort. FA asked Mom to switch seats with Son, and they did so.

SDA continued questioning Principal about Son's behavior between the end of the Level I Due Process Hearing and present. FA objected to almost every question, and was overruled on all but one. Principal summarized his thoughts on Son's behavior in this way:

What I have observed supports some of what I have heard from his classroom teacher, unruly behavior, getting into conflict with other students. At this point, 
Son's behavior interferes with our ability to educate him. In particular, any efforts made by his current classroom teacher to work with him are rejected. He is uncooperative. He will not even work with them one on one. He spends much of his time alone not interacting productively in any way in class or with the teacher. It's just not - It's - Nothing substantive has taken place to this point. Parent Cross Examination - Principal. FA asked Principal if Son was currently in a BD classroom at Watson. Principal replied, "Yes.” FA then asked Principal if Son’s primary teacher, SpEd Teacher 2, was LD and BD qualified, to which he responded, "Yes." FA asked if Son was removed for "time outs", and if so, how long they lasted. Principal replied that a time out could last up to 45 minutes, depending on when a teacher removed the student from the class. FA had no more questions of this witness.

Hearing Officer Examination - Principal. AHO2 then asked Principal what the adult - student ratio was in the classroom that Son attends. Principal responded that there are usually two adults in the room with seven to nine students, depending on the period. AHO2 then asked Principal if Son was a danger to himself or others. Principal said Son was not a threat to himself, but could harm other students as Son can be physically aggressive. AHO2 dismissed the witness.

AHO2 ordered the hearing continued until April 30, 1990. AHO2 dismissed everyone until that date.

On April 18, 1990 SDA wrote a letter to FA confirming their conversation on the same day regarding the list of three neurologists that the family could choose from for Son's neurological evaluation. 
On April 19, 1990 AHO2 wrote an Order to confirm the proceedings in the April 16, 1990 hearing. In summary, AHO2 ordered that the motion for default was denied, but a continuance was granted given the District did not produce the records in a timely manner. The continuance also allowed for a neurological evaluation to be conducted at the District's expense. AHO2 also denied the motion to recuse himself, stating the fact that his wife was a high school teacher in a neighboring district, as well as having two special needs students in the same neighboring district would not cause impartiality.

On April 20, 1990 FA responded to SDA, informing her of the parents' choice of a neurologist. FA requested that SDA contact Neurologist and ensure proper payment would be made for his evaluation.

On April 25, 1990 FA wrote SDA enclosing a four page report from an independent psychologist (Ind. Psych.) FA stated that although he "did not intend to present the testimony of Ind. Psych., he reserved the right to do so.”

Ind. Psych.’s report was dated April 24, 1990. Ind. Psych wrote that the reason the parents' referred Son for evaluation is that the parents felt the District did not believe Son had a learning disability, and the parents were also concerned about the change in placement from Watson Junior High to Rome-BEC. Ind. Psych revealed that he gave Son the Stanford Binet Intelligence Test. Son’s scores were quite consistent with the WISC scores, indicating a Son had average intelligence, with a discrepancy between his verbal and performance scores. The Kaufman Test of Educational Achievement was also administered. “Therefore, Son is currently functioning about two years below his current grade placement in the area of reading and about 2-3 years below in the area of math.” Son’s written expression was determined to be “considerably below grade level.” Son 
also had personality testing, which indicated that although his thought processes were clear, Son had these issues:

He tends to invest a great deal of his energy in attempting to control situations. He does not trust school personnel and feels that he has been mistreated by them for quite some time. These feelings are undoubtedly reinforced by his parents who feel the same way and have communicated these feelings to Son. In summary, Ind. Psych. confirmed a learning disability in the perceptual organization area, consistent with the conclusions reached in February, 1990. "Son has a long-standing history of school-related behavioral problems and continues to have a behavior disorder. While his learning and behavioral problems are enmeshed and difficult to separate, his primary handicap at the current time is behaviorally disordered." Ind. Psych had the following recommendations:

1. Placement in a residential facility was not Son's least restrictive environment. "In fact, such a placement could be detrimental considering that Son has a positive relationship with his parents and such a placement would preclude Son from continuing his Karate lessons and competition.”

2. Son needed a highly structured setting that offered both LD and BD services. “The availability of daily therapy, immediate crisis intervention, and some type of family therapy to help bridge the gap between parents and the school, are all considered to be necessary components of his educational program.”

Ind. Psych. concluded his report in this way:

This examiner does not feel that placing Son in a program which primarily serves conduct disordered students would be beneficial. In fact, it could lead to more 
behavioral problems. Considering the negative attitude the parents hold towards the school system, which has in turn helped to foster Son's attitude, it is doubtful if any program operated by the school would be successful at this point. With the above considerations in mind, a private day placement seems to be the most appropriate placement at this time.

On April 19, 1990 Neurologist sent a written report of Son’s neurological evaluation results to Asst. Supt. Neurologist reported that Son said he has no problems other than problems with the teachers at school. "He states that this has been present since third grade, but in talking with his parents, this has been present for a much longer period of time, and has not changed.” Neurologist wrote that he spoke to Dad, Mom and Son and at times got dissimilar views. For example, "His father described him as a social butterfly, but in talking with his mother afterwards she states that he cannot keep any friends." Neurologist asked Son if he thinks his behavior is right at school. "Son believes that they have it in for him; his father states they will punish him for nothing.” Neurologist also documented the following:

Son is also very concerned because he has had the same learning disability teacher for the past four years and does not like her. He had similar problems at Robert Elementary School. He states that "she gives me problems and I deliberately give her problems” and he admits he once physically grabbed her. His father states that they are harassing him all the time and when he said that Son said, "but it’s better since the lawyer has been involved."

Neurologist reviewed Son's family history, reviewed his systems, completed a social history, did a general physical examination, took Son's vital signs, and examined 
his skin, lymph, HEENT, neck, and chest. He also performed a cardiovascular, abdominal, musculoskeletal and neurological examination. Finally, he took deep tendon reflexes, and checked cerebellar, sensory, gait and mental function. Neurologist's impression was that all of the above were well within normal limits. Neurologist found that Son "does not have attention deficit disorder." He recommended that "Son and his family would benefit from intensive family counseling.” Level Two Due Process Hearing - Day Two. AHO2 commenced by asserting on the record that this was an appeal of the Level I Decision and Order. He then asked each person present to identify themselves: Mom, FA, Special Education Director (District 20), Asst. Supt., SDA, LD and BD Coordinator. AHO2 informed the parties that the neurological evaluation and report had been completed, and would be admitted into evidence. FA asked that an independent psychological report written by Ind. Psych. also be admitted into evidence. SDA objected, citing the testimony of FA on day one of the hearing, "The only thing I'm going to do with the Level II evidence is retender what I tried to get in as an offer of proof. It's just documents." SDA also objected based on the fact that if such a report was put in to evidence, she had the right to cross examine this “so called expert.” AHO2 overruled the first objection, and admitted Ind. Psych.'s report into evidence. AHO2 also said that SDA had plenty of time to subpoena Ind. Psych. and had not done so to date. Based on this, AHO2 admitted the report without availability of cross examination of Ind. Psych.

AHO2 asked if either side would like to put on additional testimony. FA said, “The parents rest." SDA called her first witness. 
District Direct Examination - LD and BD Coordinator. SDA asked the witness to review his name, educational background, place of employment and current role and responsibilities within the District. SDA then asked BD and LD Coordinator if he had ever observed Son and attended meetings concerning Son. He replied that he had. SDA asked what educational placement was recommended for Son by the team in February, 1990. BD and LD Coordinator said they recommended the Rome-BEC, that it was not a part of, nor was run by District 21, but was run by NSSEO, which served several school districts. He stated, “BEC program is a special public day school for students diagnosed primarily as behavior disordered. The day begins at 9:00 A.M. and goes to 3:15.” BD and LD Coordinator continued to discuss the details of BEC, indicating there were six classrooms at the junior high level; elective classes were offered, such as art, P.E. and home economics; the number of students in the classroom was small and each class had a teacher and an aide. He also described the behavior modification component at the school, including the positive rewards and reinforcement system and the consequences system. Finally he described the therapeutic components of the program: group and individual therapy, family and personal social work support, as well as psychological and psychiatric services by licensed professionals.

SDA asked BD and LD Coordinator if he had reviewed Ind. Psych.’s report. He indicated he had reviewed the report. SDA then asked BD and LD Coordinator if Ind. Psych. made a recommendation regarding Son's educational placement, and if so, what was that recommendation. He responded that Ind. Psych. recommended a private day school placement. SDA asked if BEC was a private day school, to which he said, "No, it is not. It is a public day school." SDA asked if the services were comparable, and "what 
would be, if any, distinguishing characteristics between a private day placement and a public day placement.” BD and LD Coordinator replied, “None.”

SDA asked LD and BD Coordinator whether or not he agreed with Ind. Psych.'s conclusion that Son should not be in a facility with conduct disordered students, as it might exacerbate Son’s inappropriate behavior. He said that conduct disorders were not of issue, as the Illinois Code chose not to use the medical model, but rather an educational model called behavior disorders. SDA confirmed with BD and LD Coordinator that Ind. Psych. had never been to BEC and therefore could not know whether the programs there would be of benefit to Son.

SDA then asked BD and LD Coordinator about the Neurologist's findings, to which he responded, "His conclusion is that Son does not have attention deficit disorder." When asked why Son's team did not make a recommendation to have a neurological evaluation done in the past, LD and BD Coordinator responded in this way:

We did not feel, after discussion, that it was an appropriate referral to make. The nature of Son's problem and problems behaviorally had - the specific kinds of behavior he had displayed over the long-haul, over four or five years, increased in severity and frequency, and they were the kinds of problems that moved from control issues to revenge and anti-authority and violent themes, and those are not typical of ADD kind of behaviors and characteristics, and it was for that reason and upon discussion with the school psychologist at the time that we did not make the referral. We made ADD or referrals for ADD evaluations frequently and many times, but in Son's case, we did not think it was appropriate.

SDA had no further questions of this witness. 
Parent Cross Examination - BD and LD Coordinator. A summary of the cross examination follows: FA asked if NSSEO was an agent of District 21, to which he replied, "Yes." FA asked what percentage of students who attend BEC return to a lesser restrictive placement. BD and LD Coordinator responded, “20 - 25 percent.” FA asked if BEC treats learning disabilities. BD and LD Coordinator said yes, but primarily this public special day school treated behaviors disorders. Neither FA nor AHO2 had any further questions for this witness. AHO2 discharged the witness.

Parents’ Closing Oral Argument. FA said the evidence does not support AHO1's decision, and does support a lesser restrictive environment. FA argued the following points:

1. Son had both a behavior disorder and a learning disability which needed to be served;

2. Son's behavior disorder was caused by his increasing frustration with the lack of support for his learning disability;

3. Watson Junior High continues to be an appropriate option for Son’s educational placement. However, it is clear from the testimony and AHO1's decision that "the parents have lost complete confidence in the school district, and it's unfortunate, it's a terrible thing, and I admit it, but they voiced that concern to Son";

4. Rome-BEC is not an appropriate placement because it would be harmful to place him with conduct disordered students, as he is not consistently physically aggressive, is not a danger to himself or others, there has been no police involvement, no schizophrenia and no substance abuse. Also, "if he placed within 
an environment with the school district itself, he's now got all these negative feelings that were in part fostered by the parents.”

5. A private special day school program within 15 - 45 minutes of his home would be an appropriate option for Son's educational placement because it would remove him from the current school district where, given his and his parents current negative attitude, he would be unable to benefit from his education. Also, he could continue his Karate lessons and competition, and he could live at home so that his positive relationship with his parents could be fostered.

District's Closing Oral Argument. SDA stated that the parents have "adopted what is an intolerably inconsistent position.” Either Son must stay in his current educational placement at Watson Junior High, or he must go to a private special day school, when the District offers the same services through its' public special day school, Rome-BEC. SDA argued the following points:

1. Son is not currently benefiting from his education at Watson Junior High because the support services and programs Son needs, per the testimony, are not offered at Watson.

2. It has been demonstrated that Son "is able to control his behavior when he so chooses, so he is not out of control. He chooses when he is going to be out of control, and he does it in defiance of authority.”

3. Testimony supports that Son needs a special day school, and the District contracts with NSSEO for just such a school: Rome-BEC.

4. The parents cannot insist on a private special day school because of their mistrust of the district. "We submit that that is not a basis recognized in either 
state or federal regulations which would permit the hearing officer to order such a placement.” The question is can Son derive any educational benefit from remaining at Watson, or is a more restrictive placement of a special day school the current appropriate placement.

5. Rome-BEC is an equivalent public placement to the private special day placement in this geographic area.

6. The District's proposed placement was substantially and adequately proved by the evidence presented at the Level I hearing. "The fact that the parents have problems with the District, ...the fact that they have a distrust of the District is not an educational need of the student which the District must address.”

Parents' Closing Oral Argument. FA said there was no inconsistency in the parent's position; it is proper form to offer an alternative after the initial decision. FA also advised AHO2 that he does not have to limit himself to either affirm or reject AHO1's decision, but can “fashion a remedy based upon the record.” FA then stated that Son's behavior has not changed since fourth grade; how it is being treated has changed. FA asked that AHO2 provide "alternative relief of either a private day placement within fifteen minutes of where Son lives. And if not, then the current school that he's in is meeting his needs, even though his parents have conflicts with it.”

AHO2 addressed FA, asking if it was the student's position that AHO1's placement recommendation was appropriate. FA responded, “Inappropriate.” AHO2 then asked SDA if the placement recommendation of AHO1 was what the District had requested. SDA said no, that the District asked for placement at the public special day school, Rome-BEC, but “the District did not appeal that portion of the hearing officer's 
Order which ordered residential placement.” AHO2 told both counsels that what was striking to him was AHO1's reasoning for ordering Son to a more restrictive placement than either party requested. He described it in this way:

...anticipating the same degree or similar type of problems that had continued in the Watson placement -- the situation between the parents and the school district. And anticipating that, should that lack of cooperation continue into the RomeBEC setting, that it struck me that the hearing officer was clearly questioning whether that was likely to be successful and whether under those circumstances, since we're setting what this child is to do for the next year, coming to the conclusion that the least restrictive environment in which this child was going to be able to succeed was a residential placement....This is a very unusual aspect to this particular appeal as far as I am concerned. Either you folks are going to cooperate with each other, and we're going to get the student progressing, or the hearing - Level I hearing officer was going to put this in a setting where the parents' and School District's involvement was all going to be removed. He was going to live there, and this kid would progress educationally. I couldn’t agree more.

AHO2 went on to say that it was his belief that AHO1 ordered Son into the interim placement at Rome-BEC, to force the parents and District to work together, which might foster cooperation and trust as opposed to the current distrust. Then maybe the parties would see that Rome-BEC "was a viable alternative as opposed to the residential setting.” FA responded in this way: 
I think a day placement would be appropriate, but other than Rome, because of the current animosity, and there shouldn’t have been animosity to begin with, there shouldn't have been all that information that Son received through his parents in a negative fashion. But at the same time, I think we're stuck with it. AHO2 said that he understood that Son was not progressing at Watson, that no one wanted Son to be placed residentially, but that the parents did not want Son to attend the public day school. "I frankly am unwilling to start calling up and finding out what is available, because that puts me into the role of fact-finder.” SDA said that there was no such facility other than Rome-BEC, or AHO1 would have placed Son there. SDA said that AHO1 also placed Son in a residential facility because of family issues; based on these facts AHO1 "believed that the more restrictive placement was appropriate..."

AHO2 said that he would have a decision to the parties in seven days, and would mail it certified to everyone. FA asked if he could submit to AHO2 via letter some alternative private special day schools that Ind. Psych. would know about. SDA “strongly objected" and AHO2 did not allow it. AHO2 then closed the hearing.

On May 2, 1990 FA wrote a letter to AHO2 memorializing a three-way conversation between AHO2, FA and SDA on April 30, 1990 in which AHO2 reversed his last ruling and asked that a list of day placements be submitted to him. FA submitted a list of three private special day school placements in the area of Son's home that had immediate availability. He said each school primarily served behavior disordered students and also had services to support learning disabilities.

On May 3, 1990 SDA wrote a letter to AHO2 also memorializing the three-way conversation AHO2, FA and SDA had on April 30, 1990: 
You had advised me and FA that you had determined to reverse your position articulated at the close of the Level II Hearing in regards to the consideration of a private day school placement for Son. We strenuously objected to the consideration of a private day school placement...In summary, no evidence had ever been presented or considered on the appropriateness or necessity of a private day school placement.

It became apparent that it would be impossible to suggest any private day schools to you for the reasons set forth below:

1. The nature and extent of services has not been determined at this time.

2. You did not establish the maximum geographical distance or transportation time which you would deem acceptable.

3. A determination of whether a particular program is appropriate can only be made at a multi-disciplinary staff meeting. That has occurred and it has already been determined that such needs could be met and would be met at Rome-BEC.

We are unaware of any determination made at any level of these proceedings that Rome-BEC could not meet Son's educational needs. AHO2 stated in our April 30, 1990 conference call that he concurred with the opinion of Ind. Psych. that because the parents did not approve of Rome-BEC, that Son was "doomed to fail” in such a program....

...The District cannot be required to provide more extensive services at public expense based upon reasons relating to parental preference, or upon issues solely related to problems in the home or with the parents....The 
parents' mere dislike of the School District cannot be utilized as a basis to impose upon the School District the additional expense of a private day school when a comparable and appropriate public program is available.

Level Two Due Process Hearing Decision and Order. On May 7, 1990 AHO2 summarized all events leading up to this decision. AHO2 summarized Son's educational history, and provided these statements:

As reflected throughout the written record and the Level I transcript, as well as observed by the Hearing Officer at the Level II hearings, an extremely adversarial and distrustful relationship exists by the parents and student toward the School District. Conduct of the mother of the student was noted by this Hearing Officer during the first hearing session expressing her displeasure to any evidentiary ruling against her counsel. Said incident only goes to demonstrate the subjective state of mind of the parents as to the adversarial or "siege" mentality that now exists. The Hearing Officer in no way wishes to suggest that this state of mind of the parents was in any way, shape or manner brought about by any improper conduct of the District.

This Hearing Officer must note the state of mind of the parents as a fact likely to effect the success or failure of the District's proposed placement at Rome-BEC. While not stated in so many words, the Level I Hearing Officer's Decision is also clearly based upon this attitude that has arisen with the parents and the student. AHO2 then expounded on the findings of fact and conclusions of law. He stated the evidence provided was of “questionable value.” However, the neurological evaluation was significant because it ruled out ADD. Also, AHO2 agreed with the 
statements made by Ind. Psych.: "A residential placement is not the least restrictive placement for the student”, and; “Considering the negative attitude the parents hold toward the school system, which has in turn helped to foster Son's attitude, it is doubtful if any program operated by the school would be successful at this time.” AHO2 wrote his opinion in this way:

No other explanation can be given to the order for residential placement other than was in the opinion of the Level I Hearing Officer that the parents were so impeding their child's educational progress as to require that he be removed from the home setting. This Hearing Officer can in no way condone the parents' conduct in this matter, which can be described at best as being obstructionist and undermining the efforts of the School District to assist their son. However, this Hearing Officer must note, as a parent, that where one's child is concerned, it is very, very, difficult to respond intellectually rather than emotionally. Instinctively, when a child is threatened, as no doubt these parents see their child being "threatened" by the School District, a parent rushes to the defense. Unfortunately, that point where emotion ebbs, and intellect once again reigns, seems unlikely to be reached in the foreseeable future in this matter.

The School District's proposed placement has been "poisoned" in the mind of the student. The student is aware that his parents would not support the efforts of the School District to control his behavior at Watson School, which doomed that placement to failure. He is likewise aware of their opposition to the Rome-BEC, and the Hearing Officer sees no reason to expect that that placement will be successful without parental cooperation. 
What is needed here is an opportunity for the parents to start anew, to work with their child's educators rather than against them. At this point that can only be achieved through a private day placement. The parents must recognize that this may well be their "last chance."

AHO2 affirmed all Level I Hearing findings of fact and conclusions of law except the residential placement. "There has not been a showing in this cause that the most restrictive placement of a residential placement is required at this time.” AHO2 ordered:

1. Son's referral to a private day school within 30 minutes commuting time from home that meets his needs as determined by a team including the parents, school and receiving private day school.

2. Parents participating weekly.

3. Related services as deemed necessary.

4. Develop a behavior intervention plan that includes no TV, staying after school, no Nintendo and no Karate.

5. Private school and parents will develop a system of communication to impose this plan.

6. Son can attend Karate as long as he meets the behavioral criteria set for him at private school.

7. This Order begins in thirty days, or at the beginning of the next school year, whichever is mutually agreeable.

8. The School District is the prevailing party in this decision. 
Eighth Grade 1990-1991

Son began his eighth grade year at Watson Junior High School in the BD classroom, mandated by the "Stay Put" clause in the Education of Handicapped Children’s Act (EHA.)

Appeal of Due Process Hearing Decision to U.S. District Court

On May 30, 1990 the School District filed a complaint in the United States District Court against Mom, Dad, AHO2 and ISBE. The District filed the complaint because the District believed AHO2 erred in his Decision.

The District's Complaint. The complaint stated the Court's jurisdiction in this matter and tendered a history of the case to date. SDA named the following reasons for appeal of AHO2's Order:

1. AHO2 did not find that Rome-BEC was an inappropriate placement for Son;

2. AHO2 considered parental preference, which is an invalid criteria when determining least restrictive educational placement;

3. No evidence supported a private day school;

4. No evidence suggested Son cannot succeed at Rome-BEC;

5. AHO2 substituted his judgment for the judgment of the District's;

6. Private school was more restrictive than public school;

7. AHO2's decision was "clearly erroneous and is not based on a preponderance of the evidence."

The complaint asked the Court to review the records, rule in the School District's favor, and order Son to attend Rome-BEC. 
On June 15, 1990 ISBE's attorney filed a motion requesting that she be allowed to expand the time frame for answering the complaint to July 20, 1990 in order to prepare and review the records and then answer the complaint. District Court's Judge Lindburg instructed the defendant to answer the complaint by July 20, 1990. He also scheduled a status hearing on July 31, 1990 in this matter.

On July 11, 1990 ISBE’s attorney filed an answer to the District's complaint. ISBE attorney deferred to the administrative record or responded that ISBE have "no personal knowledge sufficient to form a belief as to the truth of the allegations..." The attorney summarized with this statement: “The Illinois State Board of Education has no interest or position regarding the merits of the underlying dispute between the parties.”

On July 23, 1990 FA submitted an amended answer to the School District's complaint. FA admitted several points, referred to the record on several points, and denied the following:

1. Denied Son needed a more restrictive environment than Watson because he was not progressing.

2. Denied Rome-BEC was an appropriate placement for Son.

3. Denied numbers one through seven in the District's complaint.

On July 31, 1990 the parties appeared before Judge Lindburg for a status hearing, at which time a briefing schedule was set for the District and the parents.

On August 14, 1990 SDA motioned to modify the briefing schedule in this manner:

- $\quad$ District to file brief in support of its complaint by August 14, 1990;

- $\quad$ Parents to file response to District’s brief by September 4, 1990; 
- District to file reply in support of its brief by September 10, 1990.

School District's Brief in Support of its Complaint. On August 14, 1990 SDA filed the School District's brief in support of its complaint for review of the Level II administrative Decision and Order, simultaneously requesting an oral argument before the District Court. The brief explained that the District requested "a reversal of that portion of the Level II Administrative Order which requires Plaintiff to place Son in a private day school at public expense.” SDA provided a synopsis of Son’s educational background, discussed the District's proposed placement at Rome-BEC, highlighted the Level I Decision and Order, and reviewed the Level II Administrative Decision and Order. The brief asked for judicial review based on the notion that the private day school placement at public expense ordered by AHO2 "was not supported by any evidence of record, that it was inconsistent with the statutory preference for the least restrictive educational environment and that it was based upon an invalid criterion, namely parental preference.”

SDA argued the following points:

1. All children are entitled to a free, appropriate, public education, tailored to fit the unique needs of each individual child, and allow each student to benefit from his/her education (Hendrick Hudson Board of Education v. Rowley, U.S. Sup. Ct. 1982);

2. All special needs students must be educated to the maximum extent appropriate in the least restrictive environment (Education of Handicapped Children's Act, 1975); 
3. A proposed program for a student can be considered over the parents' objection. Specifically, once the courts have determined the Rowley two prong test listed above have been satisfied, the courts should defer to public education officials regarding educational policy and theory with regard to best educational practices for students, as the courts "lack the specialized knowledge and experience necessary to resolve these issues” (Lachman v. Illinois State Board of Education, $7^{\text {th }}$ Cir. 1988);

4. There was no dispute that Son had been provided FAPE in the least restrictive environment to date, but could not benefit in the current Watson Junior High Setting; Son needed a more restrictive special day school setting in order to benefit from his education;

5. Son's parents were in agreement with a placement in a private special day school, but were not in agreement with a placement in a public special day school, RomeBEC. Therefore the argument was not one of placement, but of location of services, and who would provide those services. Parents do not have the latitude to choose location, personnel, methodology, etc. (Lachman, 1988);

6. Courts recognize that neither parental preference nor parents' negative attitude toward school districts can be valid criteria for determining the appropriate educational placement for a handicapped child (Wilson v. Marana School District No. 6 of Pima County, $9^{\text {th }}$ Cir. 1984);

7. "School districts should not have to pay for a private day school placement when the District's proposed placement would maximize the child's potential in the least restrictive environment available"; 
8. AHO2 based his decision of private special day school placement on Ind. Psych.'s written report. Ind. Psych.'s written opinion that the District could not meet Son's needs because of the "parent's animosity towards the District" could not be rebutted because Ind. Psych was not there in person, and no direct or cross examination took place.

SDA wrote this conclusion:

The Administrative Record herein establishes that the student and his family have emotional problems. However, the problems of the parents in dealing with the District, created solely of their own making, do not render the student eligible for a private school placement at public expense. The District does not dispute that the student's poor attitude towards school may be derived from the parents' similar attitude. However, the purpose of the Education of the Handicapped Act is not to provide a forum for parents who are unreasonable and obstreperous in dealing with school professionals who have discharged fairly their duties towards students. Son is a student who has adapted to and succeeded in out-of -school recreational activities. His refusal to participate cooperatively in the educational process in the public schools until now has been supported by his parents. The District has, in all respects, complied with the procedural requirements of the EHA and state law in evaluating and educating Son. Nothing in any competent evidence adduced in the administrative proceedings supports the Level II Order that Son must be educated in a private school in view of the appropriate public school program which exists in close proximity to his home. In addition, the public school program is the least restrictive educational option 
available because it provides Son with the opportunity to return to his regular education public school during the current school year. To allow the Level II Order to stand herein would be to recognize parental resistance over sound educational principles of public education.

Parents' Brief in Support of the Level II Administrative Decision and Order. On September 4, 1990 FA filed the Parents' brief in support of the Level II administrative Decision and Order. FA provided a synopsis of Son's educational history, espousing that Son had a severe learning disability that in fact, caused the behavior disorder, as Son became increasingly frustrated when his learning disability was not appropriately supported by the school district. FA implicitly denied that Son refused to cooperate in his current educational environment. FA supported AHO2's decision to place Son in a private special day school at public expense for two reasons: the evidence, documentation and facts did not support AHO1's decision to place Son in the most restrictive environment of a residential school and, as Ind. Psych. wrote, "Considering the negative attitude the parents hold toward the school system, which has in turn helped to foster Son's attitude, it is doubtful if any program operated by the school would be successful at this time.” FA wrote that $\mathrm{AHO} 2$ agreed with this point, saying that "the continued irreconcilable differences between the parents and the District 'has doomed the Watson placement to failure' and that similarly there was 'no reason to expect that the proposed Rome-BEC placement will be successful without parental cooperation.” FA argued the following points:

1. AHO1 placed Son at a private residential facility; the School District did not appeal. The only thing AHO2 did was modify that decision by placing Son at a 
private day school instead of a residential school. The School District cannot now ask that this court overturn both AHO1 and AHO2 decisions; the District lost its’ right to appeal anything other than the modification of private residential placement to private day school placement by not appealing the Level I decision.

2. AHO2 "clearly made a finding" that Son could not receive educational benefit from his education if placement was within the school district because of Son's "mental disposition":

The Level II officer felt that the previous placement at Watson had failed because of the longstanding rigorous battle between the parents and the School District. There was no reason to believe the situation would change with the placement at Rome-BEC. The Level II officer noted the profound effect of this battle on Son's attitude toward school. Both hearing officers recognized that if Son was placed at Rome-BEC, his negative attitude towards the District and its proposed placement would only crystallize into disruptive behavior and poor grades, hence a lack of learning. The Level II hearing officer specifically found "[it] is doubtful if any program operated by the school would be successful at this time.”

3. AHO2 did not consider the parents' preference with regard to where Son went to school and who would be teaching him. FA wrote:

Son's parents only affected the outcome in that their unrelenting dispute with the District profoundly affected Son's attitude towards school. It was this negative attitude that both hearing officers considered. Does this Court now 
desire to hold a profoundly disabled child accountable for his parents' attitudes towards the School District?

FA concluded by restating his argument: the School District waived its' right to raise the issue of appropriateness when it did not appeal the Level I decision, and; the private special day school placement at public expense ordered by AHO2 was the most appropriate placement for Son given that his current negative attitude towards the School District, albeit caused by his parents’ negative attitude, would prohibit him from benefiting from his education.

School District’s Reply to Parents' Brief. On September 10, 1990 SDA responded to the parents' brief by informing the Court that Rome-BEC was operated by the Northwest Suburban Special Education Organization (NSSEO), not by the School District; the employees of Rome-BEC are employees of NSSEO, not the School District. Therefore, the proposed placement for Son is a public special day school run by an independent agency, and meets all of the requirements set forth by AHO2. Also, SDA informed the court that Ind. Psych.’s report “was admitted without foundation or any opportunity afforded to the school district to inquire of Ind. Psych. material, dispositive, and impeaching questions which would have drawn the context in which his opinion was rendered.” Therefore, Ind. Psych.’s report should have been inadmissible because it is “pure unsubstantiated hearsay”; if admissible, AHO2 gave Ind. Psych.'s report too much weight.

SDA disputed FA's contention that the School District could not appeal AHO2's decision because it was a modification of the Level I hearing officer's decision, and the School District did not appeal the Level I decision. SDA wrote that the District was not 
raising an issue on appeal that had not been previously raised. Specifically, the parents appealed the Order of Son's residential placement made by the Level I Hearing Officer; therefore the District could also raise the issue.

SDA wrote the following about the issue before the Court:

The issue is the appropriate educational services to be provided to Son and whether the School District was correct in seeking a more restrictive placement for him...Both orders specifically found that the School District was correct in seeking a more restrictive environment...The defendants have not substantiated their claim that the School District's proposed placement was not appropriate for Son merely on the basis of their own preferences and previous difficulties with the School District...The parents’ preferences should not be considered controlling in this case.

Finally, SDA concluded with this statement:

It is important to note that these "difficulties" were due to the attitude of the parents, and not due to any failure of the School District to observe the student's rights. To do so would be to give the parents veto power over any placement which the School District might propose and ignore the deference traditionally given to the states in determining the appropriate educational plan for each handicapped student.

On September 19, 1990 FA and SDA presented oral arguments regarding this appeal to U.S. District Judge Lindberg. No transcript of this hearing was available for review. 
U.S. District Court Memorandum Opinion and Order. On October 22, 1990

Judge George W. Lindberg wrote a Memorandum Opinion and Order. Below is a summary of the issues addressed:

1. This Court had jurisdiction over this matter;

2. Both Level I and Level II found that Son was primarily behavior disordered and secondarily learning disabled, "and is not an issue on appeal to this court";

3. The Court briefly highlighted pertinent issues regarding Son's educational history;

4. The Court believed Rome-BEC to be a public school run by the NSSEO and not the District;

5. The Court highlighted the issues raised in AHO1's findings in the Level I Due Process Hearing: Son was found to be primarily BD and secondarily LD; "Parents have what appears to be irreconcilable differences with the District";

6. The Court believes that AHO1 ruled to place Son in a residential facility, an environment more restrictive than either party requested, because of the problems caused by the parents, holding the District harmless in this regard. AHO1 ordered Son's educational placement to be in a private residential facility; while the placement was arranged, Son was to attend Rome-BEC;

7. The parents, not the District, appealed the Level I Decision and Order;

8. The District filed a brief with AHO2 stating AHO1's order for Son to be placed in a residential facility was appropriate in light of the testimony at Level I; 
9. AHO2, although concurring with AHO1's findings of irreconcilable differences between the parties, found no evidence for the need of Son to attend school at a residential facility, the most restrictive environment for educational placements;

10. The Court applied the Rowley two prong test: Did the State and District comply with all procedures outlined in the Education of Handicapped Children's Act (EHCA), and, "was the IEP developed through these procedures reasonably calculated to enable the child to receive educational benefits?” No issue was brought before the Court on the first question, so the Court considered it moot. Therefore, "judicial review will focus on the second-prong of the review, i.e., the appropriate IEP for Son”;

11. The District did not contest the fact that Son needs a more restrictive placement; the District contested that Son required a private special day school placement rather than a public one;

12. The District argued that AHO2 erred in his order to place Son in a private special day school, because he relied "upon his finding of irreconcilable differences between the parents and the District” to make that ruling;

13. The District's argument was properly before this Court;

14. The Court noted that both AHO1 and AHO2 "found the parents' attitudes and actions to have severely interfered with the District's attempts to provide Son with an appropriate education”; citing AHO2, “An extremely adversarial and distrustful relationship exists by the parents and the student toward the District”, and "The parents have adopted a siege mentality"; 
15. The Court also noted that AHO2 found "the parents' state of mind likely to affect the success or failure of the District's proposed placement at Rome-BEC”;

16. The Court found that AHO2 did not rely on the parents' preference for a private placement, but “upon his belief that the nature of the parents' attitudes had been communicated to Son, would defeat the effectiveness of a placement at RomeBEC”;

17. The Court found that Ind. Psych's report did not significantly impact AHO2's decision, as he stated in the hearing that he had already come to the same conclusion Ind. Psych. provided prior to reading the report. Therefore, the report was not given undue weight;

18. The Court found "the preponderance of the evidence supports both the Level I and Level II findings concerning negative attitudes of the parents toward the District and the fact that such had been communicated to Son and had seriously interfered with the District's attempts to educate Son”;

19. The Court defined the question as whether or not the Hearing Officer could rely on "the well-established facts” concerning number 18 above in ordering a private, as opposed to a public, special day school placement as part of the free, appropriate, public education (FAPE) as mandated by the EHCA;

20. The Court held that the EHCA specifically "envisions situations where the no cost special education necessary to provide FAPE to a handicapped child will require placement of the child in a private school at public expense”; 
21. The Court also held that "a decision to order a private versus a public placement must be based upon whether the competing placements are reasonably calculated to provide an opportunity from which the child can benefit educationally.”

Based on the information above, Judge Lindberg gave this Opinion:

It is clear in the instant case that both the Level I and the Level II hearing officers believed that Son would not be able to satisfactorily obtain the required educational benefits from the District's proposed placement in light of the history of Son's and his parent's relationship with the District. The Level I hearing officer perceived this as so problematic that she ordered private-residential placement. The District, in support of the Level I order, stated the following in its brief to the Level II hearing officer: "the education of Son can only be effectuated if the parents are not involved on a continuous basis in second guessing and undermining the disciplinary efforts of the educators.” The Level II officer, while agreeing that such a problem existed, found the least restrictive placement to be private-day school. In this way, the problems between the parents and the District could be minimized, but the child could still benefit from his relationship with his parents while living in their home. The Level II officer warned the parents that this might be their "last chance.” The District agrees with the Level II finding that residential placement is too restrictive at this time. The District only disagrees with private versus public day-school placement. The court agrees with the Level I and II officers that the parents’ attitudes, which have been communicated to Son, have seriously interfered with the ability of the District to provide Son with an appropriate education in public school. 
The court wishes to emphasize that this is not a case involving parental preference for a private versus a pubic school. The parents' and Son's negative attitudes toward the District and its educational efforts developed over a period of years and arose out of the parents' belief that Son's behavioral problems were caused by the District's failure to properly identify Son’s severe learning disability. The District consistently maintained, and all expert evaluations verified, that Son's handicapping condition is primarily a behavior disorder and only secondarily involves a learning disability. Not until the proceedings in this court have Son's parents admitted the correctness of the District's position. The Court hopes this admission represents actual acceptance by the parents of the nature of Son's handicap and that the parents will exercise renewed good-faith efforts to cooperate with Son's educators so that Son may be mainstreamed as soon as appropriate. Giving due weight to the prior administrative proceedings in this case, the Court finds a preponderance of the evidence supports the Level II hearing officer's conclusion that placement in a private day-school facility is necessary at this time in order for Son to obtain the educational benefits mandated by the EHCA. Thus, the Court agrees with the Level II order and finds it appropriate in all respects and specifically orders that an Individualized Educational Plan as outlined in paragraph 3 of the Level II order at pp. 11-12 be developed within the time constraints prescribed therein. If there are problems in implementing this order, the parties are to contact the Court as soon as possible to arrange a hearing so that Son will be appropriately placed as soon as possible. 
The Court's Memorandum and Order also included an Order that reasonable attorney fees could be awarded to the parents’ attorney, as the defendants prevailed in this case. Such request for reimbursement for attorney fees, if any, must be submitted by November 7, 1990. Also, "the District must respond by November 14, 1990, and a reply, if any, is due November 21, 1990.”

On October 24, 1990 a multidisciplinary conference was held for the purpose of determining a private day-school placement for Son. LD and BD Coordinator, NSSEO Director of Special Education, BD Teacher 3, Principal, Mom and Dad, FA and SDA were present. Four private day schools were considered and discussed. Son was referred to Cross Sight School. An intake staffing, interview and IEP meeting were scheduled at Cross Sight for October 29, 1990.

SDA wrote a letter to FA confirming the arrangements made on October 24, 1990. She also confirmed that the District had not waived its right to appeal the District Court's decision.

On November 1, 1990 SDA filed a Motion for a Stay and Injunctive Relief as well as a Motion for Temporary Restraining Order.

District's Motion for a Stay and Injunctive Relief. SDA informed the Court that a multidisciplinary staff conference was held with all parties in attendance on October 24, 1990. At that time, it was agreed that Son would attend Cross Sight Day School. Parents attended an intake interview at on October 29, 1990 as planned. On October 31, 1990 Cross Sight Day School informed the District that Son would not be accepted into the school "because of the parents' attitude toward the therapeutic environment. Specifically the parents stated that Son was not behavior disordered; neither Son nor parents were in 
need of the therapeutic services offered at the school." SDA informed the Court that it was the District's belief that the parents would veto any placement the District might be able to find that met the criteria set forth by AHO2. SDA also informed the Court of the following behaviors from the family:

Since the beginning of the 1990-91 school year and continuing to present, Son's in-school behavior has been increasingly disruptive towards teachers and students and has created untenable conditions at Watson Junior High...The District has suspended Son for five school days commencing November 1, 1990 and seeks to permanently exclude Son from Watson as a result of Son's increased uncontrollable behavior at Watson...Son's in-school behavior during the school year which has occurred on a daily and continuing basis includes: refusal to attend class; speaking out during class; walking around classrooms during instructional time; using obscene and foul language towards teachers and students; standing on furniture; encouraging misbehavior of other students; antagonizing other students; threatening other students; engaging in physical altercations with other students; wandering the halls unattended; refusing to accept any school-imposed discipline. Son's in-school behaviors have caused a suspension of the educational process to all students in his classes by a constant presentation of noise and distractions which the teachers are unable to control. Son has become increasingly aggressive and disruptive and is currently uncontrollable by school staff. 
On October 31, 1990 Principal attempted to contact the parents to advise them that Son would be suspended from school for five days due to disciplinary violations. Parents refused to speak with Principal.

At 6:00 P.M. on October 31, 1990 Principal delivered a notice of suspension to the parents at their home. At that time, the parents, in the presence of Son, told Principal that "Principal would be dead with a bullet in his head" for having imposed discipline on Son...the parents will not support the component of the IEP that include the provision of therapeutic services to Son and his parents...Son's continued attendance at Watson has caused the continuing and immediate threat of irreparable harm to staff and students and to the educational process at Watson... This irreparable harm outweighs the apparent desire of Son's parents to see him remain in the regular public school system. SDA requested that the court approve the interim placement of Son at Rome-BEC, or that Son be restrained from attending Watson while another placement is found.

Motion for Temporary Restraining Order. SDA wrote the same information as above in this Motion. She also wrote:

Unless enjoined by this court, the Defendants, parents, will enforce the "Stay Put" provisions of the Education of the Handicapped Act during the pendency of the District's appeal of the District Court's Order, posing a continuing danger and disruption to other students; faculty and unnecessarily prolonging the time during which more appropriate educational placement could be provided for Son.

\section{U.S. District Court's Order on District's Motion for Temporary Restraining}

Order. On November 7, 1990 Judge Lindberg held a hearing regarding the District's Motion for Temporary Restraining Order. The Court heard arguments from both FA and 
SDA. A transcript of this proceeding was not in the archived record. In the subsequent written Order, The Court determined it had jurisdiction over this matter, and also determined that Son "presents a continuing danger to the emotional, psychological, and physical well-being of the students at Watson Junior High, and additionally, presents a continuous disruption to the educational process.” The Court wrote the following opinion to support this finding:

The teachers and principal have testified to the nature of Son's in-school behavior and have convinced this Court that the injury to the students and staff at Watson, as well as the interference with the Board's duty to provide appropriate educational environment which is safe for the process of learning for teachers and for all students, would be irreparably damaged if Son is returned to Watson Junior High.

The Court granted the Temporary Restraining Order as requested.

\section{U.S. District Court's Order on District's Motion for a Stay and Injunctive Relief.}

On November 13, 1990 a hearing was held in Judge Lindberg's courtroom regarding the District's Motion for a Stay or Injunctive Relief. Both FA and SDA argued the merits of their cases. Again, there is no archived record of this hearing. In the Court's Order, Judge Lindberg wrote:

The Court has determined that granting a stay would not be in the best interests of the parties. Therefore, District's Motion for Stay is DENIED. The Court further determined that the Jennie Smith Memorial School is an appropriate placement for Son. Son shall be placed at the Jennie Smith Memorial School during the pendency of the District's appeal of this Court's earlier order, effective 
immediately...This order will be in effect until a final Order on appeal is entered, or until June 14, 1991, whichever shall occur first.

\section{Appeal of U.S. District Court's Decision to U.S. Court of Appeals, Seventh Circuit}

On November 21, 1990 School District 21 appealed the District Court’s Decision and Order of October 22, 1990 to the United States Court of Appeals for the Seventh Circuit. The District also wrote a Jurisdictional Statement claiming the U.S. Court of Appeals for the Seventh Circuit had jurisdiction over this matter under the Education of Handicapped Children's Act on the same date.

On February 4, 1991 FA filed a Brief in Support of Mom, Dad and Son with the Court of Appeals.

On February 11, 1991 SDA filed a Motion to Extend and File Brief; the Court of Appeals granted the Motion on February 15, 1991, ordering the brief due by March 1, 1991.

On April 4, 1991 the Court ordered "that this case be set down for oral arguments on Tuesday, May 28, 1991”; each side had no more than 20 minutes to argue their case.

On April 29, 1991 a multidisciplinary conference was held at the Jennie Smith Memorial School to review Son's placement. The following people were present: NSSEO SpEd Director, SDA, BD and LD Coordinator, Jennie Smith Principal, Jennie Smith special education teacher, District 214 SpEd Director, District 214 LD and BD Coordinator. It was noted that although the parents were invited to this meeting, they could not attend due to their work schedule. Jennie Smith Principal reviewed Son's behavior since he arrived on November 13, 1990. She described Son as having “adjustment difficulties" initially, but then settled down for several months. After that 
time, Son became extremely disruptive. Jennie Smith Principal went on to say that Son had made no academic progress while at the school; his learning disabilities were not severe and not his primary disability; Son was violent towards himself and others. Because of Son's inability to bond with peers and adults, and his “propensity towards violence”, Son was suspended on April 22, 1991 with a recommendation for expulsion. The team recommended immediate psychiatric evaluation of Son as well as the consideration of a residential placement, "which would be more capable of managing his behavior.”

On May 2, 1991 a hearing was held before Judge Lindberg in U.S. District Court to discuss the issue of Son's expulsion from Jennie Smith Memorial School. FA, SDA Mom and Dad were present. SDA reminded the Court that it had placed Son at Jennie Smith Memorial School in November, 1990 because "Son could no longer be maintained in the public school placement where he had been maintained. The Court retained jurisdiction over this matter for purposes of enforcement.” SDA reviewed Son's recent behaviors, the reason for his expulsion from Jennie Smith Memorial School on April 22, 1991, and the subsequent multidisciplinary staff conference held on April 29, 1991, in which these issues were discussed. SDA also explained to the Court that immediately after the multidisciplinary staff conference, District 214 SpEd Director researched other educational placement possibilities for Son "in the same geographic location that could deal with emotionally disturbed and behaviorally disordered students.” All but one indicated that they would not accept Son at this time due to the "late time in the school year.” One school, Learning Maps, indicated they would take Son, depending on the outcome of an interview. SDA went further to explain: 
However, it might take a while to get him placed. In the interim, District 21 asks the Court to allow the District to place Son immediately at Rome-BEC, which would accept him immediately without any contingency for the balance of the school year and pending the outcome if the psychiatric evaluation.

Judge Lindberg asked how much time was remaining in the school year, to which SDA responded, “Six weeks.”

The Court asked FA if he agreed with SDA's statements. FA said the parents were in agreement that Learning Maps would be a good school for Son, but that an interim placement at Rome-BEC was not agreeable. SDA contended that the Court must order Son’s placement at Rome-BEC if Learning Maps would not take him, as well as during the interim while arrangements were being made for Learning Maps, as Son was not getting an education while he was out of school. The following dialogue occurred:

Judge: I am going to order Son to attend Rome-BEC starting tomorrow morning-

Mom: $\quad$ Never! Never!

Judge: $\quad$-- and until the Learning Maps matter is attended to and resolved. What else do you need to know?

Mom: $\quad$ FA, never, I will not put him in that school. That school has got everything wrong with it. Three people have told me if I put him there, he will get hurt real bad. They beat him and everything there.

Judge: Let me make it clear to Mom and Dad that I am ordering Son to go to Rome-BEC. 
Mom: $\quad$ Are you going to order when he comes home hurt and when they hit him?

Judge: I am telling you, madam, that the order of the Court is that he is to report to Rome-BEC, and he is to be educated there, and the evaluation is to be performed by Learning Maps.

Mom: He is going to be dead when he comes home, FA. They got such bad kids there, I heard.

Judge: $\quad$ Mom, let me explain to you that he is to be at that school-

Mom: $\quad$ Do you want me to lose my job? That is what is going to happen tomorrow if I have to take him.

Judge: $\quad$ He is to be at Rome-BEC.

Mom: $\quad$ I can’t take him.

Judge: $\quad$ And the District is to proceed without undue delay to get the Learning Maps matter resolved to determine whether they are going to take him or not. Now, let me indicate that the record that I am familiar with here has indicated that your conduct may have been unreasonable. The record, in my opinion, displays that. I will act on that if I find that you are not cooperating. Mom then asked the Court if it would be alright if Son could live with his cousins in another town and enroll in school there for the remainder of the school year. The Judge said he would be willing to accommodate that request. The Judge said, "I am primarily interested in Son getting an education and not losing time.” The Judge reiterated that Son was to go to Rome-BEC "tomorrow and next week until such time as this evaluation has 
been achieved. If Learning Maps accepts him, he goes there. If they don't, he stays at Rome-BEC, because the number one thing is that he get an education.” The following exchange took place between the Court and Dad:

Dad: $\quad$ Your Honor, I have one thing to say. When he first started grammar school in first grade, he had a hard time tying his shoes, laces. Okay? He goes into the gym. The instructor, the lady instructor, asked him, “Well, what about your shoe laces?” He says, "I cannot tie them.” He didn’t have the coordination. Do you know what she did? She took and put him in a corner and gave him a silent lunch. Your Honor, from that day on-

Mom: $\quad$ He has been persecuted!

Dad: --till this day now it's been going on. We have written evidence that Son had wrote down for weeks and months what was going on. One other thing, he had a girlfriend. A black little girlfriend at the school, and he was talking to her in the hallway,--

Mom: $\quad$ And SpEd Teacher 2 said he should talk to his own kind and not another color. Now that is wrong!

Dad: Now, that is only two little incidents of many.

Judge: $\quad$ Any of these matters are totally irrelevant to what we are doing here.

Dad: $\quad$ Excuse me! They are not irrelevant.

Judge: $\quad$ Now, Dad, that is it.

Dad: $\quad$ Okay, okay. 
Judge: $\quad$ From now on, you will address this Court through FA.

The Court addressed SDA, stating that the District should be ready to accept Son at Rome-BEC tomorrow. SDA said the District would provide transportation for Son to Rome-BEC beginning tomorrow. The Court asked SDA to write up the Order.

On May 9, 1991 FA filed in U.S. District Court a Motion to Withdraw as the family's legal counsel, citing professional reasons. FA also indicated in his Motion that he would continue as counsel for the family during the appeal to the U.S. Court of Appeals, Seventh Circuit.

On June 10, 1991 a multidisciplinary staff conference was held to review Son’s completed psychiatric evaluation. All pertinent parties were in attendance, including Mom and Dad, Son, District 214 High School Principal, District 214 SpEd Director, LD and BD Coordinator and Learning Maps Director. The committee summarized the psychiatric report, indicating that Son was currently enrolled at Learning Maps, and that "Son's goal was to be here until June $14^{\text {th }}$." The archived record does not indicate whether or not Son ever attended Rome-BEC. Son's diagnoses were Axis I: oppositional defiance disorder and; Axis II: learning disability based on history. It was noted that Son had no history of ADD, and that Son did not take responsibility for his behaviors. Learning Maps recommended graduation from eighth grade on June 14, 1991 if Son continued to make academic progress in the basic courses in which he was enrolled. Mom and Dad informed the group that the family would be moving outside District 21 and District 214 during the summer. District 214 SpEd Director informed the parents that if they did not, "there is a full range of services within District 214 to meet Son’s 
needs, and we would have to have an MDC as soon as possible to plan Son's educational program and placement for the 91-92 school year.”

Ninth Grade 1991 - 1992

District Court: Status Hearing. On June 19, 1991 a status hearing was held in U.S. District Court before Judge Lindberg. FA and SDA were in attendance. FA reported the psychiatric report ordered by the Court was completed; a copy was provided to the Court. FA also reported that Son had graduated from District 21 on June 14, 1991 and was no longer under District 21's jurisdiction. SDA informed the Court that Son had attended Learning Maps through June 14, 1991 as ordered by the Court. She confirmed FA's statement: “There was a meeting held, and there was agreement among the parties to graduate him from eighth grade, which effectively terminates the School District’s responsibilities with regard to this child. He is now the responsibility of the high school district.” FA said that because Son had graduated from District 21, his request to withdraw as Counsel was now moot. SDA and FA agreed that the psychiatric report did not need to be made part of the record because the issues on appeal were directly related to the Court's Order and Opinion. SDA made a motion to dismiss the case before this Court because the issues were now moot; FA did not object. Judge Lindberg granted the motion to dismiss the case as moot.

FA's Motion to Suggest Mootness. On July 22, 1991 FA filed a Motion with the U.S. Court of Appeals for the Seventh Circuit to Suggest Mootness. FA argued that Son had graduated from District 21 and was no longer receiving an education within their jurisdiction. He explained the mootness in this way: "Since there is no longer an ongoing controversy between the District and the parents, the issues raised by the District 
on appeal are moot. In the case before this Court the relationship between the School District and Son has ended.”

U.S. Court of Appeals, Seventh Circuit: Judgment with Oral Argument. On July 23, 1991 U.S. Court of Appeals Judges Cummings, Wood, Jr. and Flaum “ordered and adjudged by this Court that the judgment of the District Court in this cause appealed from be, and the same is hereby, AFFIRMED, with costs, in accordance with the opinion of this Court filed this date.”

U.S. Court of Appeals, Seventh Circuit: Opinion. On July 28, 1991 the U.S. Court of Appeals issued a 14 page Opinion regarding "the sole matter of whether the District Court erred in affirming an Order of the Illinois State Board of Education directing that Son be placed in a private day school near his family’s residence.” First, the Court provided a historical synopsis of Son's education to date. In their synopsis they wrote:

The Level II Hearing Officer, like the Level I Hearing Officer, noted the extremely adversarial relationship between the family and the District, likening Mom and Dad’s mindset to "a siege mentality.” AHO2 said that "the state of mind of the parents was likely to affect the success or failure of the District's proposed placement at Rome-BEC.” In fact, he stated that because the District's proposed placement had been "poisoned” in Son's mind by the parents, there was "no reason to expect that the Rome-BEC placement will be successful.” The Court, which consisted of a panel of three judges, provided an in-depth analysis of the issue. Based on their analysis, Judges Cummings and Flaum affirmed the District Court's decision to uphold AHO2’s ruling; Judge Wood, Jr. dissented. 
The Court used the two prong Rowley test to determine whether the U.S. District court came to the correct decision. The first prong of Rowley contends that the State must comply with the procedures set forth in the Education of Handicapped Children's Act. The judges unanimously agreed the District had met its burden on this count. The second prong of the Rowley test, whether the student's educational program was reasonably calculated to enable the student to receive educational benefits, was determined to be at issue. The Court framed the issue this way: "The question is simply whether the Rome-BEC placement recommended by Son's school district was inappropriate for Son and whether the private day placement ordered by AHO2 is indeed reasonably calculated to be of educational benefit to Son.”

The Court wrote that they are not trained educators and could not substitute their own notions of sound educational policy for those of school authorities which they review. The majority agreed that the District Court applied the correct legal standards in affirming the decision of AHO2: the District Court concluded that based on the two previous due process hearings, Son would not benefit from his education if the placement was Rome-BEC, and; the District Court agreed that the least restrictive placement where Son would benefit from his education was at a private day placement. The Court discussed the Rowley test in this way:

The sole legal requirement is that the IEP be designed to serve the educational interests of the child. In this case the District Court made the factual finding that the parents' attitudes were severe enough to doom any attempt to educate Son at Rome-BEC. The court only considered the parents' attitude to the extent that it 
related to the ultimate question of whether the court could deem the Rome-BEC placement to be “reasonably calculated” to supply educational benefit to Son. The majority also discussed whether or not the parents’ preference was at issue: Lachman contends that parental preference is an invalid criterion by which to judge an IEP;...Lachman does not prevent any consideration of parental hostility...In this case, unlike Lachman, the district court and the hearing officers found that the school district's proposal simply would not meet the requirement that the IEP be calculated to benefit Son, because Son's parents had already “poisoned” the option in Son’s mind. This district judge did not elect one alternative over another viable alternative based on parents’ preferences. The school district's proposed IEP was not acceptable or appropriate because the state of relations between the family and the District guaranteed its failure.

The majority also opined that:

...allowing consideration of parental hostility to a proposed IEP to the extent that it limits the IEP's benefit to the child will result at times in the rejection of the school district's proposal, simply because the parents, perhaps irrationally, oppose it... Our concern is not rewarding or punishing parents. Were we to adopt the school district's position and hold that parental attitudes can never be considered even if they have impaired the workability of the IEP for the child, this would in effect be punishing the child for the actions of their parents...

Moreover, we do not share the school district's concern that under our ruling parents will be able to feign opposition to obtain their preferred placement. Our ruling does nothing to alter the ability of hearing officers to make credibility 
determinations in the first instance. Hearing officers are best positioned to access whether a family's hostility is manufactured or whether parental attitudes pose a real threat to the success of the proposed IEP...

We conclude that it is permissible to consider parental hostility to an IEP as part of the prospective evaluation required by the EHA of the placement's expected educational benefits. If the facts show that the parents are so opposed to a placement as to undermine its value to the child, there is no obligation under the EHA to order the placement...

The judgment of the district court is affirmed.

Judge Wood, Jr. wrote the dissent, noting that the majority opinion "fairly sets out the problem, but I would respectfully differ as to the result reached and would reverse.” Judge Wood, Jr. opined that there is "not the slightest evidence that the District's proposed placement for Son was improper or would not have met the goals and objectives under the applicable laws...the requirements of Rowley were fully satisfied by the District.” He also wrote about the parents’ behavior in this way:

The requirement of Board of Education v. Rowley, 458 U.S. 176 (1982) were fully satisfied by the District. The necessary procedures were followed and the individual educational programs developed by the District for Son were reasonably calculated to enable Son to receive educational benefits. Those programs should have been given a chance. The parents, as it is, have been allowed what is in effect absolute veto over the District's proposed educational program...The parents in this present case have carried parental involvement to an extreme far beyond reasonable bounds. To approve of this unreasonable 
parental interference will precedentially cause school authorities additional future problems they do not need....By their unreasonable interference and obstruction the parents have gained control over the educational process. The majority approves, but I cannot.

In a footnote, Judge Woods, Jr. added:

My only point is that the continually excessive obstructive conduct of the parents is not a valid reason to give in and do it their way. The district, hearing officers, district court, and I all agree it was the parents' objectionable conduct which forced this result. I simply would not approve of parental conduct as a legitimate basis for it. The district's careful plan should have been tried, but since that is not to be I hope that what is to be done for Son will prove to be just what he needs. SDA's Response to Motion to Suggest Mootness. On August 2, 1991 SDA filed a response with the U.S. Court of Appeals to FA's Motion to Suggest Mootness. SDA explained the legal history to date. She informed the Court that the issue of mootness was raised “with respect to Judge Lindberg’s Interim Order of May 2, 1991, not with respect to the underlying dispute between the parties.” SDA explained the reason the Court should allow the Appeal to continue and not render it moot in this way:

In its decision of July 23, 1991, this Court specifically found that the educational judgment of AHO2, as affirmed by the District court, was an appropriate legal standard upon which to determine the appropriateness of proposed educational placements. So long as this standard applies State-wide, the issue is clearly “capable of repetition” ... and is likely to recur given the underlying problems caused by the parents in their dealings with the public schools. 
On August 21, 1991 the Illinois Association of School Boards (IASB) requested to file a Brief as Amicus Curiae in support of District 21's request for Rehearing En Banc. The IASB explained that their organization "aided and assisted boards of education in performing their lawful functions and promoted, supported and advanced the interests of public education in Illinois” and that it represented 873 school district members, including District 21. It went on to say that the panel's decision to affirm the District Court’s private day school placement was predicated solely on "unreasonable parental obstruction”, which will “create an enormous burden on school districts as set forth in Circuit Judge Wood, Jr.'s dissent” and therefore asked to file a brief to support the Rehearing En Banc.

On August 26, 1991 The U.S. Court of Appeals denied the District’s request for rehearing. On the same date, the Court also denied the IASB's request to file a Brief as Amicus Curiae.

Appeal of the U.S. Court of Appeals, Seventh Circuit Decision to the U.S. Supreme Court

On December 3, 1991 the Illinois State Board of Education (ISBE) filed a Petition for Writ of Certiorari requesting the United States Supreme Court review the judgment and opinion of the U.S. Court of Appeals for the Seventh Circuit entered on July 23, 1991.

Petition for Writ of Certiorari to the U.S. Supreme Court. The Assistant Attorney General of Illinois (AAG) framed the questions to be posed to the U.S. Supreme Court in this way:

1. Whether the Seventh Circuit's ruling is in conflict with Hendrick Hudson Dist. Board of Education v. Rowley, 458 U.S. 176 91982), in that it imposes an 
additional obligation on the States to defer to parental hostility to the Individualized Education Program (IEP) developed for the child, when the IEP is otherwise reasonably calculated to enable the child to receive educational benefits?

2. Whether the Seventh Circuit's grant of a parental veto power over a proposed IEP conflicts with the other circuit's rulings that parental preference does not determine the appropriateness of an IEP?

AAG briefed the U.S. Supreme Court that it had jurisdiction over this matter because the U.S. Court of Appeals denied the District's petition for rehearing of this matter. AAG then reviewed the procedures the State and District must provide regarding procedural safeguards for parents of exceptional children when they disagree with a proposed placement for their child. AAG explained Illinois' two-tiered hearing procedure: the Level I hearing "is directed toward bringing out all facts necessary to render an informed decision”; the Level II hearing is "provided to any party aggrieved by the Level I decision.” AHO2 listens to oral arguments and reviews any additional evidence, then renders a final decision. If any party believes they must appeal the Level II decision, this must be done as a civil action in any court with jurisdiction.

AAG outlined the facts in this case, and provided a brief synopsis of Son's educational history to date. In a footnote, AAG informed the Court that Son was currently 15 years old “and enrolled in District 125, where he is in a self-contained classroom receiving special education and social work services for primary behavior disorder/secondary learning disability. AAG summarized the facts as follows: 
The Level I Hearing Officer concluded that Son’s education could only be effectuated if the parents were not involved on a continuous basis in second guessing the disciplinary efforts of the District...therefore ordered that Son should be placed at public expense in a private residential school...

The Level II Hearing Officer concluded that because no program for Son would be successful without parental cooperation, a private day school placement was the only program in which parental cooperation could be achieved. The Hearing Officer specifically noted the opinion of the parents' expert that it was doubtful that any program offered by the District would be of benefit to Son due to the parents' hostility toward the District...

The District appealed AHO2's decision to the federal district court...finding that the irreconcilable differences between the parents and the District necessitated a private placement was not supported by the evidence... and further alleged as error AHO2's reliance on parental hostility as determinative of the appropriate placement for Son...The district court affirmed the decision of AHO2. The court found that the parents' hostility had seriously interfered with the ability of the school district to provide Son with an appropriate education in public school.

The School District appealed to the Seventh Circuit...The Seventh Circuit affirmed the decision of the district court. The court found that the District's recommended program for Son was not acceptable or appropriate under IDEA because the relations between the parents and the District guaranteed its failure. The court agreed with the District that consideration of parental hostility to a 
proposed IEP would result in rejection of the IEP "simply because the parents, perhaps irrationally, oppose it”...The court concluded that if the parents are so opposed to an IEP as to undermine its value to the child, the IEP doe not meet the substantive requirements of the IDEA.

In a dissenting opinion, Circuit Judge Wood, Jr. viewed the majority opinion as allowing the parents absolute veto over the District's proposed educational program. The dissent found that the District fully complied with the requirements of the IDEA and the decision in Board of Education v. Rowley, 458 U.S. 176 (1982), in that the proposed IEP was reasonably calculated to enable Son to receive educational benefits. The dissent noted that the "continually excessive obstructive conduct" of the parents was not a valid reason for the majority to order a placement acceptable to the parents.

AAG briefed the reasons the U.S. Supreme Court should grant the Writ of Certiorari. She framed her argument around two issues:

1. The Seventh Circuit's opinion conflicts with this Court's ruling in Rowley that local and state educational agencies are responsible for determining and implementing an appropriate IEP for children with disabilities;

2. The Seventh Circuit's opinion conflicts with the decisions of the other Circuits that parental preference does not determine the appropriateness of an IEP.

AAG opened her first argument with this statement:

The decision of the Seventh Circuit, holding that an otherwise appropriate IEP does not meet the requirements of the IDEA solely because the parents' general hostility to the proposed IEP, results in a fundamental transformation of 
the Rowley standard. The Seventh Circuit's decision has the precedential impact of altering the carefully structured and balanced process by which educators and parents formulate individually tailored programs to provide educational and support services to children with disabilities.

AAG further supported her argument with the fact that the District Court did not apply the Rowley standard to the District's IEP, but defined the issue as whether AHO2's order of a private day placement was reasonably calculated to be of educational benefit to Son. "This test is at variance with the standard enunciated in Rowley, which has been consistently followed by the federal courts until now."

AAG also introduced other facts to support her first argument, such as:

1. The Seventh Circuit's decision has sanctioned parental rejection of a District's proposed IEP "simply because the parents, perhaps irrationally, oppose it."

2. Compliance with the Seventh Circuit’s decision will result in educators being forced to acquiesce to the demands of parents, regardless of whether or not those demands enable the child to receive any educational benefit.

3. The Seventh Circuit's decision reaches outside the language of the IDEA to measure compliance by focusing on parental approval of the education provided by the local educational agencies.

4. It is telling that none of the relief originally sought by the parties was obtained through this process. Son is now attending a public high school in a selfcontained classroom receiving special education and social work services. It appears that by moving, the parents got what they have always wanted, a regular school placement with special education support. "The Seventh Circuit’s 
articulated concern to find a program that will be of educational benefit to the child was not realized in this case.

With regard to AAG's second argument, she wrote, “The other circuits have addressed the same conflict which confronted the Seventh Circuit, with the opposite result.” AAG provided examples of other Circuit's rulings that applied the Rowley standard consistently and correctly, upholding the finding that parental preference does not take precedence when determining whether or not a child can benefit from the educational program designed for the child.

Based on the two arguments above, the Illinois State Board of Education “respectfully requests that this Honorable Court grant this petition of certiorari.”

Motion to Appear and Brief as Amici Curiae. On December 11, 1991 four national, professional, educational organizations requested to appear and provide briefs in support of the Illinois State Board of Education's argument: the National School Board's Association; the National Association of State Directors of Special Education; the Council for Exceptional Children, and; the Council of Administrators of Special Education. The U.S. Supreme Court granted these organizations status of amici curiae. Motion in Opposition to the Petitions for Writ of Certiorari. On December 18, 1991 FA filed a motion opposing the Illinois State Board of Education and amici curiae's request for Writ of Certiorari. FA presented his opposition by framing the issue as one question before the Court:

Whether the exercise of the Supreme Court's discretionary certiorari jurisdiction is warranted where the District Court and the Court of Appeals applied the standard set by this court in Hendrick Hudson District Board of Education $v$. 
Rowley, 458 U.S. 176 91982) to affirm the modifications ordered by the state educational administrative authorities, after two levels of evidentiary hearings, to an individualized educational program as initially proposed for a handicapped child by a local school district pursuant to the Education of the Handicapped Act, 20 U.S.C. Sec. 1400 et seq.

FA outlined the administrative review process envisioned by the IDEA, as well as briefed the Court on Son's educational history. FA then provided the following arguments to support the U.S. Supreme Court's denial of the requested Writ of Certiorari:

1. Both hearing officers specifically found that the "irreconcilable differences" and "adversarial and distrustful relationship" between the District and the parents was "a fact likely to effect the success or failure of the District's proposed placement at Rome-BEC”...The primary reason for a private school placement was to avoid the ongoing confrontations and disagreements between the parents and the District which had "doomed the placement to failure”...

2. The District Court appropriately applied the Rowley standard, concluding "the District Court rightly held that the Rome-BEC placement did not meet the substantive standard set by the EHA and that the IEP ordered by AHO2 in the least restrictive placement that will be of educational benefit to Son.”

3. Neither the Court of Appeals nor any other court or administrative officer ever found that the IEP as originally proposed by the District was reasonable...The findings at every administrative and judicial level were that the placement proposed by the District could not succeed. The distrust felt by the parents and 
by the student towards the District was a reef upon which any public school placement was considered sure to founder.

4. SDA wrote that the IEP as originally proposed must be adopted unless it is plainly inappropriate. If SDA is correct, then the extensive provisions of EHA for participation by parents, for due process hearing and review are rendered meaningless and the District enjoys virtual dictatorial power to enforce its IEP as originally conceived.

Given the arguments above, it was FA's position that both the District Court and the Court of Appeals followed settled law (Rowley) and correctly applied the controlling decision of this Court to affirm the rulings of State Administrative Hearing Officers in a case governed by its own facts and without precedential value. FA concluded his motion in this way:

This case was correctly resolved through the state administrative hearing process. The District court correctly upheld AHO2. The Court of Appeals followed the EHA and the controlling decision of the Supreme Court (Rowley) in affirming the District Court...The petitions for writs of certiorari should be denied.

On January 24, 1992 the U.S. Supreme Court denied the Illinois State Board of Education's request for Writ of Certiorari. Because the Writ of Certiorari was denied, the Seventh Circuit Decision and Opinion in this case stand as written to date.

Chapter five presents a synopsis of the identification and analysis of the impact of points of impasse between the parties on conflict escalation as the participants moved through the conflict resolution process in this unique case. 


\section{CHAPTER 5}

\section{FINDINGS}

The archived record of The Board of Education of Community Consolidated School District 21 v. Illinois Board of Education (BOE v. ILL., 1991) was obtained, authenticated and examined. The collection of records was comprehensive and detailed, documenting numerous points of impasse between the parties. This chapter provides a rich description of the impact of these points of impasse between the parties on conflict escalation during the conflict resolution process.

Lake and Billingsley (2000) identified eight categories of factors that influence conflict between parents and schools as follows: valuation, constraints, knowledge, reciprocal power, service delivery, discrepant view of the child or the child's needs, communication, and trust. Lake and Billingsley noted that these categories of factors could operate separately or in combination to escalate, deescalate or contain conflict. During this investigator's analysis of the archived record, it was revealed that all eight categories of factors identified by Lake and Billingsley as elements that escalate or deescalate conflict between parents and schools were present at some point in this case. Close examination of these eight categories of factors lent evidence to support their organization into three groups of categories. Following are the groups of categories that impact parent-school conflict: contributing factors, key factors, and fundamental factors.

$$
\text { Group One: Contributing Factors }
$$

This group of categories includes factors that played a subordinate role in the conflict between the parties in this case. The data suggested that one or more of these 
factors might be present during conflict, but they did not emerge as definitive factors in whether a point of impasse occurred, or conflict escalated or deescalated. These factors were easily identifiable and often satisfactorily resolved between the parties, yet underlying conflict persisted. The five categories identified as contributing factors to conflict are as follows: valuation, constraints, knowledge, reciprocal power, and service delivery.

\section{Valuation}

Lake and Billingsley defined the category of valuation as "who and what people care for and about” (p. 246.) Documents in this case bear out instances where "who and what people cared for and about” were devalued. The record supported the notion that when one party experienced criticism, belittlement or devaluation at the hands of the other party, valuation became a contributing factor in parent-school conflict.

For example, the school district professional staff wrote statements into reports and letters that seemed critical of the parent. Below is an excerpt from a report written by a school district social worker that was shared with the parent and other members of the IEP team at an IEP meeting:

Mom at times feels overwhelmed about how to best care for Son or react to his behaviors. She has on occasion hit him in view of school staff and frequently uses aggressive verbal references regarding Son (i.e. "he’s going to get it when he gets home” or "I'll beat it out of him"). She has little insight as to the nature of both Son's or the family’s problems and therefore, seeks simplified solutions to complex issues. Despite discussion regarding help for Son, the parents are unable to organize themselves sufficiently to follow up on recommendations. Son's 
behavior seems partially related to the very inconsistent boundaries within the family structure. His parents can be extremely generous at times and then emotionally unavailable to Son.

Valuation appeared to be a contributing factor in the conflict between the parent and the school district at this IEP meeting. However, the parent and school district personnel completed the student's IEP on that same day and agreed on all components of his IEP for the following year. Conflict was present, but a point of impasse did not occur.

The archived record also provided various examples of reports, memos and daily communication in which school district personnel wrote statements that seemed critical of the student. The following was written by the student's third grade teacher and shared with the parent at a multidisciplinary (MDT) staff meeting:

The biggest concern: Son's attitudes and behaviors in school. He is physically aggressive towards others. He is inattentive in class. He seems to have an attitude of failure before he starts so doesn’t put forth as much effort as he probably could. He doesn’t listen to directions. He’s inattentive in class. He draws war pictures when he should be listening, he plays with things in desk. He is off his chair 3 times a day on average. He disturbs others. How much of his difficulty is due to visual perceptual difficulties and how much are emotional problems?

Valuation again appeared to be a contributing factor in the conflict between the school and parent at this MDT meeting; yet on that date, the parent and school district came to consensus regarding the student's needs. Conflict was present, but a point of impasse did not occur. 
The parents also wrote several memos and provided testimony that seemed critical of school personnel and the parent-school partnership in this case. The following excerpt was a testimonial made by Dad, in the presence of the student, the school district personnel and the Administrative Hearing Officer (AHO1):

AHO1: Why did you request Son's teacher be changed from SpEd Teacher 1 to SpEd Teacher 2 in November?

Dad: Because we thought SpEd Teacher 1 was not doing her job properly. She was pushing, shoving, silent lunches, silent dinners, staying after school. She made him walk home in the rain because she slammed the door on him; he knocked on the door and they wouldn’t let him in. He had to walk home two miles in the rain, because they made him stay after school, and they held him after the bus had left. And that's one of the reasons why we sort of cut down on after school.

Transcripts of testimony recorded during the conflict resolution process confirm instances of valuation as a contributing factor to conflict. The following quote from the school district's attorney, made in the presence of the parents, the student, the school district personnel and AHO1, illustrates this point:

His behavior, in addition to class disruptions, has over the past year been observed and documented as bizarre and highly unusual for a student of his age, even within a behavior disordered category...We believe that all the observations, all of the evaluations, all of the evidence strongly supports-overwhelmingly supports the need for this student to receive the therapeutic services available at the Rome-BEC placement. 
These excerpts strengthen the idea that issues of valuation contributed to, but were not pivotal factors in, the conflict between the parents and the school district in this case. Resolution of these factors was irrelevant to whether or not conflict escalated into further points of impasse.

Knowledge

Lake and Billingsley wrote that the category of knowledge included factors such as lack of problem-solving strategies, an imbalance of knowledge between the parties, and insufficient knowledge to accomplish what needed to be done. The record revealed that these factors were present at certain points in this case, supporting the notion that knowledge factors contribute to parent-school conflict.

There was evidence presented early in the record substantiating the parents' lack of problem solving strategies that would allow them to work effectively with an educational system. Below is an example of the parent's lack of problem solving skills, as recounted by the school nurse after taking the child's social history from the parent during the second week of the child's first grade year. This information was shared with all members of the eligibility committee:

Mom described Son’s preschool years as “spending most of his early childhood with adults, including his parents, grandmother and grandfather.” She stated that "Son received lots of special attention before he started school and he found that very satisfying.” Mom reported that Son attended nursery school at 2.5 years of age, but "he resented me going to work.” Mom said that Son did not interact well with age appropriate peers. She conveyed that Son was "hard to get along with at school and would not share with other children; He would bang his head and 
chew the buttons off his shirt, and hit other children." Mom also stated, "Son didn't have to play with those other kids; we played with him at home anytime he wanted.”

Although no point of impasse was noted subsequent to this history being considered by the eligibility committee, there was no evidence in the record indicating that the school district offered or provided support to the parents that would teach them the problem solving skills needed to work with the school district in support of their child.

There was also documented evidence of lack of problem solving strategies among the school district staff. In the following example, SpEd Teacher 2 wrote an anecdotal note regarding a conversation she had with Private Therapist. This note was shared with all parties at the due process hearing:

According to him - Son's talking more, acting out less. He felt the situation at Robert Elementary had something to do with the Jewish faith. He believes Son had $\underline{\text { NO }}$ sense of masculine identity at beginning of treatment, so Private Therapist feels his extreme aggressiveness is okay. (He needs to know more present day happenings w/ Son's behaviors) - OBVIOUSLY! W/Gun. Private Therapist feels it will be another outlet for Son to "vent out” in; will give Son \& his Dad more time together. I told him I disagreed. Agreed that Mom is definitely a Borderline Personality Disorder - very serious - so he feels Son is doing quite well considering that fact combined w/ a weak, passive father. No subsequent evidence in the record espoused the use of problem solving techniques to address the serious issue of the student owning a weapon. The lack of knowledge of problem-solving strategies among school district personnel brought about a point of 
impasse that impacted parent-school conflict. The following excerpt from the first due process hearing transcript shows that the disagreement between the parties discussed above was resolved, yet conflict between the parents and the school district continued: Parent Direct Examination - Dad. FA asked Dad to state his relationship with Son, and he did so. FA then asked, "Does Son have any access whatsoever to any weapons?” Dad replied, “No more. They're all gone. No weapons in the house whatsoever.” FA then asked Dad if Son was still seeing Private Social Worker. Dad answered, "No. He stopped seeing him a year or so ago." Imbalances of knowledge between the parents and the school district were also evident in the archived record. If one party believed they had less knowledge than the other party, the first party looked outside the parent-school partnership for support in building their knowledge base. The following example demonstrates this notion:

On November 20, 1989 of Son’s seventh grade year, a letter was written to Mom and Dad by Asst. Supt. informing them that District 21 filed a due process hearing request, a copy of which was enclosed. This letter was sent certified and regular mail because "we have also had some difficulty reaching you with certified mail, since a letter previously sent to you was returned to me on November 20, 1989 after three attempts to deliver it.” Asst. Supt. reminded Mom and Dad that the District "remains open for any discussion concerning the proposed placement" during the due process procedure. On December 5, 1989 Asst. Supt. sent information to Mom and Dad: "If you have any questions regarding this procedure, please don't hesitate to call me.” In response to that letter, Mom contacted Asst. Supt. via telephone on December 8, 1989 and informed him that 
the family "would be seeking legal assistance” and she would contact him when that had been done.

In the example above, the parents experienced a lack of knowledge that rendered them unable to continue to work through the conflict resolution process without assistance. Although a point of impasse occurred, it was resolved when the parents hired an attorney to represent them during the continuation of the conflict resolution process.

The archived record supported the premise that knowledge factors contribute to points of impasse between the parents and the school district, and can also impact conflict. The data also confirmed that resolving knowledge issues did not bring about conflict resolution in this case.

\section{Reciprocal Power}

Lake and Billingsley explained that the category of reciprocal power was comprised of "bases of power and tactical maneuvers that were employed either consciously or unconsciously in an attempt to get what they wanted” (p. 247). The record held numerous examples of power plays constructed and executed by each party as a means to get the desired outcome. The data corroborated that the parties' tactical maneuvering and use of power plays contributed to the development of points of impasse, impacting conflict between the parties.

The record revealed that the parents consistently used reciprocal power in response to the school district whenever they experienced opposition to their point of view. One power play often documented in the record was the parents' repeated refusal to comply with school district recommendations in order to ensure that their child stayed 
in the parent-preferred program or school. The following example illustrates this concept:

The MDT reviewed four least restrictive environment options. The first option they considered was mainstream with consultation, and the MDT, including Mom, agreed that this was not structured enough for Son to succeed. The second option considered was the Robert Elementary School LD and BD resource room. This was also unanimously vetoed for the same reason. The third learning environment considered was the Student Support Center at Key Elementary School. Mom preferred this placement. All other team members felt this placement could not provide enough support given Son's current academic and behavioral needs. The school district strongly recommended the Behavior Education Center (BEC) at Rome School. (This was an alternative learning school for severely behaviorally involved youth.) Mom refused this option. It was then agreed that Son would continue in his current special education placement: the Student Support Center at Key Elementary School for the remainder of the sixth grade.

By use of this type of power play, the parent attempted to simultaneously get what they wanted and circumvent a point of impasse. When the school district acquiesced to the parents' desires, the point of impasse was resolved, but the underlying conflict continued to be present. The example below illustrates a similar use of reciprocal power by the parents, as described by school district personnel during the due process hearing:

AHO1: $\quad$ You described no parent cooperation. Can you give me specific instances of what you meant when you said that? 
Asst. Supt.: Okay. Probably the largest one particularly at Watson was not allowing the teachers to follow through with one of the normal consequences with staying for resource, staying after school for detention, those kind of things. Our meeting in November with Principal and the others was primarily to try to find some way to do that, allowing Son to participate in his karate lessons, which were very important to him.

In this instance, lack of parental cooperation undermined the efforts of the school to discipline the student. This incident did not culminate in a point of impasse; however, it contributed to the ongoing conflict.

The record also disclosed the school district's use of reciprocal power to obtain its desired outcome. The following example demonstrates this idea:

Mom and Dad will not agree to the Dist. 21 placement recommendation. Dist. 21 believes that only the Rome-BEC can meet his needs. Therefore, the family is afforded 10 days to consider this recommendation (Nov. 17, 1989.) Dist. 21 will file for due process in order to meet Son's needs if Mom and Dad reject the placement.

This example illuminates the use of reciprocal power by the school district, as they attempted to get the parents to "do it their way" by threatening legal action. This brinksmanship action produced a point of impasse, which brought about conflict escalation.

The record bears out the contributing nature of the use of reciprocal power by the parties in this case. Use of tactical maneuvers and power plays by both sides contributed 
to, but were not vital factors in, the development of points of impasse and subsequent conflict escalation.

\section{Constraints}

Lake and Billingsley defined this category of factors as “constraints on resources of time, money, personnel, materials” and team functioning (p. 241). This category encompasses factors that speak to the lack of resources needed to support a student or a student's educational needs. Public school districts are required to provide FAPE to all identified special needs students living within the school district; they are not required to provide all services to each special needs student in every school in the district. Based on the amount of time, money or personnel that must be allocated to address the student's identified needs, the student can be administratively transferred to another regular or special public school for center-based services. This factor can contribute to parentschool conflict, and did so in this case.

Constraints on resources occurred often in the record, creating points of impasse and perpetuating parent-school conflict, as the following example illustrates:

Son does not have age appropriate coping skills; Son does not have many positive social interactions with peers; Son does not take responsibility for own behavior. Son needs small structured classrooms for all academic areas, consistent behavioral expectations in all school environments, immediate and appropriate consequences for behavior, specially trained adult supervision, availability of therapeutic services on a daily basis, availability of immediate crisis intervention resources, availability of on- 
going parent support, availability of trained staff to build a cooperative, consistent effort between home and school.

Because Son would be transitioning to the junior high school for seventh grade, two placement options were presented by the school district. The first option considered was the Student Support Center at Watson Junior High. Given the nature and severity of Son's behavioral issues, the school district felt that Watson Junior High could not provide enough support in the Student Support Center to ensure Son could make progress towards mastering the goals and objectives on his IEP. The school district then recommended the Behavior Education Center at Rome School (Rome-BEC.) Mom refused both placements. She felt that Watson was full of "gangs" and Rome-BEC was a school for "bad boys". Instead, Mom requested that Son go to his home school, Clinton Junior High. This was instantly rejected by the school district because of lack of appropriate BD and related services at Clinton Junior High to support Son's current IEP as written. The school district acquiesced to Son's placement occurring at Watson Junior High’s Student Support Center, although all professional staff felt the best placement for Son would be at Rome-BEC. Mom left the IEP meeting without agreeing to this placement.

This example validated the idea that constraints on resources contributed to parent-school conflict in this case. The point of impasse created by this factor was resolved in this instance; the school district transferred the student's elementary special education teacher to the regular junior high school to support the student's needs for the upcoming year 
rather than administratively transferring the student to an alternate school. In this situation, the point of impasse was resolved, yet conflict continued to be present.

The next example also supports constraints as being a contributing factor to conflict between the parents and the school district in this case:

District 21 recommendation is that special day school (Rome-BEC) can meet Son's needs \& the self-contained BD program at Watson Junior High cannot meet Son's needs. The student could not be educated in the regular education school building with supplementary aids and services because needs are too severe. Parent rejects this option.

This example illustrates the notion that the parents did not accept the constraints outlined by the school district and rejected the school district's proposal of administrative transfer to an alternative school; the school district then opted to utilize the conflict resolution process and filed for a due process hearing. Constraints on resources were contributing factors in this parent-school conflict, facilitating a point of impasse and prompting conflict escalation.

The examples above lend support to the tenet that constraint factors were easily identifiable by the parties; they contributed to, but were not pivotal in, the conflict between the parents and the school district in this case.

\section{Service Delivery}

Lake and Billingsley defined the category of service delivery as those factors covering "the nature and length of services and program options" (p. 244). This category includes those factors that center on what educational services or programs a student needs to benefit from his or her education, how much time those services will take each 
day, and where those services will occur. The archived record in this circumstance substantiated service delivery factors as contributory to conflict between parents and the school district.

In this case, disagreements over the student's placement or time in a special education environment were a frequent focus of interaction between the parties. This is evidenced in the example below:

At the end of Son's third grade year, the IEP team "recommended Student Support Center - Parents denied permission. Placed Learning Disabilities Resource Program Intermediate.” In November of Son’s fourth grade year, LD and BD Coordinator again documented the need to look at placement:

There appears to be only two recommendations: Actively pursue with parents, once again, placement in Student Support Center, which was recommended in May; BD criteria documentation is complete. Or, if Student Support Center placement is not forthcoming, Robert Elementary staff must meet and develop a comprehensive plan to attempt to support Son's needs.

The parents strongly disagreed with placing Son in the Student Support Center, withdrew him from the school he was attending and enrolled him at his home elementary school. Within one month the parents acquiesced, and enrolled Son in the Student Support Center at Key Elementary School. In another example, during Son’s fifth grade year, SpEd Teacher 2 documented the following discussion with the parent concerning Son's current behavior and the need 
to increase in the amount of service time for Son; this would be done through a change in his placement:

Discussed: staying in area - office, etc. Problems in unstructured situations. Bathroom, hallways. Specials. Making noises, stomping, hanging on doors, standing on toilets. Lunch room - sitting at table touching other people’s stuff. Bus - Telling other kids to spit and hit. Doesn’t mind other authority figures in building. Doesn’t accept responsibility for behaviors. Antagonizing others. 2 fights in room; 1 playground. Have to number papers in folder so Son won’t throw out papers.

Discussed Son's problems and laid groundwork for Rome-Behavior Education Center (BEC). Discussed how Son will have a tough time at Clinton. Still considering Watson and now Rome-BEC. Parents want Son to go to Clinton. They don't like the violence at Watson. Parents weren't receptive to Rome-BEC but didn't get upset when it was brought up. Will initiate new intervention: daily sheet communicating to parents Son's behavior.

The examples above supported the idea that service delivery is a contributing factor to parent-school conflict. The point of impasse regarding service delivery was resolved in these instances because the school district decided to continue to serve the student in his current placement and implemented other types of supports to help him succeed.

The example below also supported service delivery as a contributing factor to parent-school conflict. In this example, the IEP team, including the parents, discussed the student's placement as he matriculated to junior high school. 
On May 30, 1989 an IEP meeting was held to discuss Son's levels of educational performance during his sixth grade year. Because Son would be transitioning to the junior high school for seventh grade, two placement options were presented by the school district. The first option considered was the Student Support Center at Watson Junior High. Given the nature and severity of Son's behavioral issues, the school district felt that Watson Junior High could not provide enough support in the Student Support Center to ensure Son could make progress towards mastering the goals and objectives on his IEP. The school district then recommended the Behavior Education Center at Rome School (Rome-BEC.) Mom refused both placements. She felt that Watson was full of "gangs" and Rome-BEC was a school for "bad boys". Instead, Mom requested that Son go to his home school, Clinton Junior High. This was instantly rejected by the school district because of lack of appropriate BD and related services at Clinton Junior High to support Son's current IEP as written. The school district acquiesced to Son's placement occurring at Watson Junior High’s Student Support Center, although all professional staff felt the best placement for Son would be at RomeBEC. Mom left the IEP meeting without agreeing to this placement. Also on May 30, 1989 a disposition of placement form was sent to Mom and Dad, indicating the IEP team's decision to place Son at the Watson Junior High Student Support Center effective August 28, 1989 and informing them of their right to request a due process hearing if they did not agree to this placement. In August, 1989 Mom and Dad enrolled Son at Watson Junior High. 
The examples above highlight the impact of service delivery factors on points of impasse and conflict escalation. In this case, the parties repeatedly disagreed on the appropriate service delivery of the student's education, yet came to consensus and resolved the point of impasse in all but one instance. Nevertheless, conflict between the parties continued to escalate. The service delivery factor contributed to the point of impasse that drove the parties into the formal conflict resolution process. However, the service delivery factor was not a key component in the continued escalation of the parentschool conflict in this case.

Upon close examination of the record, valuation, constraints, knowledge, reciprocal power, and service delivery emerged as contributing factors to conflict as evidenced in the documented interactions between the parties. The data supported that while these factors contributed to conflict, they played an important, but subordinate role in the development of points of impasse that impacted conflict escalation. These factors were readily identified and often effectively resolved, yet underlying conflict persisted between the parents and the school district. Each of these contributing factors was also impacted by the key factors discussed below.

\section{Group Two: Key Factors}

This group of categories includes factors that played a key role in the parentschool conflict in this case. The data confirmed that both of these categories of factors were always present during conflict. Once present, these factors remained unresolved throughout the conflict resolution process. From the record emerged evidence that supported the presence of these key factors in the parent-school relationship prior to any of the five contributing factors listed above. These key factors also emerged as pivotal 
elements in the parent-school conflict, setting the stage for points of impasse to occur, as well as having an influential impact on points of impasse and subsequent conflict escalation between the parents and the school district. The record also endorsed the idea that although these key factors played a critical role by opening the door to points of impasse and containing or escalating conflict, they were not essential factors in the development and perpetuation of points of impasse and conflict escalation. Further, the notion surfaced that these key factors continually interacted with each other to reduce, contain or escalate parent-school conflict. The two categories identified as key factors in parent-school conflict are as follows: discrepant view of the child, and communication.

\section{Discrepant View of the Child}

Lake and Billingsley defined this category of factors as those that focus on the differences between the parents' view of their child and the school district's view of the student. The record in this case held a plethora of examples of discrepant views of the child as evidenced in descriptions of the child or the child's needs that were dissimilar to the other party's description. These factors included discrepancies in the acknowledgement of the child as an individual, as well as documented discrepancies regarding the child's strengths, weaknesses and capabilities. The record reflected that the parties experienced a "disconnect” from one another when a discrepant view of the child was held, which weakened the parent-school partnership. This “disconnect” was evident in the record, along with a lack of communication or miscommunication, between the parties. This, in turn, created a ripe atmosphere in which contributing factors to parentschool conflict flourished, as evidenced in the examples below. 
The record showed that the parents and school district held discrepant views of this child as an individual beginning as early as the second week of the child's first grade year. This discrepant view continued throughout the child's educational tenure within the school district; there was no evidence in the record that supported the notion that the school district and parents ever resolved their discrepant view of the child, even after the implementation of the formal conflict resolution process. In the following example, Mom discusses her view of Son with the school nurse early in his first grade year:

Mom described Son’s physical attributes as being a “small boy, with beautiful dark, curly hair and sparkly eyes.” Mom described Son’s personality as “a real charmer - he can be real good and real bad." She noted that "Son is friendly, but sometimes gets his temper, but he can be reasoned with more now that he's past the ‘terrible twos'. He can be really sensitive, and cries easily.

Two days prior to the school nurse taking the above medical history from Mom, the first grade teacher wrote the following narrative:

Son was having a difficult time learning beginning sounds and is very disorganized in work habits. Son has been frustrated in doing beginning sound work \& will crumble papers or not turn them in. Son is successful when he works one-on-one, one step at a time. Son has a good personality - willing to work and a great desire to learn. He is a cooperative child but he is becoming very frustrated by his inability to achieve success in beginning reading.

The discrepant view noted above was not discussed at the eligibility committee (EC) meeting by the parents and the school district, and did not facilitate a point of impasse with the school district at that time. This discrepant view, along with lack of 
communication, laid the groundwork for the seed of conflict to take hold, as the following example illustrates. During the child's third grade year, the LD and BD resource teacher reported the following present levels of educational performance to the parents during the child's triennial review:

The biggest concern: Son's attitudes and behaviors in school. He is physically aggressive towards others. He is inattentive in class. He seems to have an attitude of failure before he starts so doesn’t put forth as much effort as he probably could. He doesn’t listen to directions. He’s inattentive in class. He draws war pictures when he should be listening, he plays with things in desk. He is off his chair 3 times a day on average. He disturbs others. How much of his difficulty is due to visual perceptual difficulties and how much are emotional problems?

Less than one month later, the parent was contacted by a social worker, and a social history was taken. The social worker wrote the parent's view of Son in this way: Mom felt “Son's grades were improving." She attributed the change to disciplinary measures implemented in the home i.e. "took away his karate lessons.” She also reported a change in his attitude toward homework: "He doesn't resent it now because I don't expect 100's only 80's.” Mom acknowledged that his frustration was her fault because of pressure to be perfect. She also believes that much of his school difficulty was related to an earlier ear problem which affected his hearing. Son's karate program has given him a sense of false pride. He appears to use karate to compensate for a perceived inferiority - if he can dominate, he feels 
successful. Mom does not acknowledge any serious difficulties. It would appear that she does need some interpretation and guidance to more adroitly meet Son's developmental needs.

This example illustrates a strong discrepant view of this child in the eyes of his parents and the school district staff. The discrepant view of the child was not identified or discussed as a factor that might escalate parent-school conflict. Although all parties agreed in this instance to resolve a point of impasse by continuing to serve the student in the LD resource room, the parents and the school district staff continued to be in disagreement about this child's individual needs. This discrepant view of the child laid the groundwork for conflict to escalate and allowed the service delivery and constraint factors to contribute to the conflict escalation between the parents and the school district. Again, the discrepant view of the child remained, perpetuating the underlying conflict. The following excerpt from an interview of the parent by a school district social worker during the child's sixth grade year provides evidence that this discrepant view of the child continued:

Mom is pleased with Son's progress in the school program. She feels that having him leave Robert Elementary School was a great decision and regrets she originally opposed the idea. She felt something happened to Son; what happened he won’t tell them. She feels his behavior has improved over the years.

Much of the family routine revolves around Son's karate practice. Son has been successful and greatly enjoys karate. The family, for recreation, also spends time target shooting. Son has a gun and is hoping to get a second one. 
The family sometimes goes to the farm owned by Private Therapist for target practice. Mom reports Son is quite skilled in firing a gun.

Mom reports Son's relationships with his parents are sometimes good and sometimes not so good. She says it depends on his mood. His relationship with his grandfather is also inconsistent. Mom states her father-in-law can be difficult to get along with as he has a "mean streak" and a selective memory. The family does not spend too much time with their extended family as there are conflicts.

Mom describes Son as very affectionate and that he is good with young children. She says that at home, Son's behavior can be very good or he can be very bad. She feels he intentionally tries to "get her goat." She says he can be very nasty at times. In terms of discipline, Mom feels that withdrawing privileges is the most effective means. Mom says that they are going to take away his gun, but Son "has hid it" to make this impossible right now.

Mom states that Son relates well to his peers. She currently likes all of his friends except one. She says he has a nice group of friends from karate. He does fight sometimes with other boys. Mom feels that his grandfather glorifies fighting too much.

In the same report, the social worker explained the school district's view of the child, which was discrepant from the parent's view:

Son is a very energetic youth who can be very charming and engaging with adults. In a group situation with peers, Son can be verbally and physically aggressive and intimidating. He insults other children but is loyal to his friends. His best friend is John. Son enjoys guns and karate. Son is a very angry youth 
who feels frustrated in school. He has shown poor impulse control. Son appears to loathe weakness of any kind and expressed hatred for students in his class that are overweight or have handicaps. He has good self-help and hygiene skills; he is very concerned about his appearance.

In school Son relates poorly with peers. He is viewed as a bully. He is mean to other students. Son needs constant adult supervision. He responds to limits set by his classroom teacher, but this is not generalized to other adult school personnel.

At the present time, Son is being cabbed to and from school as his behavior was uncontrollable on the bus. He hit a parent riding the bus when she tried to prevent his hitting another child.

Although Son has improved his behavior since entering the program, his behavior remains problematic. A major concern with Son is his obsession with power and strength. He talks continually about his gun and his desire for more guns. It is felt by this worker and other school personnel that due to Son's anger and poor impulse control, it is very dangerous for Son to have contact with firearms or any other weapons. It is recommended that Mom and Dad consider child guidance counseling to assist them in setting firm and consistent limits on Son's behavior at home.

This example epitomizes the disparity between the parents' and school district's views of the child's strengths, weaknesses and needs in this particular case. The record did not reflect that the parents' and school district's discrepant view of the child was identified or discussed as a factor in the parent-school conflict in this instance. 
The discrepant view of the child continued into and throughout the formal conflict resolution process. The factor that triggered the formal conflict resolution process was service delivery: disagreement over where the child would attend school. Yet, in the opening statements of both attorneys, the key element was the discrepant view of the child, as reflected in the in the school district's attorney's (SDA) opening remarks:

Son has disabilities in $\mathrm{BD}$ and $\mathrm{LD}$, with $\mathrm{BD}$ being the primary disability. According to the professionals that have worked with Son, it has been highly unsuccessful in delivering the services necessary for him. He needs constant and close supervision in order to be kept on task and to receive an appropriate academic instruction. His behavior, in addition to class disruptions, has over the past year been observed and documented as bizarre and highly unusual for student of his age, even within a behavior disordered category... We believe that all the observations, all of the evaluations, all of the evidence strongly supportsoverwhelmingly supports the need for this student to receive the therapeutic services available at the Rome-BEC placement.

A few moments later, the family attorney (FA) gave his opening statement, confirming the discrepant view of the child:

It is the parents' position that District 21 missed the boat with Son. The restrictive environment that they wish to place Son in is not appropriate. The reason it's not appropriate is because Son’s primary handicap as determined by all of the records that go way back to his early school is learning disabilities. They were not appropriately treated by the school district. Also, the school district has been derelict in its duty to provide Son with a medical evaluation, and has 
consistently refused to have a neurological evaluation of Son when the same was primarily indicated....

I think that the evidence will show that what's happened is the school district became frustrated with its inability to deal with Son's learning disabilities appropriately. Son started to have behavior disorders, which I think is not uncommon. Behavior disorders then became the primary concern of the school district. And somewhere along the line, all of the resources, all of the skills of the school district, all of the evaluators failed to recognize that the learning disabilities must be the primary concern of the school district, and they must give primary attention to this in order for Son's behavior disabilities to subside. Son certainly may need a contained class in a less restrictive school in order to have his learning disabilities attended to. And certainly they have not been attended to. The records reflect that. The testimony of the defense expert will establish that the school district has just missed the boat with Son by not meeting the primary need, that is teaching him to learn despite the learning disabilities.

This illustration exemplifies the key role this factor played in conflict escalation between the parents and the school district. Although the primary issue debated during the conflict resolution process was service delivery, the discrepant view of the child consistently played a major role in the parent-school conflict, providing the footing for points of impasse and conflict escalation to occur throughout the conflict resolution process. Yet, this factor was not identified or discussed as a basic issue in the continuing conflict between the parents and the schools. 
As evidenced in these examples, the discrepancy between how the parents and the school district viewed the child was a key factor in the conflict between the parties in this case. The data supported the notion that the parent-school partnership was compromised by the inability of the parties to see the child through a similar lens. Moreover, the discrepant view of the child was never consciously identified as a factor that promoted conflict between the parties; the parties never openly communicated about their discrepant view of the child, and the parent-school conflict was never resolved in this case. The presence of this unidentified factor provoked points of impasse and conflict escalation between the parents and the school district throughout this child's educational experience while paving the way for other, more conspicuous factors to contribute to and become the focus of parent-school conflict.

\section{Communication}

Lake and Billingsley defined this category of factors as "frequency of communication, lack of communication, lack of follow up, misunderstood communications, and timing of clarifying attempts...that escalate conflicts between parents and schools” (p. 248). The record was replete with examples that supported the idea that communication was a key factor that impacted points of impasse and conflict escalation in parent-school interactions. Communication factors were present prior to any contributing factor, creating fertile ground for the growth of points of impasse and the escalation of conflict. Although the points of impasse attributable to the contributing factors were often readily identified and resolved, communication factors that influenced points of impasse and subsequent conflict escalation were never clearly identified and discussed openly. 
The record also showed that communication factors seemed to accompany a discrepant view of the child held by the parents and the school district. The parties appeared to disengage from one another when communication was ineffective, which served to weaken the parent-school partnership. Communication factors played a pivotal role in fostering the development of points of impasse and subsequent conflict escalation in this case.

The first communication factor identified in the record was a lack of communication between the parent and school district. This initial lack of communication did not come to light in the record until well into the conflict resolution process, seven years after its occurrence. Below is an excerpt from the testimony of the Assistant Superintendent (Asst. Supt.) during the first Due Process Hearing:

SDA: What's the first year that Son received special ed services?

Asst. Supt.: When Son first came to my attention, September 1982, when he was in $1^{\text {st }}$ grade at Robert Elementary....Even though he lived in the Meadow attendance area, he was attending Robert Elementary at this time. Since I had nothing to do with that, I have no reason why he was at Robert Elementary.

The parents' failure to communicate the reason the child was transferred out of his home school, and the school district's failure to ask this important question of the parents, elucidates the lack of effective communication between the parties that began as early as the child's initial enrollment in the school district. This lack of communication between the parents and the school district was documented throughout the child's educational tenure. 
The record also provided examples of ineffective verbal communication between the parents and the school district staff. The parents testified in the first Due Process Hearing that the principal at the junior high school had only verbally communicated with the parents once during the child's tenure at that school:

SDA then focused on Mom's observations of Son in SpEd Teacher 2's classroom in February, 1990. She confirmed that Mom saw Son’s disruptive behavior. Mom said yes, but it was caused by "frustrations.” SDA then asked Mom if Principal told Mom that Son was actually having a good day that day. Mom said, “That was the first time; that was the first nice words he’s ever said to me. And the only words.”

This example confirms that the parents experienced little effective communication with school district personnel. This notion was repeatedly verified by an additional communication factor that impacted conflict escalation: inappropriate written correspondence. Below is an example of a letter written to the parent by SpEd Teacher 2 when the child was in sixth grade:

I know these are difficult times for you right now having to cope with Son going to and from school in a cab. I just wanted to write you a note to let you know that I, too, am concerned about Son. I also think it's important for you to realize that it's a situation which is no longer in my control.

There's nothing I can do to alter the situation.

I would really like to continue to work with you and your husband on other school related issues as we always have been able to do. I am Son’s teacher; I am not responsible for transportation. 
I am always willing to discuss Son's problems or progress as it relates to school as well as hold conferences with you. Please note the following time slots, which are the only times I can be reached during the day...

Please do no call me at home as it is inconvenient and difficult for me to be reached.

Thank you for your cooperation.

Sincerely,

SpEd Teacher 2

Upon receipt of this written correspondence from the teacher, the parent responded in writing in this manner: "I can not call you During those hours. I cannot Leave my Desk I have a Job. Just see that Son take his homework Home Son Does not Like Principal. I can’t blame him. Mom”. On that same day, the parent responded to a note the teacher sent home about the child's behavior in this way:

Who was the Remark made about, write me a note. Do Not use Son as a Scape Goat. That what it sounds like. Even on the Bus when he got kicked OFF. I am sure other kids Do thing on the Bus. Don't Push us to far. We will stick up for him my husband and I.

It is evident from the parent's responses that the teacher's written communications provoked points of impasse and escalated the parent-school conflict. Yet communication was never identified or discussed as a key factor in parent-school conflict escalation.

Another communication factor that was documented in the record as instrumental in conflict escalation was the school district's lack of follow-through when important 
information was communicated by the parent or teachers. Below is an excerpt from the child's medical history taken in the first month of first grade as reported by Mom to the school nurse over the phone:

Mom noted that Son had difficulty "with his motor - couldn't color, cut and paste like the other kids... and it was almost like he could not see the board. He couldn’t skip, either.” Son attended nursery school exhibiting similar behaviors until he enrolled in public Kindergarten.

The record indicated that the school psychologist and first grade teacher also noted fine motor delays, as well as social delays. The following was written into present levels of performance on the child's first IEP, two months later:

Son has difficulty listening \& paying attention; some trouble learning beginning sounds; disorganized work habits; difficulty performing paper pencil tasks; tires easily...Fine motor skills are poor. Has difficulty tying his shoes. He has trouble skipping. Socially immature; plays aggressively; good peer relationships; has difficulty following oral directions; difficulty attending; enjoys being helpful. Although the parent and teachers communicated this information to the IEP team, they did not follow through by writing goals and objectives to address the child's fine motor and social skills delays. There is no evidence in the record that either of these skills were addressed through specialized instruction in the regular or special education environment. The child's subsequent IEPs never addressed his fine motor concerns, and did not address his social concerns until the child's behavior became an issue. The following excerpt from the first Due Process Hearing sheds light on the impact of the lack of follow through regarding this important parent-school communication: 
Parent Direct Examination - PE Teacher 1. FA asked PE Teacher 1 to clarify her role in the District and with regard to Son. PE Teacher 1 said she was currently a physical education teacher at Watson Junior High and had Son in her class for three or four weeks. FA then asked, "Would you deem it appropriate for a gym teacher to discipline a child who has fine motor co-ordination problems because the student could not tie his shoe laces?” PE Teacher 1 responded, “No.” FA had no more questions for this witness.

School District Cross Examination - PE Teacher 1. SDA had no questions for this witness.

Parent Direct Examination - PE Teacher 2. FA asked PE Teacher 2 to clarify her role in the District and with regard to Son. PE Teacher 2 said she was the physical education teacher at Robert Elementary, where she had Son from first through fourth grades. FA asked PE Teacher 2 if she recalled once punishing Son because he was unable to tie his shoes. She answered, "I have a rule in my gym class for safety reasons that they have to have their shoes tied in order to participate in gym. So if he didn't he didn't get to take gym.” FA had no more questions for this witness.

School District Cross Examination - PE Teacher 2. SDA asked PE Teacher 2 to refer to a document which stated that the gym teacher was having "a continuing problem with Son trying to get him to keep his shoes tied." SDA said that the document referred to Son's refusal to lace his shoes, and asked PE Teacher 2 if she knew if Son could tie his shoes. PE Teacher 2 responded that Son could tie his shoes with no problem in first, second and third grade. When SDA asked PE 
Teacher 2 if her exclusion of Son from PE class was because he refused to tie his shoes, not because he could not tie his shoes, PE Teacher 2 responded, "Correct.” SDA had no further questions of this witness.

This example illustrates the impact of lack of follow through on parent-school conflict. The child's fine motor concerns were communicated to the IEP team, but the communication was ineffective due to lack of follow through by the school district. Not only did the IEP team not address the reported fine motor concerns, but they neglected to inform the P.E. teacher of this issue. This lack of follow through allowed conflict to arise, and promoted its escalation throughout the child's educational tenure in the school district.

In this case, the record corroborated the argument that communication and discrepant views of the child are pivotal factors that impact parent-school conflict. These key factors were always present during parent-school conflict. They preceded the appearance of any contributing factor. Communication and discrepant view of the child were not identified by the parties as factors that escalated parent-school conflict. These key factors facilitated points of impasse and subsequent conflict escalation by opening the door to one or more of the contributing factors to simultaneously influence conflict. The record also showed that communication and discrepant view of the child were influenced by the fundamental factor that impacted conflict escalation and the breakdown of the parent-school partnership as described below.

\section{Group Three: Fundamental Factor}

This group includes the category of factors that played a fundamental role in parent-school conflict. This group emerged as the essential factor that impacted points of 
impasse and conflict escalation between parents and school districts. Other factors were present in various combinations, and contributed to or played key roles in the parentschool conflict throughout this case. However, this category encompassed the critical element that shaped the parents' and school district's ability to successfully navigate parent-school conflict when it arose. The category identified as the fundamental factor that impacted parent-school conflict was trust.

Trust

Lake and Billingsley (2000) did not define trust, but described trust in this way: If trust was intact, parents felt a certain amount of predictability and security about the actions of school personnel...Conversely, parents in broken trust relationships with schools described having difficulty accepting suggestions from school personnel....Parents reported turning points in their ability to trust and remembered the point at which they were no longer willing to risk the hurt and disappointment that may result if they took the risk of trusting again (p. 248). The record provided the following examples that supported the notion that trust was initially present between the parents and the school district:

The parents enrolled the child in the first grade at a school within School District 21, which was not the child's home school district; within two weeks of enrollment, the school district asked parental permission to evaluate the child to determine if he had special needs. The parents agreed to allow the child to be evaluated; they also agreed to the child's initial placement in special education. The school suggested the child be held back in the first grade; the parents agreed to retain their child in the first grade. The parents also agreed to the contents of the IEP for the second and third grades. The 
parents gave permission for the school district to complete a reevaluation of their child; an eligibility committee (EC) meeting was held in January of the child's third grade year. The parents and the school district agreed that the child continued to be eligible for and would receive special education services. The parents also agreed to the school district's suggestion of adding social work support, which began in late January of the child's third grade year.

These examples lend credence to the idea that the parents felt a certain amount of predictability and security about the actions of school district personnel, and went along with their recommendations. This notion provides evidence that trust initially existed between the parents and the schools.

As discussed previously in this chapter, the record also documented instances of discrepant views of the child and ineffective communication between the parents and the school district during this same time period. Lake and Billingsley explained that when trust was intact:

[parents] were able to tolerate negative events periodically, without attaching too much importance to any one single event...These parents appeared willing to give the school personnel the benefit of the doubt when minor events became problematic in the course of a school week (p. 248).

Key factors that impacted conflict were present from the beginning of the parent-school relationship in this case. Yet conflict did not escalate prior to the end of the child's third grade year. The record supported the idea that when trust was present, it influenced the key factors when they occurred by diminishing their impact on parent-school conflict. 
The record also documented a specific turning point at which trust dissolved and mistrust overshadowed the parent-school partnership. Beginning in January of the child's third grade year, the school social worker began seeing the child weekly per the child's agreed upon IEP. In late April of that same year, the school district requested the parents come in for a parent-school conference on May 12. At this meeting, the school district informed the parent, "The feeling is that Son is not succeeding in class, because of several behavioral and emotional problems. Our intermediate LD/BD program would not be able to give Son the services he needs next year.” Also at this parent-school conference, a completed BD criteria documentation form was presented to the parents. The anecdotal notes on this form stated: “It's as if he has tried so hard for so long and can’t meet his parents' expectations that he has just given up...Parent over reacts. Becomes aggressive towards child. Will talk about hitting Son. Has unrealistic expectations for child.” At the end of the parent-school conference, the school district requested that the parents attend an IEP meeting later in May to discuss the child's present levels of educational performance and possible change in schools.

In preparation for the child's IEP meeting, the school social worker observed the child and reviewed his records. In the school social worker's summary of observations, he wrote:

Son is a nine year old child who appears to be dealing with intense internal conflicts regarding aggressive impulses. This aggression becomes focused on himself at times in a destructive way...he will make comments about "killing" himself although he does not present an overt affect of depression. 
Mom at times feels overwhelmed about how to best care for Son or react to his behaviors. She has on occasion hit him in view of school staff and frequently uses aggressive verbal references regarding Son (i.e. "he’s going to get it when he gets home" or "I'll beat it out of him"). She has little insight as to the nature of both Son's or the family’s problems and therefore, seeks simplified solutions to complex issues. Despite discussion regarding help for Son, the parents are unable to organize themselves sufficiently to follow up on recommendations. Son's behavior seems partially related to the very inconsistent boundaries within the family structure. His parents can be extremely generous at times and then emotionally unavailable to Son. Son's internal conflicts compound his already established learning difficulties and need to be addressed specifically in the context of his education... a more intensive educational program would be beneficial in addition to individual counseling. The social worker's written summary of his observations and review of the record was provided to the child's IEP team, including the parents, in May for consideration. There was no documented evidence in the record that the school social worker spoke to the parents concerning his findings, or shared this report with the parents prior to the IEP meeting. This written report was considered at the IEP meeting along with all other information presented. After all information was reviewed and the child's present levels of education were discussed, the school district again made specific recommendations regarding services and placement for the child. For the first time, the parents denied permission to allow the school district to implement its recommended services and placements. The school district acquiesced, and changed the services and placements as 
requested by the parents. The child began his fourth grade year in September; the school district followed the IEP developed the previous May. In January of his fourth grade year, the parents withdrew the child from District 21 and enrolled him in his home school. One month later, the parents re-enrolled the child in School District 21, but revoked consent for social work services, opting instead to hire a private therapist. When asked during the first Due Process Hearing why she insisted the school social worker stop seeing her child, Mom said:

I didn't think it was for our benefit. I think it was for their benefit. If I need someone, I will get my own; I don't need them. The school is never for the child; it's always for the school district...At the meeting, my husband and I were there, and I said, "No way. You are going to be for the school and never for my child.”; he was stuck up. “I don’t want you on this case. I want someone there for us, not for them.” I want my own, that I have confidence and would never give it out to anybody.

This example offers strong evidence that there was a specific turning point in the parents' ability to trust the school district. The record showed that the parents were willing to overlook communication issues and tolerate the school district's different view of their child given the notion that, regardless of their differences, the parents trusted the school district to do the "right thing" for the child. Once the parents determined that trust was broken, they no longer believed that the school district would do the "right thing” for the child. At this point, the parents began looking at parent-school differences of opinion regarding their child and lack of appropriate parent-school communication through the lens of mistrust. Where the lens of trust served to diffuse factors that 
impacted parent-school conflict in the past, the lens of mistrust focused a laser-like beam on these key factors and subsequent contributing factors that served to heat up parentschool conflict to the boiling point.

Evidence of mistrust and its impact on parent-school conflict was present throughout the record after the parent-school breakdown in trust occurred. Examples in the record substantiated the idea that mistrust between the parents and the school district influenced the potential for key factors to impact points of impasse and escalate parentschool conflict. For example, during the child's fifth grade year, the record showed that SpEd Teacher 2 spoke with the child's private therapist without parental permission to do so. Her anecdotal notes lend support to the view that the school district no longer trusted the parents to work with the school district to make appropriate educational decisions for the child. The school district's view of the child was considerably different than the parents' and private therapist's view as expressed in SpEd Teacher 2's notes:

According to him - Son's talking more, acting out less. He felt the situation at Robert Elementary had something to do with the Jewish faith. He believes Son had $\underline{\text { NO }}$ sense of masculine identity at beginning of treatment, so Private Therapist feels his extreme aggressiveness is okay. (He needs to know more present day happenings w/ Son’s behaviors) - OBVIOUSLY! W/Gun. Private Therapist feels it will be another outlet for Son to "vent out” in; will give Son \& his Dad more time together. I told him I disagreed. Agreed that Mom is definitely a Borderline Personality Disorder - very serious - so he feels Son is doing quite well considering that fact combined w/ a weak, passive father. 
Another example in the record that supported the idea that mistrust between the parents and the school district influenced the potential for key factors to impact parentschool conflict escalation follows: In December of the child's sixth grade year, SpEd Teacher 2 sent a daily communication home to Mom and Dad per their agreement. She wrote, "Son had trouble lining up today after lunch. Pushing in line. Principal sent him to the back of the line and Son called Principal an asshole. Keeping you informed.” Mom signed, and returned the communication with this note on the bottom: "The Next Time Principal touches him I will call the Police. I mean it Tell him hands off my child or any other child.” There was no indication in the record that the principal physically interacted with the child. There was also no documented evidence in the record that the teacher or the principal ever spoke to the parent concerning this incident in an effort to defuse the parental concern of possible physical abuse by school district personnel.

These examples supported the idea that trust between the parties played a fundamental role in parent-school conflict escalation. When trust was present, it softened the impact of key factors on parent-school conflict. When trust was absent, the key factors that impacted parent-school conflict were not held in check; conflict had the opportunity to escalate.

Parental mistrust of the school district also manifested itself in the parents' continued focus on readily identifiable contributing factors on points of impasse and parent-school conflict. The record showed that the parents disagreed with the school district's recommendations of services and placement proposals at each IEP meeting subsequent to the occurrence of the breakdown of trust. For example, at the end of the child's sixth grade year, the parents disagreed with the school district's proposal that their 
child attend the alternative school, Rome - BEC. The school district offered a placement at the regular junior high school as an alternative to the Rome - BEC, but the parent left the meeting without agreeing to that placement.

Although the parents ultimately acquiesced and enrolled the child in the seventh grade at the junior high school in September, their continued mistrust of the school district staff thwarted the school's attempts to implement the services as written on the child's IEP. The record provided the following example of the school district's attempt to provide consequences for the child's behavior, as summarized in a letter written to the parent by the principal, which memorialized an agreement between the parent and the principal:

1. We would notify Mom any day Son would have to be kept until 5:15. Son can ride the 5:15 bus home daily, except on Wednesdays when Mom will pick him up at 5:00 for Karate lessons.

2. We will do our best to discipline Son within our school setting. However, should his misbehavior warrant suspension, we will continue to suspend him from school.

3. Mom indicated she would be contacting Son's pediatrician as well as Omni House. She also indicated that she would consider the Omni "Big Brother" program.

4. We also talked about Son's use of a gun as a means of releasing energy and agreed that this indeed was inappropriate and we strongly encouraged Mom to seek out an alternative recreation. 
5. We agreed to meet again next Thursday, October 26 (or sooner if needed) at 1:30 to discuss the progress being made.

Yet School District 21's Assistant Superintendent (Asst. Supt.) testified to the following in the first Due Process Hearing:

Asst. Supt. We had a meeting with the parents to kind of discuss where we were with the problem. Basically, that was an attempt to get some co-operation in having Son see the consequence of his actions, and we were not getting any cooperation from the parents at this time...

AHO1: $\quad$ You described no parent cooperation. Can you give me specific instances of what you meant when you said that?

Asst. Supt.: Okay. Probably the largest one particularly at Watson was not allowing the teachers to follow through with one of the normal consequences with staying for resource, staying after school for detention, those kind of things...

The examples above confirmed that trust played an essential role in the impact of contributing factors on parent-school conflict escalation. Yet trust was not identified, acknowledged or discussed by the parties as a factor that impacted parent-school conflict escalation prior to the initiation of the formal conflict resolution process.

When trust broke down in this case, key and contributing factors affected points of impasse, escalating conflict between the parents and the school district. Ultimately, the parents and the school district could not come to agreement on where the child would receive his services. In order to circumvent this point of impasse, the formal conflict 
resolution process was called into play. The record established that both Administrative Hearing Officers, a District Judge and a majority of Circuit Court of Appeals Judges agreed that the issue to be resolved was where the child would receive services. To resolve this issue, they had to determine the least restrictive environment in which the child could benefit from his education. The AHOs and Judges held that trust was the fundamental factor that impacted their decision in this case; the parents and schools distrusted each other to the point that the child could not benefit from a free, appropriate, public education (FAPE) within the school district. The following examples support this concept:

In an excerpt from her Opinion, the Administrative Hearing Officer (AHO1) identified trust as the fundamental factor that impacted the parent-school partnership in this way:

The parents share their negative opinions about the school and staff with the child; he also realizes that parents believe his statements to be more credible than those of all the professionals. Further, he has been privy to derogatory statements made about the staff, ill-advised statements that cannot help but sabotage and undermine whatever educational program the District develops.

The parents have what appear to be irreconcilable differences with the District. It is questionable if even minimal success for the child will result from any except the most restrictive placement which can provide the most comprehensive structured program with immediate consequences, at all times.

AHO1 called into question the ability of the child to receive a FAPE given the absence of trust between the parties. Based on AHO1's belief that the child could not be provided 
with FAPE within the school district due to irreconcilable differences, she ordered an outof district residential placement for the child at the school district's expense. The parents appealed; the school district did not.

Prior to the second Due Process Hearing, the school district attorney (SDA) described the parents' position in her written brief to AHO2 in this way: "Mom openly admitted her failure to cooperate with the School District based upon her mistrust of the individuals and officials therein.” The family attorney (FA) claimed during his closing argument that "the parents have lost complete confidence in the school district, and it's a terrible thing, I admit it, but they voiced that concern to Son.” During her closing argument, SDA stated "The fact that the parents have problems with the District,...the fact that they have a distrust of the District is not an educational need of the student which the District must address.

After hearing the arguments on both sides, AHO2 wrote the following excerpts from his Opinion:

As reflected throughout the written record and the Level I transcript, as well as observed by the Hearing Officer at the Level II hearings, an extremely adversarial and distrustful relationship exists by the parents and student toward the School District. Conduct of the mother of the student was noted by this Hearing Officer during the first hearing session expressing her displeasure to any evidentiary ruling against her counsel. Said incident only goes to demonstrate the subjective state of mind of the parents as to the adversarial or "siege" mentality that now exists. 
This Hearing Officer must note the state of mind of the parents as a fact likely to effect the success or failure of the District's proposed placement at Rome-BEC. While not stated in so many words, the Level I Hearing Officer's Decision is also clearly based upon this attitude that has arisen with the parents and the student...Considering the negative attitude the parents hold toward the school system, which has in turn helped to foster Son's attitude, it is doubtful if any program operated by the school would be successful at this time...

The School District's proposed placement has been "poisoned" in the mind of the student. The student is aware that his parents would not support the efforts of the School District to control his behavior at Watson School, which doomed that placement to failure. He is likewise aware of their opposition to the Rome-BEC, and the Hearing Officer sees no reason to expect that that placement will be successful without parental cooperation.

AHO2 concurred with AHO1, but modified the order to an out-of district placement at a private special day school at the school district's expense. The school district appealed; the parents did not.

The following excerpt from the District Court's Opinion also supported the idea that trust was the fundamental factor that impacted parent-school conflict escalation:

The Court found the preponderance of the evidence supports both the Level I and Level II findings concerning negative attitudes of the parents toward the District and the fact that such had been communicated to Son and had seriously interfered with the District's attempts to educate Son; 
The Court also held that a decision to order a private versus a public placement must be based upon whether the competing placements are reasonably calculated to provide an opportunity from which the child can benefit educationally... It is clear in the instant case that both the Level I and the Level II hearing officers believed that Son would not be able to satisfactorily obtain the required educational benefits from the District's proposed placement in light of the history of Son's and his parent's relationship with the District... The court agrees with the Level I and II officers that the parents' attitudes, which have been communicated to Son, have seriously interfered with the ability of the District to provide Son with an appropriate education in public school.

The following excerpt from the Circuit Court of Appeals provided another example in the record that substantiated the notion that trust was the fundamental factor that impacted point of impasse and parent-school conflict:

In this case the District Court made the factual finding that the parents' attitudes were severe enough to doom any attempt to educate Son at Rome-BEC. The court only considered the parents' attitude to the extent that it related to the ultimate question of whether the court could deem the Rome-BEC placement to be "reasonably calculated" to supply educational benefit to Son.

The majority also discussed whether or not the parents' preference was at issue: Lachman contends that parental preference is an invalid criterion by which to judge an IEP;...Lachman does not prevent any consideration of parental hostility...In this case, unlike Lachman, the district court and the hearing officers found that the school district's proposal simply would not meet the requirement 
that the IEP be calculated to benefit Son, because Son's parents had already "poisoned" the option in Son's mind. This district judge did not elect one alternative over another viable alternative based on parents' preferences. The school district's proposed IEP was not acceptable or appropriate because the state of relations between the family and the District guaranteed its failure... Were we to adopt the school district's position and hold that parental attitudes can never be considered even if they have impaired the workability of the IEP for the child, this would in effect be punishing the child for the actions of their parents...

We conclude that it is permissible to consider parental hostility to an IEP as part of the prospective evaluation required by the EHA of the placement's expected educational benefits. If the facts show that the parents are so opposed to a placement as to undermine its value to the child, there is no obligation under the EHA to order the placement...

The record of the formal conflict resolution process in this case provided evidence that trust was the fundamental factor that impacted points of impasse and parent-school conflict. Trust emerged as the determining factor in whether or not conflict between the parties escalated. Trust was either present, or it was not present. When trust was present, points of impasse did not frequently occur; the impact of key and contributing factors on parent-school conflict was attenuated. When trust was broken, points of impasse occurred more frequently; the impact of key and contributing factors on parent-school conflict was amplified. The family attorney, in his brief to the United States Supreme Court, said it this way: "The distrust felt by the parents and by the student towards the 
District was a reef upon which any public school placement was considered sure to founder.” 


\section{CHAPTER 6}

\section{DISCUSSION}

\section{Background}

The purpose of this study was to provide a rich description of the relationship between the factors that impacted points of impasse and parent-school conflict during the conflict resolution process as evidenced in the archived record of the court case, The Board of Education of Community Consolidated School District 21 v. Illinois Board of Education (1991). This case was chosen because it was the only known case involving parental hostility that exhausted the special education conflict resolution process.

To obtain the data necessary for this descriptive case study, a duplicated copy of the complete, archived record of The Board of Education of Community Consolidated School District 21 v. Illinois Board of Education (1991) was sent to this investigator upon receipt of payment for the record. The record was reviewed by this investigator to ensure that all documents, transcripts and exhibits were accounted for per the docket sheet. All documents were also reviewed for authenticity. Once authenticated, the archived record was analyzed using the constant comparative method (Maycut \& Morehouse, 1994). The initial coding categories were the following eight factors that escalated or deescalated conflict between parents of students with disabilities and school districts as identified by Lake and Billingsley (2000): valuation; knowledge; constraints; reciprocal power; service delivery; communication; discrepant views of a child or a child's needs; and trust. This investigator closely examined all eight categories of factors and propositions to uncover relationships and reveal emergent patterns. Data retrieved from the archived 
record of this unique case did indeed provide a rich description of the relationships between the factors that impacted points of impasse and parent-school conflict during the conflict resolution process.

\section{Summary}

The findings from this study supported the organization of Lake and Billingsley’s (2000) eight categories of factors that contribute to parent-school conflict into three groups that impacted points of impasse and parent-school conflict: fundamental factors, key factors, and contributing factors.

Trust was identified as the fundamental factor that impacted points of impasse and parent-school conflict in this case. Yet, neither the parents nor the school district recognized trust as a factor that impacted points of impasse and conflict escalation between the parents and school district. Trust was the critical element that shaped the parents' and school district's ability to successfully navigate parent-school conflict when it arose. The impact of all other factors on parent-school conflict rested on the foundation of trust. When trust was present in the parent-school relationship, the impact of key and contributing factors on parent-school conflict was minimized; parent-school conflict did not escalate. There was a definitive point when parent-school trust broke down. When trust was not present in the parent-school relationship, key and contributing factors exacerbated points of impasse; parent-school conflict escalated. When trust was not present, its absence was seen as the result of conflict escalation between the parties, rather than as the fundamental factor that impacted points of impasse and parent-school conflict in the parent-school relationship. 
The key factors of communication and discrepant view of the child were not essential factors in the development and perpetuation of points of impasse and conflict escalation. However, these key factors played pivotal roles in parent-school conflict in this case. Discrepant view of the child and communication factors were always present during conflict. These key factors continually interacted with the fundamental factor of trust and each other to deescalate, contain, or escalate parent-school conflict. If trust was not present, these factors remained unresolved throughout the conflict resolution process. These key factors influenced points of impasse and subsequent conflict escalation between the parents and the school district. These factors were present in the parentschool relationship prior to any of the five contributing factors. Discrepant view of the child and communication played an important role by opening the door for contributing factors to impact points of impasse and parent-school conflict; they set the stage for contributing factors to escalate parent-school conflict. Communication and discrepant view of the child were not recognized by the parties as factors that impacted points of impasse and parent-school conflict. Therefore, they were not the focus during the conflict resolution process in this case.

The five categories identified as contributing factors are as follows: valuation, constraints, knowledge, reciprocal power, and service delivery. Contributing factors played a subordinate role in the conflict between the parties in this case. One or more of these factors were present at some time during parent-school conflict. Contributing factors did not define whether a point of impasse occurred, or parent-school conflict escalated or deescalated. These factors were easily identifiable by the parties. If trust was present, the impact of these factors was greatly diminished. If trust was not present, 
these factors frequently became a focus of parent-school conflict. Contributing factors were often satisfactorily resolved between the parties, but underlying conflict persisted.

The Power of Trust in Parent-School Partnerships

In his book, The $8^{\text {th }}$ Habit, Stephen Covey (2004) stated, “Almost all the work in the world is done through relationships with people” (p. 162). People are social beings. They interact with each other. Their interactions provide the opportunity for the development of relationships. The role they play in those relationships defines who they are. An individual can play a variety of roles in many dynamic relationships on a daily basis: husband, wife; doctor, patient; brother, sister; boss, employee; teacher, student; parent and child. Dunst and Paget (1991) hold that partnerships are developed when people interact with each other and work collaboratively to attain a common goal over a period of time.

The U.S. Congress has long acknowledged the unique relationships between parents and schools, and that these relationships lead to strong parent-school partnerships. Congress also recognized that these partnerships are the cornerstone on which the education of special needs students should be built. Congress set this cornerstone into the Individuals with Disabilities Education Act (IDEA). The IDEA requires that parents and school districts work in partnership to provide a free, appropriate, public education (FAPE) to children with special needs in the least restrictive environment.

Covey (2004) wrote, “Trust is the key to all relationships...” (p. 147). In strong parent-school partnerships, parents and school personnel trust each other; they trust that the end result of their mutual endeavor, whatever that may be, will be in the child's best interest. Although conflicts periodically occur, parents and staff are willing to "let go" of 
the differences that inevitably spring up from working together over a long period of time. The findings in this study support the idea that the following contributing factors could impact conflict between parents and schools: valuation, constraints, knowledge, reciprocal power, and service delivery. However, when trust was present, these factors were of little consequence, and the conflict could be easily resolved. Covey (2004) wrote, "When trust is present, mistakes are forgiven and forgotten” (p. 162). The findings in this study also confirmed that if trust was not present, these factors contributed considerably to conflict escalation, as these factors were easily identifiable as sources of conflict by the parties.

Strong parent-school partnerships can develop even though parents and schools view the child through different lenses. Parents see their child through the eyes of love and possibility - a unique individual that holds the promise of tomorrow. School personnel see the student through the eyes of duty to educate and ability to learn - one of many students who must be provided specially designed instruction to "close the gap" between his current performance and that of his peers. The findings in this study endorse the notion that when trust is present between parents and school personnel, this discrepant view does not unduly influence other factors that may escalate conflict; it does not jeopardize the parent-school partnership. The results of this study also support the premise that when trust breaks down, a discrepant view of the child impacts parentschool conflict directly, and opens the door for the following contributing factors of valuation, constraints, knowledge, reciprocal power, and service delivery to escalate conflict. 
In strong parent-school partnerships, the parties effectively communicate with each other to reach a mutual goal: an appropriate education for the child. Covey (2004) wrote that communication in a trusting relationship is “easy, it's effortless, it's spontaneous...” (p.162). The findings in this study confirm the notion that when trust is present between parents and school personnel, communication between the parties does not excessively influence other factors that may escalate conflict; it does not jeopardize the parent-school partnership. Stephen Covey wrote the following about communication when trust was not present:

But what is communication like when there is no trust? It's impossible. It's like walking through a minefield. What if your communication is clear and precise, yet there is no trust? You'll always be looking for hidden meanings and the hidden agenda. A lack of trust is the very definition of a bad relationship” (p. 162).

This study bears out the idea that when trust is not present, communication impacts parent-school conflict directly, and opens the door to allow the contributing factors to impact points of impasse and escalate conflict.

Dunst, et. al. (1992) identified mutual respect and trust in each other as two of the strongest indicators of the perception of a strong parent-school partnership. The findings in this study verify the idea that parent-school partnerships are founded on trust. Trust is the fundamental factor that impacts whether conflicts between parents and schools will be easily resolved, and thereby deescalated, or whether the conflict will reach a point of impasse and in so doing, escalate conflict between parents and schools. When trust is present, other factors do not have the tendency to impact points of impasse when conflict 
arises. When trust is not present, other factors have the propensity to impact points of impasse and escalate conflict between parents and schools.

\section{Implications}

Covey wrote, "Trust is the glue of life. It is the glue that holds...relationships together” (p. 162). This study gave evidence to the notion that trust is the fundamental factor in determining whether or not conflict will escalate when it exists between parents and schools. A solid foundation of trust is essential to constructive parent-school relations. All parties in the parent-school partnership must be cognizant of this powerful premise and vigorously strive to maintain trusting relationships. Educational stakeholders also have a duty to promote law, policy and action that supports and maintains trust in parent-school partnerships. In support of this endeavor, relevant points specific to each stakeholder are discussed below, followed by suggestions for their consideration.

\section{Implications for Teachers}

Special education teachers are the professionals in the school district who interact with the parents of a special needs child most frequently. Although other teachers and school administrators periodically see and interact with the child, they do not often interact with the child's parents. The parents and the special educator are the primary participants in the parent-school partnership. The findings of this study confirmed that this partnership is founded on trust. Stephen Covey asked and answered this question: "Where is the very best place to give trust, to communicate people’s worth and potential? Without question, it is the family...Where is the next best place? The school. The 
teacher becomes like a surrogate parent who begins the trusting process...” (2004, p. 182).

At times, teachers find themselves at odds with parents. Often teachers have difficulty identifying the exact nature of the issue that has become the focus of conflict. Without the requisite skills to identify the root of the concern, teachers become frustrated and view the parent as being difficult. This study illuminated the notion that teachers and parents do not identify trust as the most important factor that impacts whether the problem at hand will mushroom into a point of impasse, and possibly escalate conflict. Teachers must become cognizant of the importance of trust in their relationships with parents, and the compelling influence it wields over the parent-school partnership.

This study verified the idea that communication plays a key role in whether or not points of impasse occur, and conflict escalates in parent-school partnerships. When trust is present between parents and school personnel, teachers must use communication effectively to maintain that trust. When trust is absent, teachers must realize that communication between the parents and the teacher can act as a catalyst, impacting points of impasse and escalating conflict.

Teachers should reflect on the following suggestions to maximize the positive outcomes and minimize conflict generated by parent-school partnerships:

1. Recognize that trust is the fundamental factor that impacts parent-school conflict. Value the trust parents put in you to do "what is right" for their child. Seek to build trust with parents.

2. Take advantage of opportunities for training in the following skill areas: identifying conflict, conflict resolution, relationship building, trust building, 
mediation, peer counseling, non-verbal communication, effective communication and maintaining confidentiality. Proactively use these new skills.

3. Recognize pitfalls which may undermine trust. Carefully scrutinize all written correspondence and verbal communication with a sensitivity toward preserving trust.

4. Recognize that the readily identifiable contributing factors of valuation, service delivery, reciprocal power, knowledge, and constraints become the focus of parent-school conflict when it occurs. Allow yourself to delve deeper into the parent-school relationship. Examine the underlying factors of trust, communication and discrepant view of the child; consider the impact of these factors on parent-school conflict.

\section{Implications for School Administrators}

School administrators are viewed as the educational leaders of the school or school district. They are considered master teachers and problem solvers. School personnel, parents, and other school administrators seek answers at their door, especially if conflict has arisen between parents and teachers, and has escalated to a point of impasse. All too often school administrators are not aware of a parent-school conflict prior to its escalation; the first they hear of it is when the parent or the teacher "pop in" the office and hurriedly give a brief synopsis of the problem as they have experienced it. At the same time, it is customary for the parent or teacher to expect the school administrator to pronounce a resolution to the problem immediately after hearing the problem. This creates the possibility of the school administrator becoming an arbiter. This, in turn, pushes the situation into a win-lose scenario. If the school administrator 
sides with the parent, the teacher could lose respect and trust for the administrator: "He didn't back me in this situation - I can't trust him to back me.” If the administrator sides with the teacher, the parent could lose trust for the administrator: "I knew he would back the teacher and not care about my child.” School administrators must realize that when trust breaks down, points of impasse become more prevalent and conflict can escalate. This study found that trust was not readily identified by parents or school personnel as a factor that escalates conflict. All interactions between the parents and the schools become suspect. The discrepant view the parties had of the child that went unnoticed when trust was present, looms like a large elephant in the living room when trust breaks down. Communication that once flowed between the parties dries up. School administrators must recognize the impact that trust, or lack thereof, has on parent-school partnerships.

Stephen Covey (2004) wrote, “Thinking win-win is a frame of mind and heart that seeks mutual benefit and mutual respect in all interactions” (p. 152). School administrators must avoid win-lose scenarios, and approach conflict within the parentschool partnership from the perspective of "win-win". This investigator acknowledges that there will be times when parent-school conflict will escalate regardless of how hard school personnel attempt to defuse the situation. But these instances have the potential to drop markedly if school administrators advocate for and model a "win-win” philosophy. Stephan Stolp (1994) noted that it is important for school administrators to model behavior: "The actions of the principal are noticed and interpreted by others as 'what is important”” (p. 3). 
Below is a list of ideas that will help school administrators become more adept at promoting positive parent-school partnerships within the school district:

1. Recognize that trust is the fundamental factor that impacts parent-school conflict. Value the trust parents put in you to do "what is right” for their child.

2. Directly interact with parents and school personnel as often as possible. Seek to build trust with parents and school personnel.

3. Survey staff to determine if they have had any formal or informal training in the following skill areas: identifying conflict, conflict resolution, relationship building, trust building, mediation, peer counseling, non-verbal communication, effective communication and maintaining confidentiality.

4. Offer as many professional development opportunities as possible to staff to help build their skills in the following areas: identifying conflict, conflict resolution, relationship building, trust building, mediation, peer counseling, non-verbal communication, effective communication and maintaining confidentiality. Provide time and incentives for teachers to take advantage of these opportunities.

5. Take part in the professional development opportunities noted above. Model those skills whenever possible.

6. Recognize pitfalls that may undermine trust. Set high expectations and proactively coach school personnel in constructive communication and trustbuilding techniques.

7. Offer to act as a mediator to deescalate conflict when deemed appropriate.

8. Practice a "win-win" approach to dealing with conflict between parents and schools. 


\section{Implications for Parents}

Parents love their children and want what is best for them. Parents want their children to be safe, warm, happy and successful. They also want their children to learn to be productive citizens, have friends, and live independently. Most parents are willing to work in partnership with schools to ensure these things occur. Parents seem to inherently trust that the school district will ensure these things occur when the child is at school.

When trust is present and the parents have a different idea about how something should be done, they are willing to be flexible and problem-solve with the school to find a solution that both parties feel will work for the child. They are willing to forgive "the little things”. But trust can break down. The findings in this study support the notion that parents have a breaking point at which they stop trusting the school district to do what they believe is right for their child. As this study found, broken trust can ultimately lead to a denial of a free, appropriate, pubic education (FAPE) for the child. Therefore, it is imperative that trust be recognized as a crucial component of the parent-school partnership, and that every effort is made to maintain trust and impede its breakdown.

Most parents want a healthy, positive relationship with their child's school. At times, however, parents feel that school personnel do not hold high expectations of their child because of the identified disability, or simply do not like their child. At times, parents do not believe that school personnel are telling them everything they need or want to know about the child's day at school. This study verified that the parties did not identify or purposely focus on communication and discrepant view of the child as factors that impact points of impasse and conflict escalation. Parents must recognize the impact of communication and discrepant view of the child on conflict as it arises, and practice 
effective communication to diminish these factors' impact on the parent-school partnership.

Parents should consider the following suggestions as they work towards maintaining a positive parent-school partnership:

1. Recognize that trust is the foundation of the parent-school partnership. Actively work to build trust with teachers and administrators.

2. Acknowledge that trust is the fundamental factor that impacts parent-school conflict escalation. Avoid the breakdown of trust.

3. Value the notion that educators are doing what they believe is right for the child.

4. Visit the Parent Education Resource Center or other parent support groups for more information about building strong parent-school partnerships. Practice what you learn.

5. Interact frequently with your child's teacher and school administrators. Let school personnel know that they can trust you.

6. If conflict arises, immediately call it to school personnel's attention. Schedule a meeting time to talk openly about it. Be open and willing to work through the issue.

\section{Implications for Higher Education}

Colleges and universities that offer training programs for teachers and school administrators have a powerful influence on public education in the United States. The information imparted by college and university professors to school personnel through the preparatory coursework of their degree programs is the knowledge that is applied in the public school environment. Most colleges and universities that offer teacher 
preparatory programs require significant coursework in curriculum and instruction for the completion of a degree in education. Administrator preparatory programs include coursework in leadership, supervision, finance, facilities management and school law. Educational preparatory programs should also offer instruction on how to build and sustain relationships with educational stakeholders such as parents.

The findings in this study substantiated the notion that trust between parents and schools is the foundation on which parent-school partnerships are built. The research findings also supported that a breakdown in the parent-school partnership could jeopardize the ability of a child to receive a free, appropriate, public education within the school district. Professors in higher education should recognize these findings and examine the content of each course offered in educational preparatory programs to ensure that at some point in the program, students are trained in how to develop and maintain trusting parent-school partnerships, identify conflict when it occurs and apply a "winwin” philosophy to deescalate the conflict. This will serve the overall mission of both public education and higher education: to improve educational services for children.

Constituents of higher education should consider the following suggestions as they work towards preparing public school personnel to improve educational services to children:

1. Recognize that trust is the fundamental factor that impacts parent-school partnerships. Carry this notion into every course curriculum.

2. Provide direct instruction to educators on how to maintain and support parentschool partnerships. Also provide direct instruction on identifying and deescalating conflict between parents and schools. 
3. Value the trust that public school educators put in higher education to teach them what they need to know so they might improve educational services to children.

4. Support continued research in the area of parent-school relationships and conflict resolution in education.

\section{Implications for Legal Advocates}

When conflict between parents and schools escalates to the point that either party, or both, believe they do not have the skill or knowledge base to continue representing themselves, they might look to a third party who is expert in special education issues for support and guidance through the conflict resolution process. Parents and school districts are relieved to have someone who can navigate the technical, legal process of the special education conflict resolution process. They are also happy to have someone "on their side”, who will listen to them, and represent their position as the parties try to resolve their conflict.

IDEA 2004 does not stipulate that a parent or school district must be represented. A parent may represent themselves, or the parties can choose the advocate they are most comfortable with representing them. Legal advocates have varying educational degrees, background, and experience in special education law and the special education conflict resolution process. Examples include licensed attorneys who specialize in special education law, general plaintiff's attorneys, trained advocates that work for federal public or private advocate groups, and other parents or relatives who have been through the special education conflict resolution process. These advocates have varying degrees of training with regard to conflict resolution. Most training received by these advocates centers around a win-lose model of arbitration: the issues are outlined (frequently they 
are contributing factors to conflict escalation), the parties put on evidence before a hearing officer, and the hearing officer decides whose position is right and writes an order that makes both parties adopt that position. In this win-lose model, advocates literally fight for their parties' position to be the one adopted by the hearing officer: "I win - you lose.”

Some advocates have been trained in mediation. Yet current mediation mentality follows a "win-lose-draw" model. The mediator cannot tell the parties what to do, or insist that a mediation agreement is reached. But the mediator applies pressure to both sides, pulling the parties towards a compromise. All too often mediation agreements are reached that the parties can live with, but the agreement does not solve the underlying problem of broken trust in the parent-school partnership. The findings in this study support the notion that trust is the foundation on which parent-school partnerships are built. The break down of trust between parents and schools impacts points of impasse and conflict escalation when conflicts occur. When trust is not present, communication and discrepant view of the child also impact points of impasse and conflict escalation, as well as opens the door for contributing factors to impact conflict.

Like parents and schools, legal advocates identify the tangible issues, such as service delivery and constraints, as the issues to be mediated. Legal advocates must recognize trust as the fundamental factor that impacts points of impasse and conflict escalation. They should advocate for parent-school partnerships that are founded on trust, and strive to help rebuild trusting parent-school relationships. Legal advocates should actively pursue alternative avenues of conflict de-escalation that preserves and 
strengthens trust and leads to a win-win resolution. Only then will the legal advocates be able to guide the parents and schools through the conflict resolution process successfully. Below is a list of ideas that will help legal advocates become more adept at resolving parent-school conflict and promoting positive parent-school partnerships within the school district:

1. Recognize that parent-school partnerships are founded on trust.

2. Recognize that trust is the fundamental factor that impacts parent-school conflict.

3. Attend as many professional development opportunities as possible to help build your skills in the following areas: identifying conflict, conflict resolution, relationship building, trust building, mediation, peer counseling, non-verbal communication, effective communication and maintaining confidentiality. Take part in the professional development opportunities noted above. Utilize those skills whenever possible.

4. When listening to your client's point of view, identify the issues as you have in the past. Then delve deeper to identify when trust broke down between the parties and the reason for the break down.

5. Discuss the importance of parent-school partnerships with your client. Offer to lead discussions, and if possible, trust-building sessions with the parties to build trust and deescalate the conflict.

6. If an issue must go to resolution session, mediation, or due process, press for the mediation agreement or Order to have a component that addresses the rebuilding of trust and the parent-school partnership. 


\section{Implications for Policy Makers}

On December 4, 2004 President George W. Bush signed into law the reauthorization of the Individuals with Disabilities Education Act (IDEA 2004).

It is evident that policymakers continue to recognize that parent-school partnerships are the cornerstone on which the education of special needs students must be built. IDEA 2004 has strengthened the requirement that parents and school districts work in partnership to provide a free, appropriate, public education (FAPE) to children with special needs in the least restrictive environment, as evidenced in the changes in the conflict resolution process as explained in a position paper published by the Council for Exceptional Children (2004):

The new bill requires that both parties must submit a due process complaint notice before accessing a due process hearing.

The new bill allows mediation to be requested prior to the filing of a complaint and strengthens the provisions for developing a written binding confidential agreement that is enforceable in any State or district court of the United States. The new bill creates an additional dispute resolution process called "resolution session”. The LEA must convene the session prior to a due process hearing unless the parents and the LEA agree in writing to waive the meeting or go to mediation. The session must be conducted within 15 days of the request for the hearing and the complaint must be resolved within 30 days of the request or a due process hearing may occur. If successful resolution is reached, a binding signed written settlement agreement must be developed and is enforceable in any State or 
district court of the United States. Either party may void this agreement within 3 business days.

The new bill includes provisions related to decisions made by the hearing officer...A hearing officer may find that a child did not receive a free appropriate public education (FAPE) only if the procedural errors impeded the child's right to FAPE, significantly impeded the parent's opportunity to participate in the decision making process regarding the provision of FAPE, or caused a deprivation of educational benefits.

A party bringing a civil action has 90 days from the date of the hearing officer's decision to bring a civil action or the time period allowed by the State law (pp. 21-22).

These changes in IDEA encourage parents and school district personnel to informally resolve or mediate the identified conflict between them. Yet, this study's findings revealed that parents and school districts do not identify trust, communication or discrepant view of the child as factors that impact points of impasse and conflict escalation between the parties. Instead, the parties focus on the easily identifiable contributing factors that have escalated conflict, such as valuation, knowledge, constraints, reciprocal power, and service delivery. Although a resolution session or mediation might be able to solve the issues related to the conflict escalated by the contributing factors, the fundamental factor of mistrust would not be identified, discussed, or resolved. Policymakers must recognize and use this study's finding that trust is the fundamental factor that impacts points of impasse and conflict escalation, and 
look to provide avenues for trust to be addressed and if possible, rebuilt between the parties.

IDEA 2004 continues to hold out arbitration through the use of a due process hearing as the primary mode of dispute resolution between parents and school districts. This method of conflict resolution is grounded in a win-lose philosophy. The findings in this study support the idea that trust is the foundational element that impacts the possibility of conflict escalation. Policymakers must adopt a proactive "win-win" approach to conflict resolution between parents and school districts to ensure that trust remains intact, securing the foundation of a strong parent-school partnership.

IDEA 2004 also does not acknowledge that trust is the foundation of parentschool partnerships, and therefore does not articulate the need for, or provide an avenue for the proactive development and maintenance of trust within the parent-school partnership. As this study supports, conflict between parents and school districts can escalate if trust breaks down; the breakdown of trust can lead to the child being denied a FAPE. It is imperative that policymakers acknowledge the impact trust has on conflict escalation between the parties and provide opportunities to build trust between the parties.

With the reauthorization of IDEA, policymakers attempted to ensure IDEA 2004 would work in tandem with No Child Left Behind. In Counterpoint, East and Cashman wrote:

What makes this reauthorization and regulation process different from previous ones is the realization that this is not a stand-alone law. By this we mean that one must look at other laws, most notably the No Child Left Behind Act (NCLB), to 
get a more complete understanding of what is required. The big picture goes much beyond what we read in IDEA 2004 and the proposed regulations. These two laws, viewed together, provide children and youth with access and opportunity only dreamed of a few years ago (p. 1).

Congress put forth the expectation that these two "Titans" of educational law would be followed simultaneously. Because this is a new development in special education, an unknown "Clash of the Titans" might spark conflict in parent-school partnerships. This study supports the notion that if trust is present in these partnerships, points of impasse will not occur as parents and school district personnel work through the present conflict. If trust is not present, conflict that might arise from the melding of these two laws can bring about a point of impasse; conflict between parents and school districts could escalate. Policymakers should be aware of the possibility of this conflict, and ensure there are avenues to deescalate conflicts that may occur between parents and schools due to the linking of these two laws.

Policymakers at all levels should consider the following suggestions that will foster support and maintain positive parent-school partnerships and ensure that all students with exceptionalities are provided with a FAPE:

1. Recognize that parent-school partnerships are founded on trust.

2. Recognize that trust is the fundamental factor that impacts parent-school conflict.

3. Revise current laws, regulations, policies and procedures to encourage strong parent-school partnerships. Provide a proactive means to build trust between parents and school districts; fund these initiatives. 
4. Require resolution sessions, mediation, and due process hearings to include party participation in instruction on and follow-through with identifying and re-building trust between the parties.

5. Carefully watch the consequences of braiding the regulations of NCLB and IDEA together. Request studies that examine the results of this integrative initiative to determine if there is improvement in the services to exceptional students.

\section{Recommendations for Further Study}

Based on the results of this study, the following recommendations were made for additional research:

1. An examination of how parents and school districts define trust;

2. A study that identifies how trust between parents and school districts is built up or broken down;

3. A study that focuses on how trust, communication, and discrepant view of the child interact in the parent-school partnership;

4. A study that determines if teachers, education administrators, and legal advocates for special needs students have had professional training and development in mediation and trust-building techniques.

5. An evaluation of the integration of NCLB with IDEA to determine its impact on the improvement of services to exceptional students and overall student achievement. 


\section{References}

Alexander, K., \& Alexander, M. D. (1995). The law of schools, students and teachers. St. Paul, MN: West.

Blue-Banning, M., Summers, J., Frankland, H., Nelson, L., \& Beegle, G., (2004).

Dimensions of family and professional partnerships: Constructive guidelines for collaboration. Exceptional Children, Winter, 167-184.

Board of Education of Community School District No. 21 v. Illinois State Board of Education, 938 F.2d 712 (7 $7^{\text {th }}$ Cir. 1991), cert. denied, 502 U.S. 1066 (1992).

Brown v. Board of Education, 347 U.S. 483 (1954).

Clyde K. v. Puyallup School District, 35 F.3 1396 ( $9^{\text {th }}$ Cir. 1994).

Council for Exceptional Children. (2004, November). The new IDEA: CEC's summary of significant issues. Arlington, VA: Council for Exceptional Children.

Covey, S.R. (2004). The $8^{\text {th }}$ habit. NY: Free Press.

Denzin, N. K., \& Lincoln, Y. S. (1998). Collecting and interpreting qualitative materials. Thousand Oaks, CA: Sage.

Different Strokes/Different Research Methods. (n.d.). Retrieved March 13, 2005, from http://books.valdosta.edu/mlis/stats/diffstrokes.html

Dinnebeil, L. A., \& Hale, L .M. (1996). A qualitative analysis of parents’ and service coordinators' descriptions of variables that influence collaborative relationships. Topics in Early Childhood Special Education, 16(3), 322-348.

Dinnebeil, L. A., \& Rule, S. (1994). Variables that influence collaboration between parents and service coordinators. Journal of Early Intervention, 18, 349-361. 
Dinnebeil, L. A., Rule, S., \& Fox, C. (1996). Influences of collaborative relationships: Differing perspectives of parents and service coordinators. Manuscript submitted for publication.

Dobbs, R. F., Primm, E. B., \& Primm, B. (1991). Mediation: A common sense approach for resolving conflicts in special education. Focus on Exceptional Children, 24, 111.

Dobbs, R. F., Primm, E. B., \& Primm, B. (1993). Mediation. In the proceedings of the $14^{\text {th }}$ National Institute on Legal Issues of Educating Individuals with Disabilities. Horsham, PA: LRP.

Dunst, C. J., \& Johanson, C., Rounds, T., Trivette, C. M., \& Hamby, D. (1992). Characteristics of parent-professional partnerships. In. S. L. Christenson \& J. C. Conoley (Eds.), Home-school collaboration: Enhancing children's academic and social competence (pp. 157-174). Silver Spring, MD: National Assoc. of School Psychologists.

Dunst, C. J., \& Paget, K. D. (1991). Parent-professional partnerships and family empowerment. In. M. J. Fine (Ed.), Collaboration with parents of exceptional children (pp.25 - 44). Brandon, VT: Clinical Psychology.

East, B., \& Cashman, C. (2005, Fall). IDEA 2004: Accountability with flexibility. Counterpoint. p.1.

Education for the Handicapped Act of 1970, Pub. L. 91-230, 84 Stat. 175 (1970).

Elementary and Secondary Education Act of 1965, Pub. L. 89-750, 80 Stat.1204 (1966).

Feidler, C. P. (2000). Making a difference: Advocacy competencies for special education professors. Boston: Allyn \& Bacon. 
Feinberg, E., Beyer, J., Moses, P. (2002). Beyond mediation: Strategies for appropriate early dispute resolution in special education. Unpublished manuscript. National Center on Alternative Dispute Resolution (CADRE): Eugene, OR.

Gallant, C. (1982). Mediation in special education disputes. Silver Spring, MD: National Association of Social Workers.

Garner, B.A. (Ed.) et al. (1979). Black’s law dictionary. Fifth edition. St. Paul, MN: West Publishing. (Contributing Authors)

Getty, L. \& Summy, S., (2004). The course of due process. Teaching Exceptional Children, Jan., 40-43.

Girard, K. \& Koch, S. (1996). Conflict resolution in the schools: a manual for educators. San Francisco, CA: Jossey-Bass.

Goldberg, S. S., \& Huefner, D. S. (1991). Evaluating the fairness of special education hearings. Exceptional Children, 62, 546 - 554.

Goldberg, S. S. and Kuriloff, P. J. (1991). Evaluating the fairness of special education hearings. Exceptional Children, 62, 546-554.

Goldberg, S. S. (1995). Can alternative dispute resolution build a community. Journal for a Just and Caring Education: 1(2), 232-237.

Grapevine-Colleyville Independent School Dist., 21 IDELR 875 (Tex SEA 1994).

H.R. Rep. No. 332, $94^{\text {th }}$ Cong., $1^{\text {st }}$ Sess. 4 (1975).

Individuals with Disabilities Education Act of 1997, 20 U.S.C. Section 1400, et seq.(1997).

Individuals with Disabilities Education Act Regulations, 34 C.F.R. Section 300, et seq. (1999). 
Keith, J. A. (1999). How to prepare for a due process hearing. Paper presented the meeting of the $20^{\text {th }}$ National Institute on Legal Issues of Educating Individuals with Disabilities, Seattle, WA.

Lake, J., \& Billingsley, B. (2000). An analysis of factors that contribute to parent-school conflict in special education. Remedial and Special Education, 21(4), 240-251.

Landau, S. (Ed.) et al. (1966). The reader's digest great encyclopedic dictionary. Pleasantville, NY: Reader’s Digest Assoc.

Law Reports. (2004, May 12). Retrieved March 13, 2005, from University of Queensland Library Web site: http://www.library.uq.edu.au/law/research/lawreports.html. Marshall, C. \& Rossman, G. (1989). Designing qualitative research. Newbury Park, CA: Sage.

Maycut, P. \& Morehouse, R. (1994). Beginning qualitative research: A philosophic and practical guide. Bristol, PA: Falmer Press.

Merriam, S. B. (1990). Case study research in education: A qualitative approach. San Francisco: Jossey-Bass.

Mohr, Richard. (2004, February 19). Interpretation. Retrieved March 13, 2005, from http://www.uow.edu.au/law/postgraduate/research/interpretation.html Monongalia County Board of Education v. Jessica Justice and Individually and as the Mother of her Physically and Mentally Impaired Child, Bryan Howard, Civil Action No. 1:99CV119 (N.D. W.Va. 2000).

Morton, B. M. (2000). Crossing alligator river: The power of conciliation in special education. Paper presented at the meeting of the $21^{\text {st }}$ National Institute on Legal Issues of Educating Individuals with Disabilities, New Orleans, LA. 
Murphy v. Timberlane Regional School District. 22 F.3d at 1186. (1 $1^{\text {st }}$ Cir. 1994).

Nash, D. \& Perras, P. (1996). "Parent involvement in successful alternative dispute resolution”. As cited in Shaw, V. (1999). “Alternative dispute resolution: Why and how?”. In paper presented at the meeting of the $20^{\text {th }}$ National Institute on Legal Issues of Educating Individuals with Disabilities, Seattle, WA.

Newcomer, J., \& Zirkel, P. (1999). An analysis of judicial outcomes of special education cases. Exceptional Children, 65, 469-480.

Oberti v. Board of Education. 789 F. Supp. 1322, (D.N.J. 1992), aff'd, 995 F.2d 1204 (3 Cir. 1993).

Patton, M. Q. (1990). Qualitative evaluation and research methods. Newbury Park, CA: Sage.

Reusch, G. M., (Ed.). (1996). Special education law and practice: A manual for the special education practitioner. Horsham, PA: LRP.

Schrag, J. A. (1996). Mediation and other alternative dispute resolution procedures in special education. Final report. Washington, DC: Special Education Programs (ED/OSERS). As cited in Shaw, V. (1999). "Alternative dispute resolution: Why and how?”. In paper presented at the meeting of the $20^{\text {th }}$ National Institute on Legal Issues of Educating Individuals with Disabilities, Seattle, WA.

Sean R. v. Town of Woodbridge Board of Educ., 794 F.Supp. 467 (D.Conn. 1992).

Shaw, V. (1999). Alternative dispute resolution: Why and how?. Paper presented at the meeting of the $20^{\text {th }}$ National Institute on Legal Issues of Educating Individuals with Disabilities, Seattle, WA.

St. Mary’s School Dist., 20 IDELR 46 (Penn. SEA 1993). 
Stolp, S. (1994). Leadership for school culture. Eugene, OR: ERIC Clearinghouse on Educational Management. (ERIC Document Reporducation Service No. ED 370 198)

Turnbull, A.P., \& Turnbull, H.R. (1986). Families, professionals, and exceptionality: a special partnership. Columbus: Merrill Publishing Co.

U.S. Const. amend. XIV.

U.S. Const. art. 1, section 8, cl. 1.

Wilson, B. W. (1997). A comparison of local and state level alternative dispute resolution procedure in special education. Unpublished doctoral dissertation, University of California, Berkeley.

Yell, M. L. (1998). The law and special education. Saddle River, NJ: Prentice-Hall.

Yin, R. K. (1984). Case study research: Design and methods. Beverly Hills, CA: Sage.

Zirkel, P. (1998). A special education case of parental hostility. Education Law Reporter, 1-10. 


\section{Appendix}

\section{IYFARTHAW \\ Writer's direct phone \\ (312) 269-8862 \\ Writer's o-moil \\ jgale@seyfarth.com}

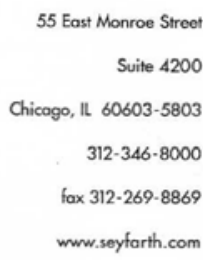

October 11, 2002

Ms. Deede Lundeen

c/o Harry Rubenstein, Esq.

50 Clay Street

Morgantown, WV 26501

Re: Representation of Deede Lundeen

Dear Ms. Lundeen:

Thank you for retaining Seyfarth Shaw to represent you. The scope of our engagement will be to represent you with respect to gathering information from the client record on a special education proceeding. Naturally, the scope of our representation may be limited or expanded from time to time. We look forward to working with you in this engagement and to developing a mutually satisfactory relationship.

The purpose of this engagement letter is to confirm our engagement as your counsel and to provide you with certain information concerning our fees, billing and collection policies and other terms that will govern our relationship and to discuss such important conflict of interest issues as may be suggested by our relationship or the nature or scope of our engagement. Although we do not wish to be overly formal in our relationship with you, we have found it to be a helpful practice to confirm with our clients in writing the nature and terms of our representation. Attached to this letter are our Firm's standard Terms of Engagement, which will govern our relationship except as specifically stated otherwise in this engagement letter. Please review these terms and let me know if you have any questions about them.

Our fees for this engagement will be based upon the hourly billing rates for each attorney and paralegal who devotes time to your service. Our billing rates for attorneys currently range from $\$ 160 /$ hour for new associates to $\$ 265 /$ hour for our most senior associates and from $\$ 260 /$ hour for junior partners to $\$ 450 /$ hour for senior partners. Derrick Brummell, a paralegal, has been assigned to this project. His rate is $\$ 130 /$ hour.

You are aware that the Firm represents many other companies and individuals. It is possible that during the time we are representing the Company, some of our present or future clients have or will have disputes or transactions with the Company. The Company agrees that we may continue to represent or may undertake in the future to represent existing or new clients in any matter that is not substantially related to our work for you even if the interests of such clients in those other matters 
are directly adverse to the Company and/or its affiliates, including, for example, representing adverse parties in litigation. We agree, however, that your prospective consent to conflicting representation contained in the preceding sentence shall not apply in the instance of any matter where, as a result of our representation of you, we have obtained proprietary or other confidential information of a nonpublic nature, that, if known to such other client, could be used in such other matter to your material disadvantage. You should know that we have a policy of including similar agreements in engagements letters with other clients.

If the terms described above and in the Terms of Engagement are satisfactory, please so indicate by signing in the space provided below and please return the signed copy to me at your earliest convenience. We look forward to working with you.

Very truly yours,

SEYFARTH SHAW

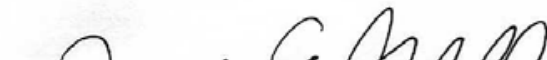

By

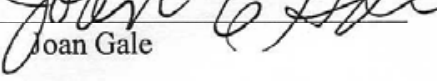

JEG:ko

Enclosure

Agreed: $\quad$ Harry Rubenstein on behalf of Deede Lundeen

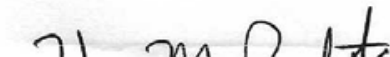

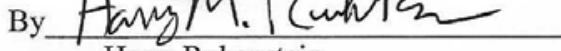

Harry Rubenstein

CH1 10436312.1 
MERRILL

COMMUNICATIONS LLC

Location: DMS-CHICAGO 250 S WACKER

Kay, Casto \& Chaney

50 Clay Street

MORGANTOWN, WV 26501

Attn: Harry Rubenstein
Any Inquiries Call: 312-454-8500

Invoice \#: 146835

Invoice Date: $30-A U G-02$

Merrill Order \#: 002-171532

Client Matter \#: seyfarth docs

Date Received:

Salesperson: COLLINS, CHRISTINA L

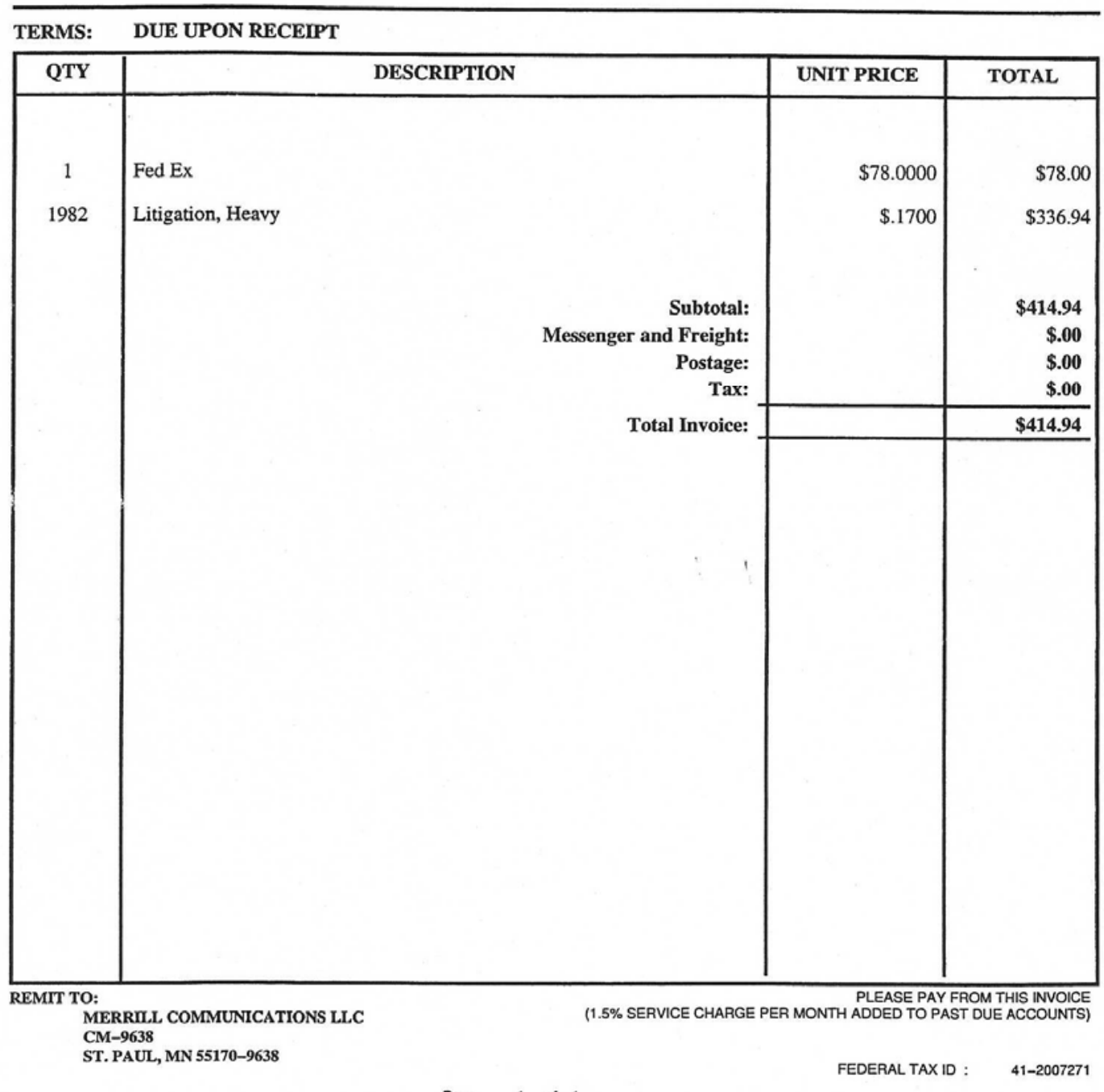




\section{SEYFARTH \\ attorneys SHAW}

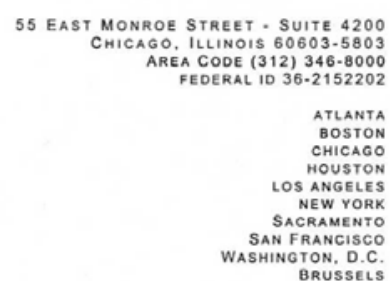

November 2002

Invoice No. 825065

$0186 / 87045$

Deede Lundeen

1600 Heather Street, \#6

Morgantown, WV 26505

For legal services rendered through the month of October 2002

\section{Labor General}

\begin{tabular}{|c|c|c|c|c|}
\hline Date & Attorney & Hours & $\underline{\text { Value }}$ & Description \\
\hline $10 / 28 / 02$ & D. Brummell & 1.50 & 195.00 & $\begin{array}{l}\text { Review received case background information; } \\
\text { conference with } \mathrm{M} \text {. Rubenstein regarding case } \\
\text { background, needs, and collect necessary information; } \\
\text { contact Federal archive Center to make arrangements } \\
\text { for viewing and copying file and to determine protocol } \\
\text { of same. }\end{array}$ \\
\hline
\end{tabular}

Total Fees This Matter

$\$ 195.00$

\begin{tabular}{|c|c|c|c|}
\hline Attorney & Bours & $\underline{\text { Rate }}$ & Value \\
\hline D. Brummell & 1.50 & $\$ 130.00$ & $\$ 195.00$ \\
\hline Total & 1.50 & & $\$ 195.00$ \\
\hline
\end{tabular}

Total Fees and Disbursements This Matter

Total This Statement
$\$ 195.00$

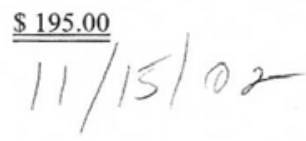


$\frac{\text { SEYFARTH }}{\text { ATORNEYS SHAW }}$

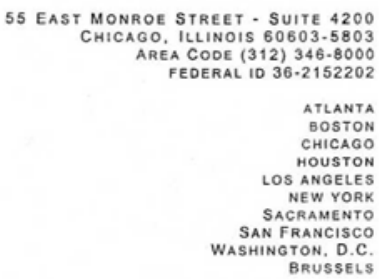

December 2002

Invoice No. 832655

$0186 / 87045$

$\mathrm{K} 3$

Deede Lundeen

1600 Heather Street, \#6

Morgantown, WV 26505

For legal services rendered through the month of November 2002

Labor General

$\begin{array}{llr}\underline{\text { Date }} & \underline{\text { Attorney }} & \text { Hours } \\ 11 / 05 / 02 & \text { D. Brummell } & .50 \\ 11 / 08 / 02 & \text { D. Brummell } & 4.00\end{array}$

Total Fees This Matter

Attorney

D. Brummell

Total

\section{Disbursements}

Federal Express/Messenger

Travel

Meals on 11/8/02 for DERRICK BRUMMELL-ER

$11 / 8 / 02$.

\section{Value Description \\ 65.00 Arrange for the rescheduling of the viewing and copying of case documents at Federal Archive Center; advise M. Rubenstein on developments. \\ 520.00 Go to Federal Archive Center; review case file and arrange for copies of select volumes of Administrative records; fed ex resulting copies to client; advise $\mathrm{M}$. Rubenstein on developments.}

$\$ 585.00$

\begin{tabular}{|c|c|c|}
\hline Hours & $\underline{\text { Rate }}$ & $\underline{\text { Value }}$ \\
\hline 4.50 & $\$ 130.00$ & $\$ 585.00$ \\
\hline 4.50 & & $\$ 585.00$ \\
\hline
\end{tabular}

\section{$\underline{\text { Value }}$}

42.80

78.85

$\vee 8.71$

BILLS ARE DUE AND PAYABLE UPON RECEIPT WHICH 


\section{SEYFARTH

attorneys SHAW

Deede Lundeen

Other/Copies on 11/8/02 for DERRICK BRUMMELL-ER 11/8/02.

Total Disbursements This Matter

Total Fees and Disbursements This Matter

Total This Statement
Invoice No. 832655

$0186 / 87045$

Page 2

246.50

$\underline{\$ 376.86}$

$\$ 961.86$

$\$ \underline{\underline{\$ 961.86}}$ 